Aus dem Institut Neuro- und Sinnesphysiologie

(Prof. Dr. rer. nat. S. O. Rizzoli)

im Zentrum Physiologie und Pathophysiologie

der Medizinischen Fakultät der Universität Göttingen

\title{
Therapeutischer Einfluss des Radikalfängers Trolox in einem Mausmodell für das Rett-Syndrom: Bewertung oxidativer Stressmarker in zerebralem Gewebe
}

\author{
INAUGURAL - DISSERTATION \\ zur Erlangung des Doktorgrades \\ der Medizinischen Fakultät der \\ Georg-August-Universität zu Göttingen
}

vorgelegt von

Marc Albert Hüser

aus

Steinheim

Göttingen 2016 
Dekan:

Referent:

Ko-Referent/in:

Drittreferent/in:

Tag der mündlichen Prüfung:
Prof. Dr. rer. nat. H. K. Kroemer

Prof. Dr. rer. nat. M. Müller 
Hiermit erkläre ich, die Dissertation mit dem Titel "Therapeutischer Einfluss des Radikalfängers Trolox in einem Mausmodell für das RettSyndrom: Bewertung oxidativer Stressmarker in zerebralem Gewebe" eigenständig angefertigt und keine anderen als die von mir angegebenen Quellen und Hilfsmittel verwendet zu haben.

Göttingen,,$\ldots \ldots \ldots \ldots \ldots$ 


\section{Inhaltsverzeichnis}

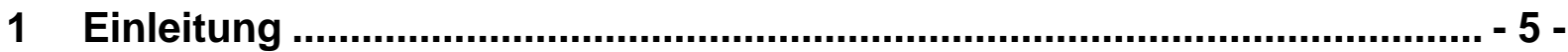

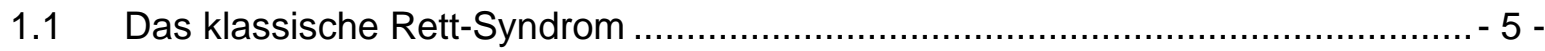

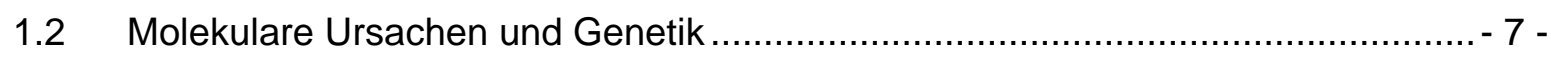

1.3 Mitochondriale Veränderungen beim Rett-Syndrom ................................... 10 -

1.4 Reaktive Sauerstoffspezies und ihre Bedeutung ....................................... 12 -

1.5 Reduktion von oxidativem Stress als therapeutisches Ziel ............................. 14 -

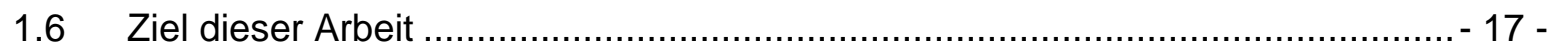

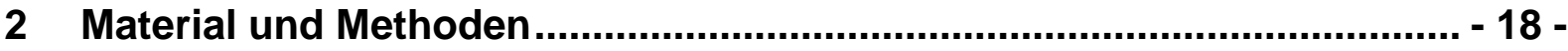

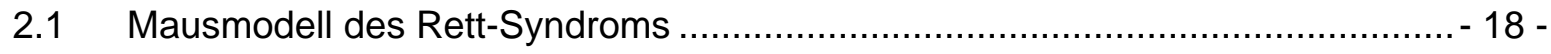

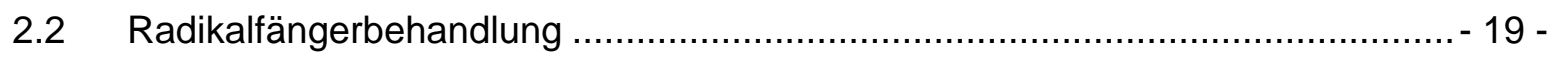

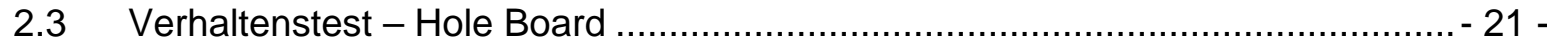

2.4 Präparation, Probengewinnung und -aufbewahrung ................................... 22 -

2.5 Optische Messung - Rhodamin123 ....................................................... 24 -

2.5.1 Chemikalien und Aufbau - Das Prinzip............................................. 24 -

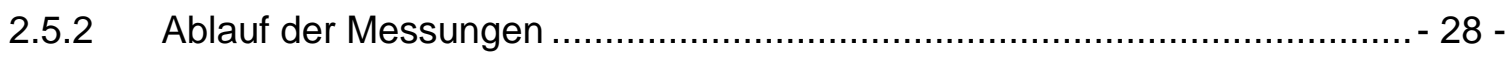

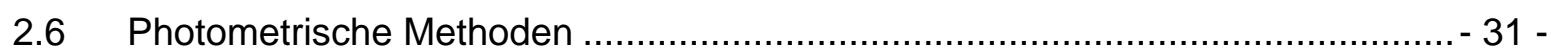

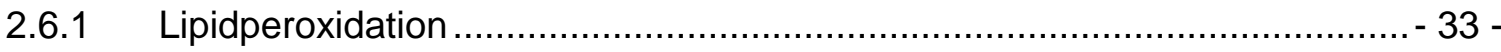

2.6.2 Proteincarbonylierung …................................................................ 35 -

2.7 Morphologische Beurteilung durch Nissl-Färbung ........................................ 39 -

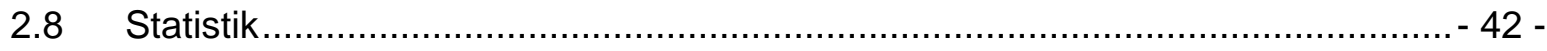

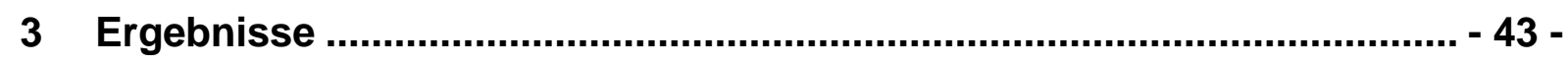

3.1 Beurteilung des explorativen Verhaltens ........................................................ 44 -

3.2 Optische Messungen zur Mitochondrienfunktion ........................................ 49 -

3.3 Oxidative Veränderungen auf Gewebeebene ............................................... 53 -

3.4 Morphologische Gewebeanalyse ............................................................. 59 -

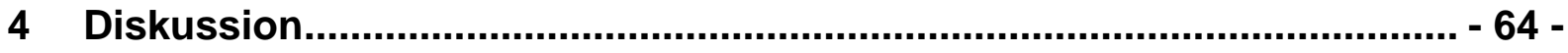

4.1 Exploratives Verhalten nach Trolox-Behandlung …................................... 67 -

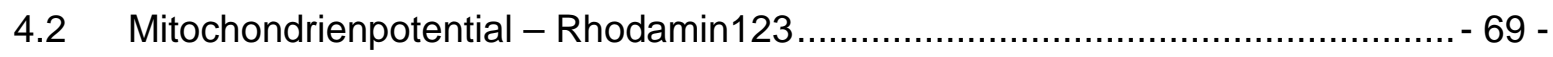




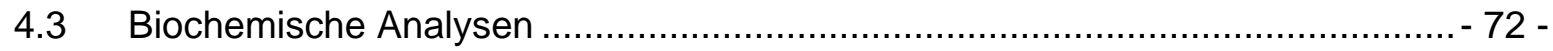

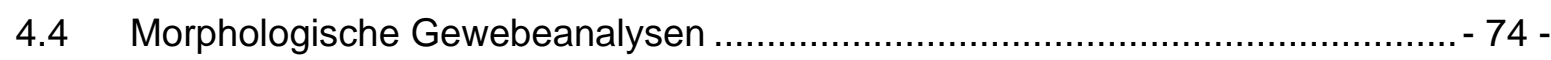

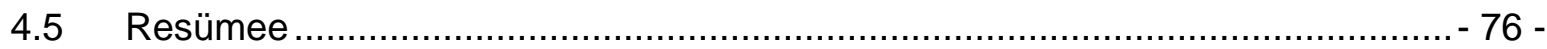

5 Zusammenfassung und Ausblick........................................................

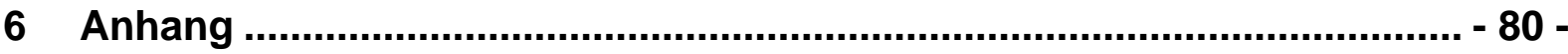

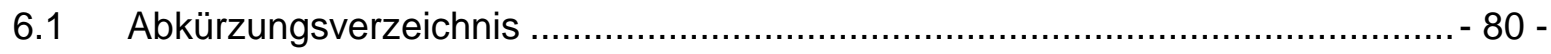

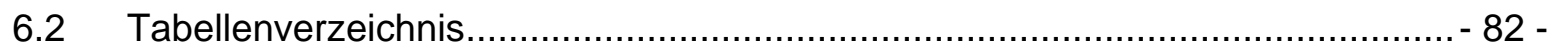

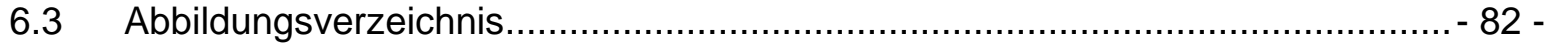

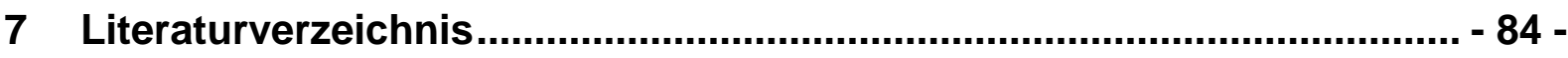




\section{$1 \quad$ Einleitung}

\subsection{Das klassische Rett-Syndrom}

Bei der Erkrankung Rett-Syndrom handelt es sich um eine nach dem österreichischen neuropädiatrischen Arzt Andreas Rett benannte postnatal progressiv verlaufende, neurologische Entwicklungsstörung (Rett 1966), die nahezu ausschließlich Mädchen betrifft. Das Rett-Syndrom zählt nach der ICD-10 Klassifikation zu den Entwicklungsstörungen (ICD-10-GM-2016; F84.2).

Mit einer Inzidenz von 1:10.000 - 1:15.000 bei Mädchen ist das Rett-Syndrom die zweithäufigste tiefgreifende Entwicklungsstörung nach der Trisomie 21-Erkrankung bezogen auf das weibliche Geschlecht (Hagberg et al. 1985; Leonard et al. 1997). Es gibt einige charakteristische Merkmale, die auf das Rett-Syndrom hinweisen. Ursprünglich waren nur wenige Kriterien (Hagberg et al. 1985) bekannt, deren Anzahl über die Jahre aber stetig gewachsen ist und heute zur besseren Diagnostizierbarkeit der Erkrankung beiträgt. Grundsätzlich sollte die Diagnose Rett-Syndrom in Betracht gezogen werden, wenn ein unter anderem postnatal verlangsamtes Kopfwachstum auffällig wird. Zu den weiteren Hauptkriterien zählt der partielle Verlust der Handmotorik sowie der Sprache. Außerdem werden häufig die klassischen hand washing movements beobachtet. Dabei handelt es sich um stereotype Handwaschbewegungen der Mädchen. Die Atmung der RettPatientinnen ist in den Wachphasen irregulär mit Apnoe oder Hyperventilation (Stettner et al. 2008). Während des Schlafes hingegen ist die Atmung regulär (Julu et al. 2001). Beim Auftreten von Symptomen innerhalb der ersten sechs Lebensmonate handelt es sich vielmehr um eine Variante des Rett-Syndroms und weniger um die klassische Form der Erkrankung. Bei der klassischen Form der Erkrankung wird der Symptomeintritt erst ab dem sechsten Lebensmonat beobachtet. Kriterien wie zum Beispiel Atempausen während der Wachzeiten, abnormaler Muskeltonus oder Wachstumsveränderungen des Rumpfskelettes weisen wiederum auf einen eher atypischen Verlauf der Erkrankung hin. Dennoch können diese Symptome auch Teil einer klassischen Rett-Erkrankung sein. Eine eindeutige Differenzierung ist in diesem Fall schwer (Chahrour und Zoghbi 2007). 
Inzwischen sind viele weitere Kriterien für das klassische Rett-Syndrom und auch für die jeweiligen Varianten bekannt. Diese gliedern sich grundsätzlich in notwendige, die Diagnose unterstützende und die Diagnose ausschließende Kriterien (Weaving et al. 2005). Dennoch wird nach wie vor ein bedeutender Teil der Erkrankten fehldiagnostiziert.

Der klassische Verlauf der Rett-Erkrankung wird in vier Stadien gegliedert (Hagberg und Witt-Engerström 1986; Chahrour und Zoghbi 2007):

Das Stadium I der Erkrankung beschreibt den frühkindlichen Entwicklungsstillstand, der zumeist zwischen dem sechsten und 18. Lebensmonat eintritt. Viele Mädchen haben bis zu diesem Zeitpunkt bereits eine initial normale Entwicklung durchlaufen und Fähigkeiten wie etwa das Laufen oder das Sprechen einiger Wörter erlernt (Chahrour und Zoghbi 2007). Diese Fähigkeiten werden bei Vorliegen des RettSyndroms nicht weiter ausgebildet. Hinzu kommt, dass auch das Körperwachstum der Mädchen abnimmt. Dabei ist zuerst das verminderte Wachstum des Schädels zu beobachten, gefolgt von Gewichtsabnahme und stagnierender Muskelspannung. Weiterhin wird in diesem Stadium beobachtet, dass Betroffene den Blickkontakt zu ihren Bezugspersonen verlieren.

Im Stadium II, bekannt als Regressionsphase, gehen bereits gelernte Fähigkeiten verloren. Dazu gehören beispielsweise der funktionelle Gebrauch der Hände sowie die Fähigkeit des Sprechens. In dieser mehrere Wochen bis Monate andauernden Phase können auch Symptome wie irreguläre Atmung, Ataxie und Apraxie auftreten. Jenes Stadium der Erkrankung tritt zumeist zwischen dem ersten und dem vierten Lebensjahr ein und zeigt erstmals auch die charakteristischen Handbewegungen (washing movements). Ebenfalls wird häufig ein sozialer Rückzug beobachtet, einhergehend mit autistischen Zügen, die zu einer häufigen Fehldiagnose leiten.

Stadium III wird auch als Plateau- oder pseudostationäre Phase bezeichnet und tritt zumeist zwischen dem zweiten und zehnten Lebensjahr auf. Es stellt sich zunächst eine gewisse Stabilisierung mit leichtem Abklingen der Symptomatik ein. Autistische Züge werden seltener beobachtet, die Patientinnen zeigen sich kontaktfreudiger und beginnen besser mit ihrer Umwelt zu interagieren. Dennoch bleiben Symptome wie die stereotypen Handbewegungen, Zähneknirschen, Apraxie und Ataxie erhalten oder können sich sogar verstärken. 
Im IV. Stadium (ca. ab dem zehnten Lebensjahr) verschlechtert sich die Grobmotorik weiter. Es kommt zu vermehrten Spasmen, erhöhtem Muskeltonus und häufig zu Skoliose. Dieser Progress zwingt den überwiegenden Teil der Patientinnen in den Rollstuhl. Die Kontaktfreudigkeit und das Interesse an sozialer Interaktion nehmen hingegen weiter zu und auch die Pubertät scheint unbeeinflusst. Ebenso zeigen sich Fortschritte in der kognitiven Leistungsfähigkeit.

Dennoch sind die betroffenen Mädchen ein Leben lang physisch und psychisch deutlich beeinträchtigt, sodass sie auf dauerhafte Hilfe und Unterstützung angewiesen sind. Die eingeschränkte Motorik und die nicht ausreichende Kommunikationsfähigkeit erschweren das Leben. Hinzu kommt, dass RettPatientinnen kardiorespiratorisch vorbelastet sind. Die Überlebenswahrscheinlichkeit ist in einer aktuellen Kohortenstudie mit 77,6\% bei einem Alter von 20 Jahren, $71,5 \%$ für 25 Jahre und 59,8\% für 37 Jahre angegeben (Anderson et al. 2014).

Nach aktueller Datenlage gibt es nach wie vor keine kurative Therapie für das RettSyndrom. Es sind lediglich supportive Ansätze bekannt wie beispielsweise der Einsatz von Antikonvulsiva zur Vermeidung epileptischer Perioden. Außerdem wird der Physiotherapie ein großer Stellenwert eingeräumt. Weiterhin werden Therapieformen wie Musiktherapie, Ergotherapie und Hippotherapie eingesetzt. Alle Ansätze mit kurativer Zielsetzung befinden sich noch in der Erprobungsphase (Guo et al. 2014).

\subsection{Molekulare Ursachen und Genetik}

Dem klassischen Rett-Syndrom liegt in der Mehrzahl der Fälle eine Mutation im MECP2-Gen (>95\%) zugrunde (Amir et al. 1999; Huppke et al. 2000). Das MECP2Gen befindet sich auf dem langen Arm (q) des X-Chromosoms an Position 28 (Xq28). Es handelt sich dabei um ein Gen, welches für das Protein methyl-CpGbinding-protein 2 (MeCP2) codiert (Lewis et al. 1992).

Dieses Protein übernimmt als Transkriptionsmodulator vielfältige Aufgaben. Es bindet selektiv an CpG (Cytosin phosphat Guanin)-Inseln - an diesen findet über Methylierungen eine Konformationsänderung der DNA statt - und vermittelt die Unterdrückung der Transkription (Amir et al. 1999). Neuere Erkenntnisse zeigen, 
dass von einer alleinigen inhibitorischen Wirkung nicht mehr die Rede sein kann. Stattdessen scheint MeCP2 vielmehr sowohl inhibierende als auch aktivierende Einflüsse auf die Transkription auszuüben (Chahrour et al. 2008). Bei den vorliegenden Mutationen handelt es sich zum Großteil um de novo Mutationen, die prävalent in der Keimbahn des Mannes entstehen und bei denen ein Austausch zwischen Cytosin und Thymin stattfindet (Wan et al. 1999; Trappe et al. 2001).

Da der Mann sein X-Chromosom immer nur an weibliche Nachkommen übergibt, scheint hier einer der Gründe zu liegen, weshalb in der absoluten Mehrheit das weibliche Geschlecht von der Erkrankung des Rett-Syndroms betroffen ist deshalb wird zur besseren Übersichtlichkeit von Patientinnen gesprochen, was nicht bedeutet, dass keine männlichen Patienten beschrieben sind (Christen und Hanefeld 1995). Weiterhin ist beim weiblichen Geschlecht bekannt, dass nach der Lyon-Hypothese (Lyon 1961) im Zuge der Embryonalentwicklung ein XChromosom inaktiviert wird. Diese Inaktivierung erfolgt vollkommen zufällig. Da nur ein Allel des heterozygoten weiblichen Chromosomensatzes betroffen ist, kann, dem Zufall überlassen, der Phänotyp der Erkrankung verschieden ausfallen. Rein statistisch geht man dabei von einer 50\%igen Wahrscheinlichkeit aus, also davon, dass die Hälfte der Zellen betroffen ist, die andere nicht. Es zeigen sich aber extrem unterschiedliche Ausprägungen der Erkrankung. Eine sehr milde Form des Rett-Syndroms kann sogar vererbt werden, nämlich dann, wenn die Mutter mit der sehr milden Ausprägung zur Konduktorin wird (Zoghbi et al. 1990). In einem weiteren Fall wird beschrieben, dass die Mutter selbst nicht Trägerin der genetischen Aberration ist, es aber trotzdem zu einer familiären Häufung der Erkrankung kommt. Dabei wird vermutet, dass die Mutter eine Keimbahnmutation in Form eines genetischen Mosaiks aufweist (Amir et al. 1999).

Kommt es zum seltenen Fall eines betroffenen männlichen Nachkommens, so erlangt das erkrankte Allel in allen Körperzellen vollständige Penetranz. Der männliche Nachkomme erleidet entweder eine sehr extreme Ausprägung des RettSyndroms oder erliegt sogar intrauterin der veränderten Genetik. Aber auch bei männlichen Betroffenen kann nicht eindeutig differenziert werden, denn beim männlichen Karyotypen 47, XXY - dem so genannten Klinefelter Syndrom - ist wieder eine andere Ausprägung der MECP2-Mutation zu erwarten (Schwarzman et al. 2001). 
Das MECP2-Gen ist ein Gen, welches knapp 76.000 Basenpaare umfasst. Es wird deutlich, dass es nicht eine einzige Mutation gibt, die das Rett-Syndrom hervorruft, sondern vielmehr etliche Mutationen an vielfältigen genloci, die ursächlich für das Rett-Syndrom sein können (Huppke et al. 2000). So ist nicht nur eine Art Genmutation der Erkrankung zuzuordnen, sondern es sind sowohl missense (eine falsche Aminosäure wird eingebaut), nonsense (ein Stopp-Codon wird eingebaut), frameshift (das Leseraster verschiebt sich) als auch die komplette Depletion eines Exons bekannt (Christodoulou et al. 2003). Dabei können der Ort und die Art der Mutation prognostische Hinweise liefern. Diese vielfältigen Mutationen können mittels Gentest nachgewiesen werden (Buyse et al. 2000). Es sollte dabei aber nicht unerwähnt bleiben, dass nicht jeder positive MECP2-Gentest auch die Diagnose Rett-Syndrom nach sich zieht. Andererseits ist nicht bei jeder phänotypischen Rett-Patientin eine Mutation im MECP2-Gen zu finden (Suter et al. 2014).

Neben Mutationen im MECP2-Gen sind nämlich noch zwei weitere Gene bekannt, deren Mutationen zu vergleichbaren Phänotypen führen können. Dabei ist zum einen das Gen cyclin-dependet kinase-like 5 (CDKL5) betroffen. Mutationen in diesem Gen zeigen einen Rett-ähnlichen Phänotyp, der aber durch das frühzeitige Auftreten der Symptomatik und der hierbei häufigen Spasmen gekennzeichnet ist (Tao et al. 2004; Scala et al. 2005). Eine der Aufgaben dieser Kinase ist die Vermittlung der Phosphorylierung von MECP2, sodass von einem gemeinsamen biochemischen Signalweg gesprochen werden kann (Mari et al. 2005). Diese Überschneidung erklärt die Bedeutung von genetischen CDKL5-Tests, die bei MECP2 negativen Ergebnissen angewandt werden. Zum anderen können Mutationen im forkhead box 1-Gen (FOXG1) mit der angeborenen Form des RettSyndroms in Zusammenhang gebracht werden (Ariani et al. 2008).

Letztlich bleibt festzuhalten, dass das Rett-Syndrom nach wie vor eine klinisch zu stellende Diagnose ist und durch die Vielfalt an genetischen Aberrationen keinen eindeutig direkten Zusammenhang zwischen Geno- und Phänotyp zulässt. 


\subsection{Mitochondriale Veränderungen beim Rett-Syndrom}

Wurde früher postuliert, dass es sich bei dem Rett-Syndrom um eine metabolische Erkrankung handelt (Matsuishi et al. 1994), ist heute eindeutig, dass die Erkrankung genetischen Ursprungs ist. Dennoch scheint es eine nicht zu vernachlässigende metabolische Komponente zu geben.

Inzwischen liegt in jedem Fall ein großes Augenmerk auf Veränderungen der Mitochondrien. Die Mitochondrien einer Zelle übernehmen vielfältige Aufgaben. Die prominenteste ist hierbei wohl die Bereitstellung von Energieäquivalenten in Form von Adenosintriphosphat (ATP). Die biochemischen Reaktionen der oxidativen Phosphorylierung, die in den Mitochondrien abläuft, stellen den überwiegenden Teil des Energieträgers bereit (Erecinska und Silver 1989). Neben diesem Prozess sind die Mitochondrien aber auch für die Regulation der zytosolischen Kalziumkonzentration zuständig. Sie sind an der Induktion der Apoptose beteiligt und können Einfluss auf den intrazellulären $\mathrm{pH}$-Wert nehmen. Schließlich entsteht bei der zellulären Atmung in den Mitochondrien auch ein großer Teil der reaktiven Sauerstoffspezies, engl. reactive oxygen species (ROS). Den Mitochondrien kommt in einer Vielzahl von neurodegenerativen Erkrankungen und deren therapeutischen Ansätzen eine entscheidende Bedeutung zu (Foster et al. 2006; Moreira et al. 2010).

Das Rett-Syndrom stellt zwar keine neurodegenerative Erkrankung dar, zeigt aber trotzdem signifikante morphologische Alterationen in Neuronen und Mitochondrien (Eeg-Olofsson et al. 1988; Ruch et al. 1989; Cornford et al. 1994) sowie biochemische Alterationen der Mitochondrien (Gibson et al. 2010; Großer et al. 2012; Müller und Can 2014). Die Veränderungen der mitochondrialen und neuronalen Morphologie des Kortex und des Hippokampus sind für das Mecp2-/y Mausmodell bestätigt worden (Belichenko et al. 2009). Weiterhin konnte mittels Frontallappenbiopsie im dritten Lebensjahr und Frontallappenbiopsie post mortem im zwölften Lebensjahr bei derselben Patientin gezeigt werden, dass trotz einer gewissen Stabilisierung der neurologischen Symptomatik generell die mitochondrialen Veränderungen voranzuschreiten scheinen (Cornford et al. 1994).

Biochemische Analysen an Muskel- und Frontallappengewebe bei RettPatientinnen zeigten verminderte Konzentrationen der Zytochrom-c-Oxidase, der 
Zytochrom-c-Reduktase und der Succinat-Zytochrom-c-Reduktase, selbst bei morphologisch unauffälligen Mitochondrien (Dotti et al. 1993; Coker und Melnyk 1991). Es zeigte sich auch, dass die Enzymaktivität des Komplexes IV der Atmungskette in post mortem gewonnenem Hirngewebe hochreguliert war (Gibson et al. 2010) und weiterhin eine Untereinheit des Komplexes III - das kernkodierte ubiquinol-cytochrome c reductase core protein 1 (Uqcrc1) - überexprimiert wurde. Hieraus scheint eine erhöhte respiratorische Aktivität mit erhöhtem Sauerstoffverbrauch zu folgen (Kriaucionis et al. 2006).

Ergänzend ergaben Voruntersuchungen in der Arbeitsgruppe Müller mittels Autofluoreszenz von Flavin-Adenin-Dinukleotid/Nikotinamidadenindinukleotid (FAD/NADH), dass eine erhöhte basale mitochondriale Respiration vorliegt (Großer et al. 2012), die die These eines Protonenlecks erhärtet. Auch konnte in der Arbeitsgruppe festgestellt werden, dass erwachsene MeCP2 defiziente Mäuse einen um etwa 30\% geringeren Blutzuckerspiegel aufwiesen (Janc 2015). Diese Erkenntnisse stimmen mit dem veränderten Kohlenhydratstoffwechsel von RettPatientinnen, der schon seit Langem bekannt ist, überein (Haas et al. 1995; Villemagne et al. 2002).

Trotz all dieser Erkenntnisse ist bislang nicht eindeutig geklärt, welche zellulären Signalwege von Aberrationen des MeCP2 Proteins betroffen sind. Kürzlich erst wurden in Lymphozyten des peripheren Blutes von Rett-Patientinnen 482 modulierte Gene festgestellt (Pecorelli et al. 2013). 430 von diesen Genen wurden als hochreguliert eingestuft. 146 Gene wurden mit Schlüsselfunktionen der Mitochondrien, der Ubiquitinierung, dem Falten von Chromatin und dem Prozessieren der Ribonukleinsäure (RNA) in Verbindung gebracht. Diese vielfältigen Prozesse, gerade auch die Ubiquitinierung, zeigen, wie groß die Tragweite der MECP2 Mutation ist und wie unvollständig und zum Teil auch widersprüchlich nach wie vor der Stand der Forschung ist. 


\subsection{Reaktive Sauerstoffspezies und ihre Bedeutung}

Der Begriff reaktive Sauerstoffspezies steht für eine ganze Gruppe besonders reaktionsfreudiger Substanzen, vornehmlich radikale Sauerstoffverbindungen, die durchaus eine physiologische Bedeutung haben. Es werden ihnen Signalfunktionen zugeschrieben und auch bei der zellulären Immunantwort spielen sie als Zellgifte eine Rolle (Valko et al. 2007). Diese Radikale sind bei den ablaufenden Reaktionen Oxidationsmittel. Sie werden also reduziert. Dementsprechend wird der Reaktionspartner oxidiert. Die Oxidation einer Substanz geht häufig aber auch mit dem eigenen Funktionsverlust einher, sodass den ROS eine Beteiligung an Alterungsprozessen zugeschrieben wird. Auch in der Entstehung neurodegenerativer Erkrankungen wie Multiple Sklerose (Gilgun-Sherki et al. 2004) oder amyothrope Lateralsklerose (Kong und Xu 1998) spielen ROS eine nicht zu vernachlässigende Rolle.

In die Kategorie der ROS fallen diverse Sauerstoffverbindungen, einige von innen sind besonders reaktiv, andere relativ reaktionsträge. Allen ist gemein, dass sie ein ungepaartes Elektron aufweisen. Den ROS sind verschiedene Substanzen, darunter Enzyme, entgegengestellt, die die Reduktion und Oxidation in der Zelle in der Waage halten und die so genannte zelluläre Redox-Balance gewährleisten sollen. Zu den Enzymen zählt unter anderem die Superoxiddismutase (SOD), die Superoxid-Anionen in Wasserstoffperoxid $\left(\mathrm{H}_{2} \mathrm{O}_{2}\right)$ umwandelt. Wasserstoffperoxid ist auch ein Oxidationsmittel, jedoch weniger reaktionsfreudig. $\mathrm{H}_{2} \mathrm{O}_{2}$ kann durch Glutathion - ebenfalls ein Radikalfänger - und die Glutathion-Peroxidase unschädlich gemacht werden. Neben diesen enzymatischen Schutzmechanismen gibt es molekulare Verbindungen, zum Beispiel Vitamine, die ebenfalls Radikale reduzieren können. Dazu zählt sowohl die Ascorbinsäure als auch $\alpha$-Tocopherol. Tocopherol ist im Speziellen für den antioxidativen Schutz der Lipide verantwortlich. Letztendlich tragen diese Mechanismen zur Aufrechterhaltung der zellulären Redox-Balance bei.

Der überwiegende Teil der ROS entstammt der oxidativen Phosphorylierung, also der Zellatmung. Gerade an Komplex I und III der Atmungskette fallen große Mengen an Radikalen an (Boveris et al. 1976; Turrens 1997; Turrens und Boveris 1980). Insgesamt produzieren die Mitochondrien einer Zelle etwa $80 \%$ der anfallenden ROS. Diese stehen in direktem Zusammenhang mit der 
mitochondrialen Atmung (Boveris und Chance 1973). Der geringere Teil der ROS fällt durch zytosolische Oxidasen im Hyaloplasma an (Boveris und Chance 1973).

Gerät die Redox-Balance zugunsten der ROS aus dem Gleichgewicht, spricht man von oxidativem Stress. Oxidativer Stress richtet sich auf molekularer Ebene gegen Proteine, Lipide und Nukleinsäuren. Dementsprechend kann ein Ungleichgewicht fatale Folgen haben und schlussendlich die Zellen degenerieren. Gerade neuronale Zellen benötigen zur Aufrechterhaltung ihrer Membranpotentialien besonders viel Energie und damit Sauerstoff. Hierbei fallen auch besonders hohe Mengen an ROS an (Uttara et al. 2009). Folglich sind gerade neuronale Zellen besonders empfindlich gegenüber Veränderungen in der Redox-Balance.

Für das Rett-Syndrom ist inzwischen bekannt, dass die Lipidperoxide und Proteincarbonyle - beides Parameter für das Ausmaß des oxidativen Stresses - im Blut der Patientinnen erhöht sind. Gleichzeitig sind die Superoxiddismutase und das Tocopherol vermindert (Sierra et al. 2001; Formichi et al. 1998; De Felice et al. 2009). Andererseits zeigt eine weitere Studie, dass oxidationsspezifische Gene, die unter anderem für die SOD 1 codieren, in menschlichen Lymphozyten hochreguliert sind (Pecorelli et al. 2013). Ähnliches wurde auch schon für Mecp2-ly Mäuse auf genetischer Ebene bestätigt (Großer et al. 2012). Hinter diesem Prozess könnte ein kompensatorisches Profil liegen. Eine aktuelle Studie erweitert die Ergebnisse auf das primär erkrankte Organ - das Gehirn. So konnte in MeCP2 defizienten Mäusen festgestellt werden, dass auch Hirngewebe einem erhöhtem oxidativem Stress ausgesetzt ist und hierbei im Besonderen die Lipide signifikante oxidative Schäden aufweisen (De Felice et al. 2014). Möglich wäre auch, dass die Hypoxie verursacht durch Apnoe und Hyperventilation - zu diesem Anstieg der oxidativen Parameter beiträgt.

Neueste Untersuchungen zeigen, dass nicht nur der Verlust der vielfältigen Funktionen des MECP2-Gens mit erhöhtem oxidativem Stress einhergeht, sondern auch das MECP2 duplication syndrom (Signorini et al. 2016). Dabei handelt es sich um eine genetische Erkrankung, bei der nicht wie beim Rett-Syndrom der Verlust von MECP2 ursächlich ist, sondern eine Verdoppelung.

Nach wie vor ist nicht eindeutig geklärt, ob beim Rett-Syndrom vermehrt Radikale anfallen, sei es aufgrund der erhöhten mitochondrialen Atmung, oder aufgrund von Protonenlecks, die einer Kompensation bedürfen, oder ob die zytosolischen 
Schutzmechanismen nicht ausreichend vorhanden sind, beziehungsweise gebildet werden. Nicht auszuschließen ist weiterhin, dass beide Komponenten an der Pathogenese beteiligt sind. Als gesichert gilt hingegen, dass die extramitochondriale Produktion von ROS nicht ursächlich verändert ist (Großer et al. 2012).

\subsection{Reduktion von oxidativem Stress als therapeutisches Ziel}

Inzwischen ist nachgewiesen, dass auch einige Untereinheiten der Komplexe der Atmungskette durch MeCP2 reguliert werden (Kriaucionis et al. 2006). Dabei handelt es sich um Komplex I und III, die wie oben beschrieben entscheidend an der Bildung von ROS beteiligt sind. Angesichts der erwähnten Literatur scheint gesichert, dass Rett-Patientinnen unter erhöhter ROS-Belastung leiden. Fraglich bleibt, ob die vermehrt anfallenden ROS ursächlich für die Symptomatik sind, oder ob sie nur eine Begleiterscheinung der Rett-Erkrankung darstellen.

In jedem Fall ist oxidativer Stress ein greifbares Ereignis der Erkrankung und stellt damit einen potentiellen Therapieansatz dar. Natürlich kann dabei nicht zwingend von einem kurativen Ansatz ausgegangen werden, da das Rett-Syndrom primär genetischen Ursprungs ist. Gehört die Entstehung der ROS aber zur direkten Pathogenese der Erkrankung und sind die Sauerstoffradikale für Teile der Symptomatik ausschlaggebend, so könnte sich eine Therapie der Redoxbalance als durchaus vielversprechend erweisen.

Als therapeutische Angriffspunkte kommen dabei drei Prozesse in Frage: Zunächst könnte versucht werden, die Entstehung der überschüssigen ROS (1) zu verhindern. Auf der anderen Seite des Gleichgewichts könnten sowohl die so genannten Radikalfänger (2) hochreguliert, oder den Zellen größere Mengen an Antioxidantien (3) zur Verfügung gestellt werden (Abb. 1). Ziel ist es dabei immer, das Redox-Gleichgewicht wieder herzustellen, beziehungsweise zu stabilisieren.

Der dieser Arbeit zu Grunde liegende therapeutische Ansatz befasst sich mit der Supplementierung von Antioxidantien, genauer dem wasserlöslichen Vitamin EDerivat Trolox (6-hydroxy-2,5,7,8-tetramethylchroman-2-carboxylisäure), welches 
aus vorherigen Ergebnissen an isoliertem Gewebe (Großer et al. 2012; Janc und Müller 2014) einen vielversprechenden Ansatz darstellt. Dort wurde bestätigt, dass Trolox an hippokampalen Zellkulturen von MeCP2 defizienten Mäusen die RedoxBalance verbessert und partiell die sonst übermäßige Antwort auf oxidativen Stress verbessert. Auch an akuten hippokampalen Hirnschnitten von symptomatischen $M_{\text {ecp2 }}{ }^{-/ y}$ Mäusen, die akut mit Trolox behandelt wurden, konnte gezeigt werden, dass die erhöhte neuronale Erregbarkeit gedämpft, die synaptische Plastizität erhöht und die Hypoxietoleranz verbessert werden konnte (Janc und Müller 2014).

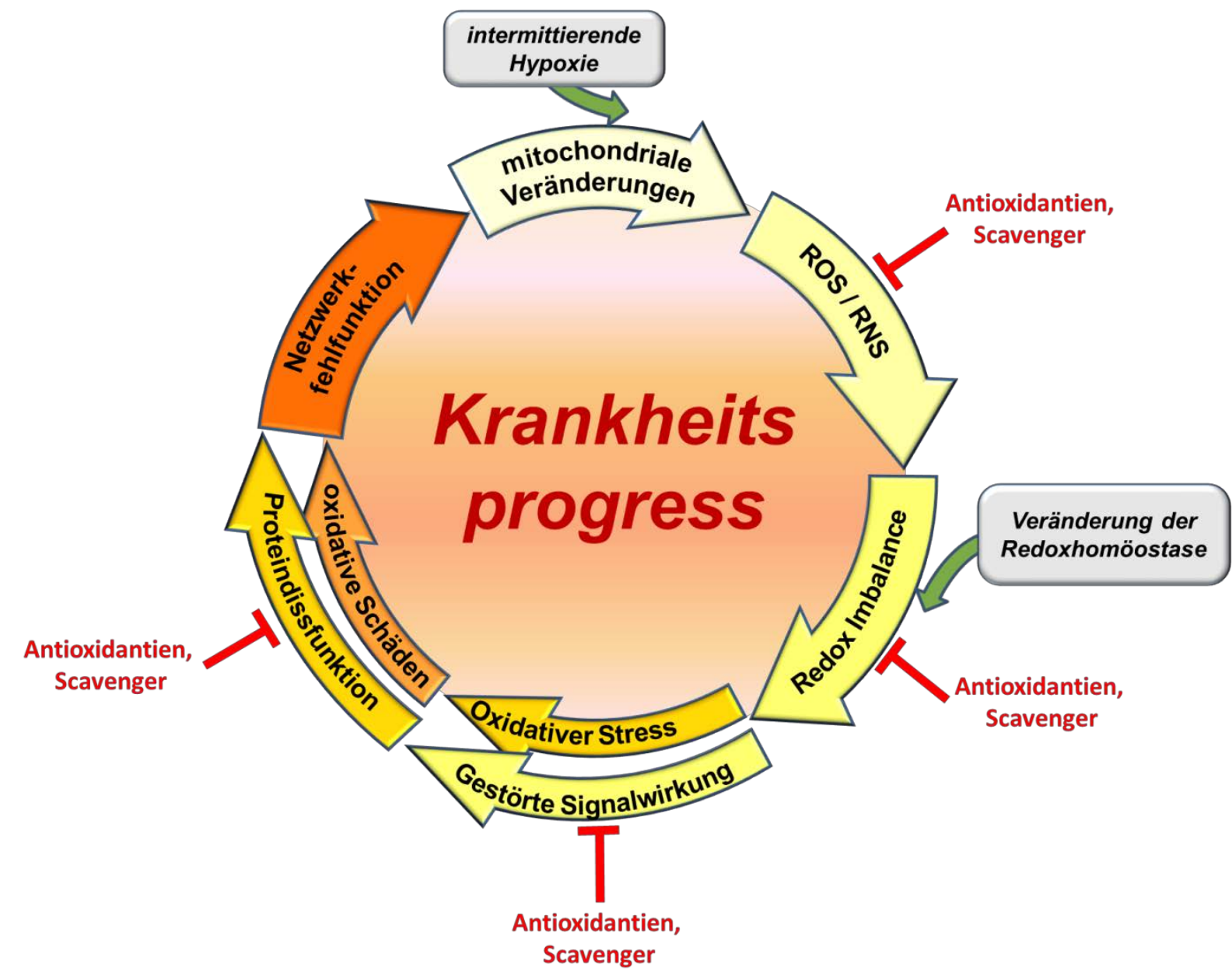

\section{Abbildung 1: Schematische Darstellung der therapeutischen Angriffspunkte}

Die gestörte Redoxbalance bietet mögliche Angriffspunkte für ein therapeutisches Vorgehen. RNS bezeichnet reaktive Stickstoffspezies, die ebenfalls zum Redox-Gleichgewicht beitragen.

Auch in anderen Forschungsgruppen konnten erste Erfolge mit Antioxidantien erzielt werden. Es wurde gezeigt, dass Curcumin - ein natürlich vorkommender Farbstoff und NO-Synthase Hemmer - in Mecp2 heterozygoten weiblichen Mäusen die erhöhten Superoxidspiegel senkt (Panighini et al. 2013). Weiter konnte in einer 
Studie mit 20 Patientinnen gezeigt werden, dass eine früh begonnene $\omega-3$ fettsäurehaltige Diät die klinische Symptomatik bessert und verschiedene oxidative Stressmarker senkt (De Felice et al. 2012). Inzwischen ist auch eine Phase II Studie in Italien eingeleitet, die den therapeutischen Effekt eines Vitamin EDerivates - EPI-743 - auf oxidativen Stress erprobt (http://edisonpharma.com/wpcontent/files_mf/1409757666RettSyndromepressrelease140903.pdf). Auch für Valproat - ein Antiepileptikum - ist ein positiver Einfluss bei Mecp2 Mäusen bestätigt (Guo et al. 2014). Bei der antiepileptischen Behandlung von RettPatientinnen scheint Carbamazepin den größten Effekt zu erzeugen (Huppke et al. 2007).

Es müssen jedoch weiterhin Anstrengungen zur Erforschung der exakten Pathogenese unternommen werden. Hierbei stellen sich noch viele Fragen: Inwieweit ist der Energiemetabolismus der Mitochondrien Teil der Pathogenese? Wie groß ist die Rolle der Redoximbalance? Und welchen Einfluss hat MEPC2 auf die Mitochondrien? Um eine adäquate Verbesserung der Symptomatik von RettPatientinnen zu erlangen, muss die Pathogenese im molekularen Detail verstanden werden. Nur so kann die Erforschung einer kurativen Therapie zielführend verfolgt werden. 


\subsection{Ziel dieser Arbeit}

Schon 1998 wurde gezeigt, dass bei neun von 28 Patientinnen mit Rett-Syndrom verminderte Vitamin E-Spiegel im Blut vorherrschten (Formichi et al. 1998). Auch heute sind diese Erkenntnisse Gegenstand der Forschung. Die Arbeitsgruppe um Professor Müller konnte bereits positive Effekte von Trolox - einem Vitamin EDerivat - bei einer in vitro-Behandlung in Zellkulturen und auch an akuten hippokampalen Schnitten nachweisen (Janc und Müller 2014; Großer et al. 2012).

Diese Arbeit ist Teil der in vivo-Untersuchung und der präklinischen Erprobung des Radikalfängers Trolox bei Mecp2 ${ }^{-/ y}$ Mäusen. Die Arbeit zielt auf den potentiellen Erfolg einer intraperitonealen (i.p.) Behandlung MeCP2 defizienter Mäuse ab und dient der präklinischen Beurteilung von Trolox, immer unter der Prämisse der Erprobung eines potentiell kurativen Therapieansatzes für Rett-Patientinnen. Alle Versuche sind vergleichend sowohl an Wildtypen als auch an Mecp2-ly Tieren ausgeführt worden, die jeweils verblindet zwei verschiedene Konzentrationen Trolox oder Kontrolllösung (PBS) erhalten haben.

Das anfallende Gewebe der behandelten Mäuse wurde in größtmöglichem Umfang verwertet. Es wurden Versuche $\mathrm{zu}$ verschiedenen Teilbereichen der Neurowissenschaften ausgeführt. Angefangen bei optischen Messungen, die Aussagen über die Reaktion der Mitochondrien auf oxidativen Stress zulassen, bis zu morphologischen Beurteilungen von fixierten Hirnschnitten, die mögliche Veränderungen der zellulären Morphologie und der kortikalen Schichtdicke im Hirn erfassen sollten.

Zur Messung der Proteincarbonylierung und Lipidperoxidation sei erwähnt, dass die Methoden für die Fragestellung anhand der Herstellerprotokolle im Rahmen der Gegebenheiten vollständig neu etabliert wurden und so die Bewertung zusätzlicher, bisher nicht erfasster Parameter und Gegebenheiten auf neuen Gebieten erlaubten.

Weiterhin wurde ein Verhaltenstest (Hole Board) durchgeführt, der Aufschluss über das explorative Verhalten der Tiere geben konnte, aber auch Hinweise zur Aktivität der Tiere mit sich brachte. 


\section{Material und Methoden}

Alle Versuche, die mit in vivo-Behandlungen in Zusammenhang stehen, sind von der Tierschutzkommission der Universitätsmedizin Göttingen und dem Niedersächsischen Landesamt für Verbraucherschutz und Lebensmittelsicherheit (LAVES) genehmigt worden und werden unter dem Aktenzeichen G12/0944 geführt. Bis auf den Verhaltenstest (Hole Board) erfolgten die Versuche ausschließlich an isoliertem Gewebe von zuvor behandelten Mäusen. Es wurde entweder kryokonserviertes, perfusionsfixiertes oder akutes Hirngewebe genutzt. Die maximale Nutzbarkeit des Gewebes konnte mit den gewählten Versuchen gewährleistet werden.

Die notwendige in vivo-Behandlung der Tiere mit Trolox oder Placebo (phosphatgepufferte Salzlösung: PBS) wurde von fachkundigen Kollegen mit entsprechender Berechtigung durchgeführt. Alle Versuche wurden im Rahmen einer Blindstudie ausgeführt.

Die Chemikalien sind, solange nicht anders erwähnt, von der Firma Sigma-Aldrich bezogen worden.

\subsection{Mausmodell des Rett-Syndroms}

Inzwischen gibt es einige Mausmodelle für das Rett-Syndrom (Guy et al. 2001; Shabazian et al. 2002; Brendel et al. 2011; Wegener et al. 2014), die durch verschiedene Arten der genetischen Modifikation das Rett-Syndrom imitieren und je nach Art der Mutation unterschiedlich schwere Phänotypen zeigen.

Im Rahmen dieser Arbeit wurde das Mausmodell der Zuchtlinie B6.129P2(C)Mecp $2^{\text {tm-1-1Bird }}$ verwendet, welches per Cre-loxP-Technologie erzeugt wurde und das Fehlen der Exons 3 und 4 des Mecp2-Gens (Genlokus: X-gekoppelt) aufweist (Guy et al. 2001). Die heterozygoten Mecp $^{+/-}$Weibchen wurden von Jackson Laboratories, Bar Harbor, ME bezogen und mit C57BL/6J-Männchen (Wildtyp, WT) verpaart, sodass heterozygote Weibchen $\left(\operatorname{Mecp}^{+/}\right)$, hemizogyte Männchen $\left(M e c p 2^{-/ y}\right)$ und Wildtypen generiert werden. Hierbei weisen die hemizygoten Männchen eine vollständige Penetranz der genetischen Aberration auf. Die 
männlichen $M e c p 2^{-/ y}$ Mäuse weisen vielfältige Symptome auf, unter anderem eine eingeschränkte Mobilität, verzögertes Kopf- und Körperwachstum, irreguläre Atmung mit Apnoe- oder Hyperventilationsphasen sowie verminderten Hirnwuchs mit verkleinerten Zellsomata in Kortex, Kleinhirn und Cerebellum (Chen et al. 2001; Guy et al. 2001; Fischer et al. 2009). Weiter konnte bereits früher durch die Arbeitsgruppe Müller gezeigt werden, dass die zelluläre und mitochondriale Redoxbalance gestört ist (Großer et al. 2012; Müller und Can 2014).

Bei weiblichen heterozygoten Tieren besteht die Problematik, dass die XChromosomeninaktivierung zufällig erfolgt und eine große Variabilität der Phänotypen nach sich zieht. In der Regel weisen die Weibchen einen deutlich milderen Phänotyp auf, welcher zu einem wesentlich späteren und variablen Zeitpunkt zur Ausprägung kommt. Folglich wurden in dieser Arbeit ausschließlich männliche $M e c p 2^{-/ y}$ Mäuse und die entsprechenden Wildtypen verwendet.

Die Tiere wurden in einem zwölfstündigen Tag-Nacht-Rhythmus in der zentralen tierexperimentellen Einrichtung der Universität Göttingen (Tierstall der Physiologie) gehalten und hatten dauerhaften Zugang zu Futterpellets und Wasser ad libitum. Die Genotypisierung wurde durch die technische Assistentin der Arbeitsgruppe mittels Schwanz-Biopsie und Polymerase-Kettenreaktion an allen behandelten Tieren ausgeführt.

\subsection{Radikalfängerbehandlung}

Die Behandlung der Tiere ist nicht Bestandteil dieser Arbeit. Das genutzte Gewebe stammt allerdings von behandelten Tieren, weshalb die Behandlung hier kurz beleuchtet wird.

Bei Trolox handelt es sich um ein Derivat des fettlöslichen Vitamins $\alpha$-Tocopherol, welches das häufigste Isomer der Substanzgruppe ausmacht. Die im Oberbegriff Vitamin E genannten Substanzen haben im Körper von Säugetieren vor allem antioxidative Eigenschaften. So reagieren freie Radikale mit Vitamin $E$ unter Bildung eines mesomeriestabileren und weniger reaktiven Produktes, welches in weiteren Schritten mithilfe von Glutathion reduziert werden kann (Alberto et al. 2013). 
Die Mäuse, die für diese Arbeit genutzt wurden (Janc 2015), sind ab dem postnatalen Lebenstag p10-11 in Abständen von $48 \mathrm{~h}$ mit Trolox, respektive Kontrollgruppe, verblindet intraperitoneal behandelt worden (Abb. 2).

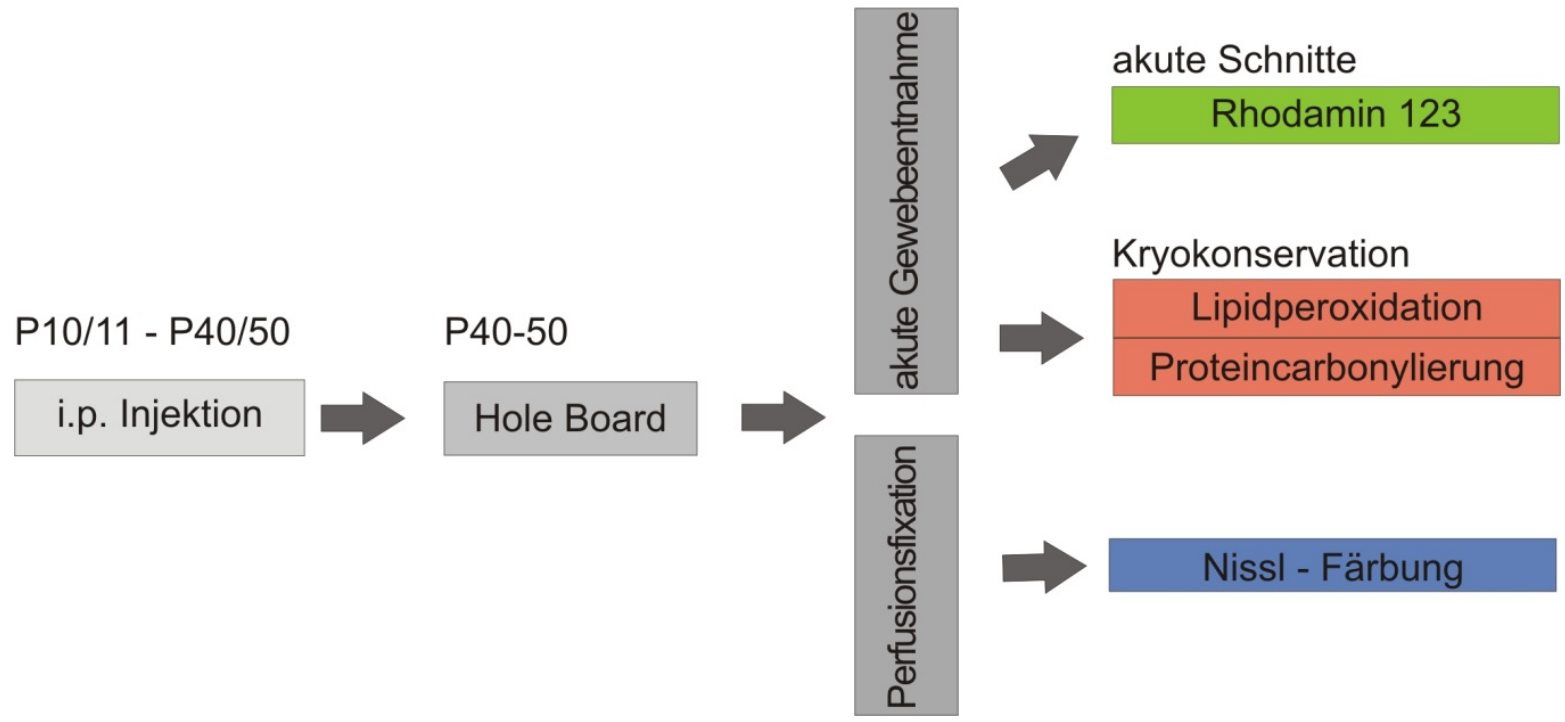

\section{Abbildung 2: Schematische Darstellung der Versuche}

Ab p10-11 wurden die Tiere für die folgenden Wochen alle $48 \mathrm{~h}$ mit der jeweiligen Testlösung intraperitoneal injiziert. Um den 45. Tag erfolgte die Isolation des Hirngewebes, zeitnah wurden die Versuche durchgeführt, wobei die Rhodaminmessung an akuten Hirnschnitten erfolgte, die anderen Versuche an kryokonserviertem oder perfusionsfixiertem Gewebe.

Die Einteilung der Tiere erfolgte zufällig in drei Gruppen: Eine Gruppe erhielt PBS als Kontrollgruppe. Die mit Trolox behandelten Mäuse wurden in zwei Gruppen sortiert, die sich in der Dosierung des Trolox unterschieden. So wurden, wie im nachfolgenden Schema (Abb. 3) verdeutlicht, sowohl Wildtyp als auch Mecp2-/y mit der jeweiligen Substanz behandelt (Janc 2015). 


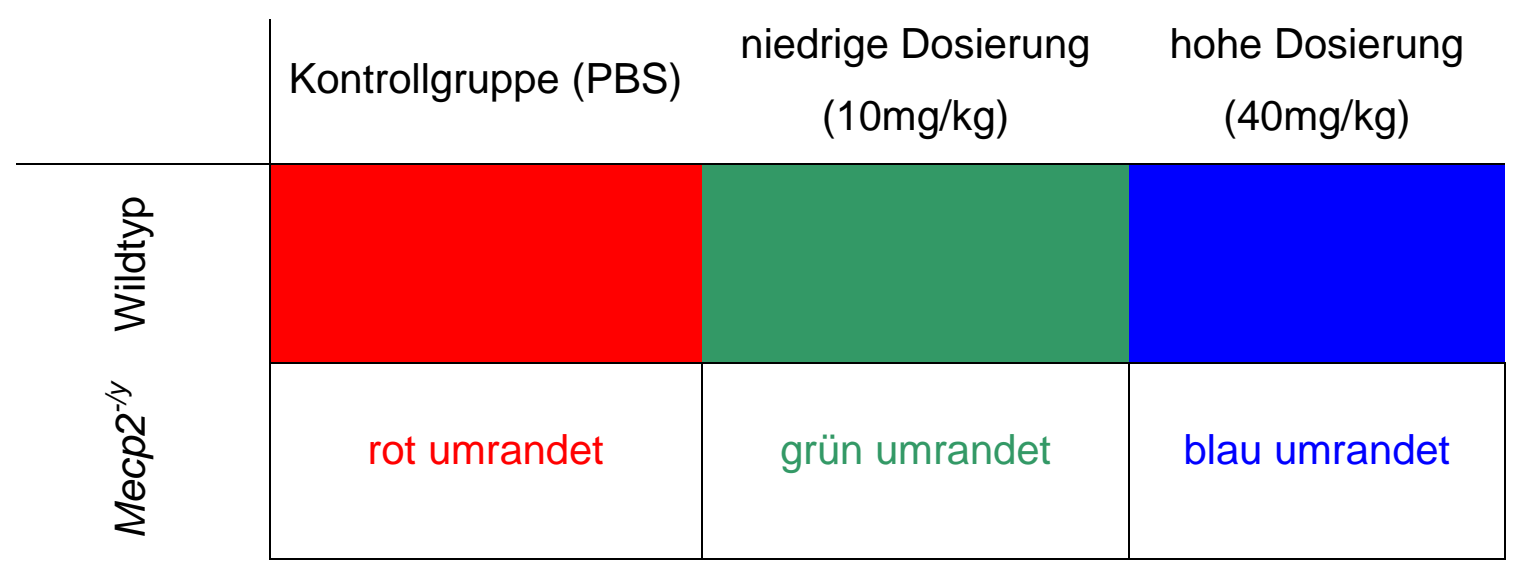

\section{Abbildung 3: Schema der Trolox-Behandlung}

Die Tiere wurden jeweils in drei Gruppen für $M e c p 2^{-/ y}$ und WT eingeteilt, sodass sowohl der Vergleich zwischen Mecp2 ${ }^{-/ y}$ und WT als auch der Vergleich zwischen Kontrolle und Pharmakon möglich wird.

\subsection{Verhaltenstest - Hole Board}

Der Hole Board-Test stellt einen Verhaltenstest für Mäuse dar. Vielfach findet er sowohl bei Erkrankungen des Nervensystems - beziehungsweise den jeweiligen Mausmodellen -, als auch bei medikamentös behandelten Tieren Anwendung (Nolan und Parkes, 1973). Beim Hole Board-Verhaltenstest, kurz Hole Board, wird das zu testende Tier auf ein $45 \times 45 \mathrm{~cm}$ großes Versuchsfeld gesetzt, um Aktivität und exploratives Verhalten zu bewerten. Das Versuchsfeld weist 16 gleichgroße Löcher auf, die in regelmäßigen Abständen angelegt sind. Die Aktivität der Tiere wird dann über zwei Rahmen, die mit jeweils 16 gitterförmigen Infrarotdetektoren beziehungsweise gegenüberliegenden Infrarotdioden ausgestattet sind, aufgezeichnet. Dem oberen Rahmen obliegt die Detektion des Bewegungsmusters und des Bewegungsumfangs. Der untere Rahmen misst die Anzahl der explorativen Aktionen, also wie häufig die jeweilige Maus eines der 16 Löcher auskundschaftet (Abb. 4).

Für die Gesamtzeit der jeweiligen Messung (5 min) war der Versuchsaufbau zu allen vier Seiten blickdicht gestaltet und der Raum wurde verlassen. So wurden mögliche Störfaktoren beseitigt. Nach jeder Maus wurde der Versuchsaufbau mit Ethanol (70\%) gereinigt. Die Daten wurden bereits während der Messung auf einen Computer übertragen und vorausgewertet. Später erfolgte mit der Software 
ActiTrack v2.7.13 (Panlab, Harvard Apparatus) die detaillierte Auswertung der Aktivitätsmuster.

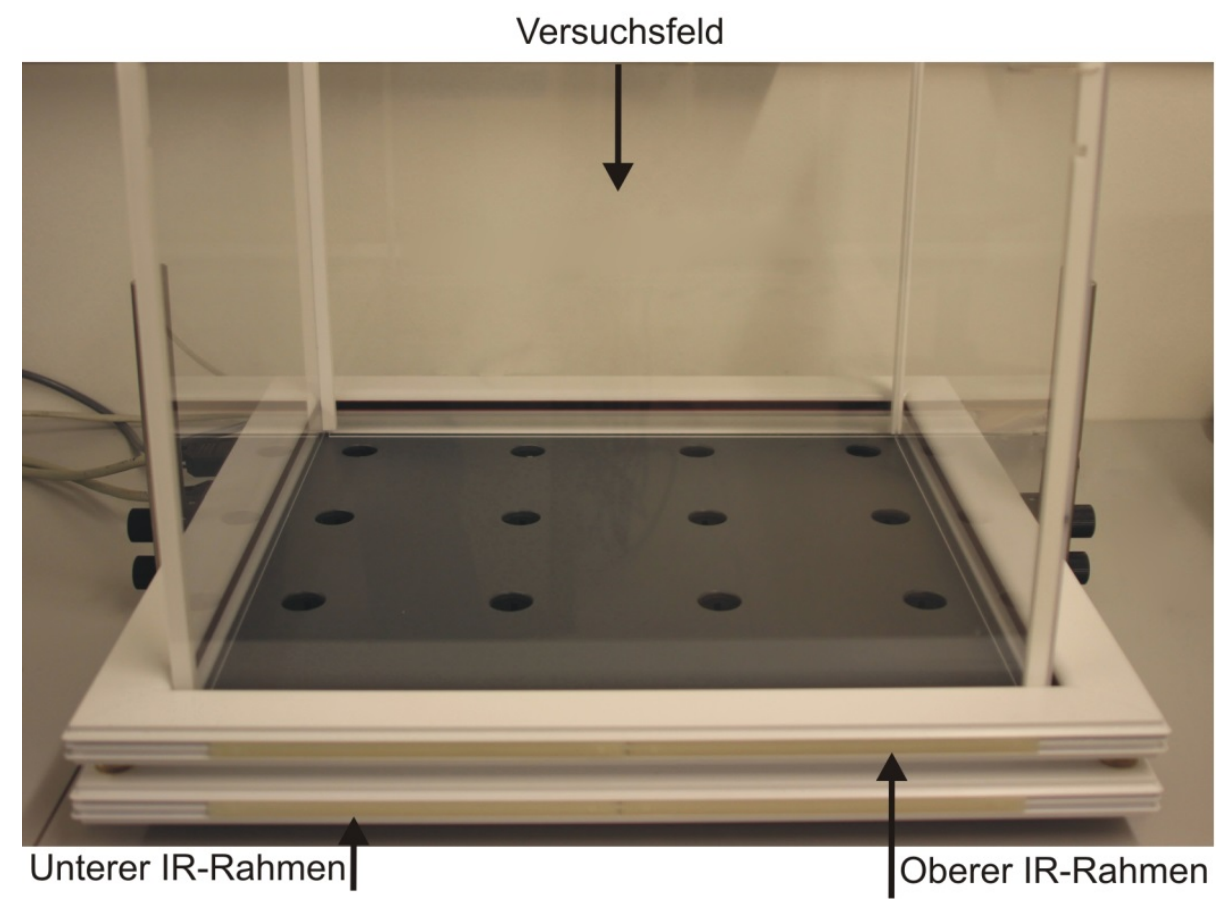

\section{Abbildung 4: Versuchsaufbau Hole Board}

Der Versuchsaufbau war zu allen vier Seiten blickdicht verkleidet und ist hier zur besseren Darstellung der Testarena einsehbar. Die beiden Infrarot-Rahmen sind in ihrer Position fixiert.

\subsection{Präparation, Probengewinnung und -aufbewahrung}

Soweit nicht anders erwähnt, sind alle Gewebeproben des Frontalkortex während der Erstellung der akuten Hirnschnitte, welche von einer erfahrenen Arbeitskollegin ausgeführt wurde, angefallen. Die akuten Hirnschnitte wurden sofort für die Fluoreszenzmikroskopie genutzt, wohingegen der Frontalkortex in flüssigem Stickstoff kryokonserviert wurde, um zu einem späteren Zeitpunkt für die Bestimmung der Lipidperoxidation und Proteincarbonylierung zur Verfügung zu stehen. So konnte der Parametergewinn für jedes Präparat maximiert werden.

Im Zuge der Präparation wurden die Tiere mithilfe von Diethylether in einem Exsikkator tief betäubt und anschließend dekapitiert. Zügig wurde das Hirn herauspräpariert und in eisgekühltes ACSF überführt. Daraufhin konnte das Hirn unter Zuhilfenahme eines Vibroslicer (Campden Instruments, 752M Vibroslice) mit 
einer Schnittstärke von $400 \mu \mathrm{m}$ geschnitten werden. Es wurden nur jene Hirnanteile geschnitten, die die Hippokampusformation enthalten. Frontalkortex und Kleinhirn wurden separat in Mikroreaktionsgefäße für spätere Analysen überführt und in flüssigem Stickstoff gefroren. Die längerfristige Lagerung von Frontalkortex und Kleinhirn erfolgte bei $-80^{\circ} \mathrm{C}$. Die akuten Hirnschnitte hingegen wurden in der Mittellinie in hemislices getrennt und in einer Präinkubationskammer für mindestens 60 min aufbewahrt. Die akuten Hirnschnitte wurden grundsätzlich in artifizieller cerebrospiraler Flüssigkeit (ACSF) aufbewahrt und bearbeitet. ACSF besteht aus (in mM): $130 \mathrm{NaCl}$ (Merck), $3.5 \mathrm{KCl}$ (Merck), $1.25 \mathrm{NaH}_{2} \mathrm{PO}_{4}$ (Merck), $24 \mathrm{NaHCO}_{3}$, $1.2 \mathrm{CaCl}_{2}, 1.2 \mathrm{MgSO}_{4}$ (Merck) und 10 Glukose (Merck). Zusätzlich wurden sie mittels Carbogen $\left(95 \% \mathrm{O}_{2}\right.$ und 5\% $\mathrm{CO}_{2}$ ) zur Adjustierung des $\mathrm{pH}$-Wertes $(\mathrm{pH} 7,4)$ begast. So können die Schnitte einige Stunden überleben, und ihre Aktivität kann auf vielfältige Art untersucht werden.

Die akuten Hirnschnitte wurden dann für die Fluoreszenzmikroskopie verwendet, wohingegen speziell der Frontalkortex für die Messungen des Oxidationsstadiums der Proteine und Lipide benutzt wurde.

Die Beurteilung der Morphologie mittels Nissl-Färbung erfolgte an perfusionsfixiertem Gewebe. Die Tiere wurden transkardial perfundiert und fixiert. Diese Aufgabe wurde ebenfalls ausschließlich von erfahrenen Kollegen mit entsprechender Berechtigung durchgeführt. Diese transkardiale Perfusion ist ebenfalls im Rahmen des Vorhabens G12.944 explizit genehmigt.

Die gewonnenen Proben wurden über $24 \mathrm{~h}$ in 4\% Paraformaldehyd (PFA) verwahrt und anschließend in PBS überführt. Aus dem so vollständig fixierten Hirn wurden nachfolgend mit koronaler Schnittführung im Bereich des Hippokampus $30 \mu \mathrm{m}$ dünne Schnitte angefertigt. Dazu erfolgte zuerst die vorbereitende Präparation des fixierten Gehirns. Frontalkortex und Kleinhirn wurden dabei mit einem scharfen Skalpell abgetrennt. Im Anschluss konnten unter einem Binokular die häufig sehr steife arachnoidea mater und Gefäße wie der circulus arteriosus cerebri entfernt werden. Das Gehirn wurde dann auf der entsprechenden Präparat-Trägerplatte des Vibratoms (Leica VT1200S; Abb. 5) mit Sekundenkleber (Roti coll 1, Roth) befestigt und zur zusätzlichen Stabilisierung mit Agar pyramidenförmig eingegossen. 


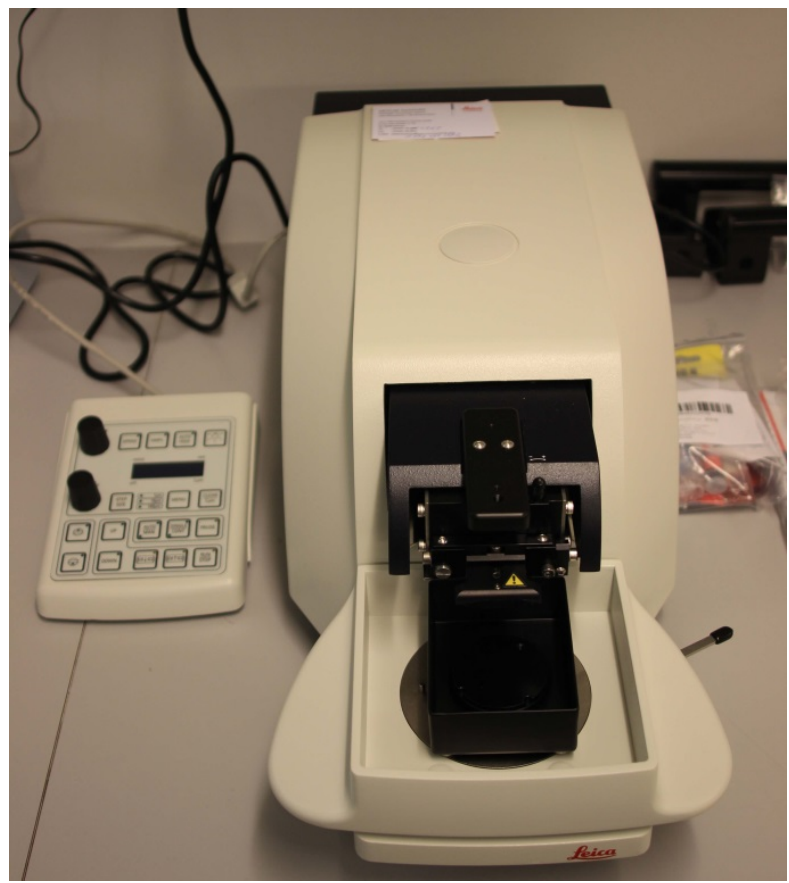

\section{Abbildung 5: Leica VT1200S Vibratom}

Erstellung von $30 \mu \mathrm{m}$ Schnitten mithilfe des Vibratoms. Während des Schneidevorgangs befand sich das Hirn dauerhaft in PBS, um etwaige Elektrolytverschiebungen sowie ein Austrocknen des Gewebes zu vermeiden. Die $30 \mu \mathrm{m}$ Schnitte wurden mit einer Geschwindigkeit von 0,7 mm/s Vorschub und einer Amplitude von 1,20 mm erstellt. Diese Einstellungen erwiesen sich in den eigens durchgeführten Tests als optimal, um Schnittartefakte möglichst gering zu halten.

Im Folgenden wurden die Schnitte auf Superfrost Plus Objektträger (Thermo Scientific, Menzel-Gläser) aufgezogen und ca. 30 min zum Trocknen in einer möglichst staubfreien Umgebung aufbewahrt. Anschließend erfolgte die NisslFärbung.

\subsection{Optische Messung - Rhodamin123}

\subsubsection{Chemikalien und Aufbau - Das Prinzip}

Die optischen Messungen wurden an akuten Hirnschnitten vorgenommen. Dabei wurde der Hippokampus, im Speziellen die cornu ammonis (CA) 1 Region, betrachtet und die Fluoreszenz in allen drei strati (st. pyramidale, st. radiatum, st. oriens) gemessen. Bei der Auswertung liegt der Schwerpunkt auf dem st. radiatum. 
Für die optischen Messungen wurde der Fluoreszenzfarbstoff Rhodamin123 (Rh123) verwendet. Dabei handelt es sich um ein Kation, welches eine uneingeschränkte mitochondriale Membrangängigkeit aufweist. Das Kation akkumuliert im Zuge des Färbens innerhalb der Mitochondrien, da diese ein besonders negatives Potential aufweisen. Es hindert sich aber bei Anregung aufgrund seiner hohen Konzentration selbst an der Emission („Quenching“). Kommt es zu einer mitochondrialen Depolarisierung und zum gleichzeitigen Ausstrom der Rh123 Kationen über die Mitochondrienmembran zytosolwärts, kann eine suffiziente Emission des anregenden Lichtes stattfinden („Dequenching“). Auf diese Weise kann die Änderung $(\Delta \psi \mathrm{m})$ des Mitochondrienmembranpotentials ermittelt werden (Emaus et al. 1986; Duchen 1999).

Zur Beeinflussung der mitochondrialen Potenzialdifferenz wurden Zyanid ( $\left.\mathrm{CN}^{-}\right)$, ein Hemmer der Zytochrom-c-Oxidase (Komplex IV der Atmungskette), und Carbonylzyanid-p-trifluoromethoxyphenylhydrazon (FCCP), ein künstlicher Atmungskettenentkoppler, genutzt. Dabei war $\mathrm{CN}^{-}$zunächst in destilliertem Wasser $\left(\mathrm{H}_{2} \mathrm{O}\right)$ und FCCP in Dimethylsulfoxid (DMSO) vorgelöst, um Stammlösungen zu erstellen.

Bei dem verwendeten Mikroskop (Abb. 6) handelte es sich um ein aufrechtes Fluoreszenzmikroskop (Axioskop I, Zeiss), auf welchem eine sensitive chargedcoupled device (CCD) Kamera (SensiCam, pco.imaging) angebracht war. Als Lichtquelle kam eine Xenon-Hochdrucklampe (Polychrome II, TILL Photonics) zum Einsatz. Polychrome und CCD-Kamera wurden über die Software TILL Vision (Version 4.0, TILL Photonics, Imago QE) gesteuert. Die Software übernahm auch die Datenerfassung sowie die Datendarstellung. 


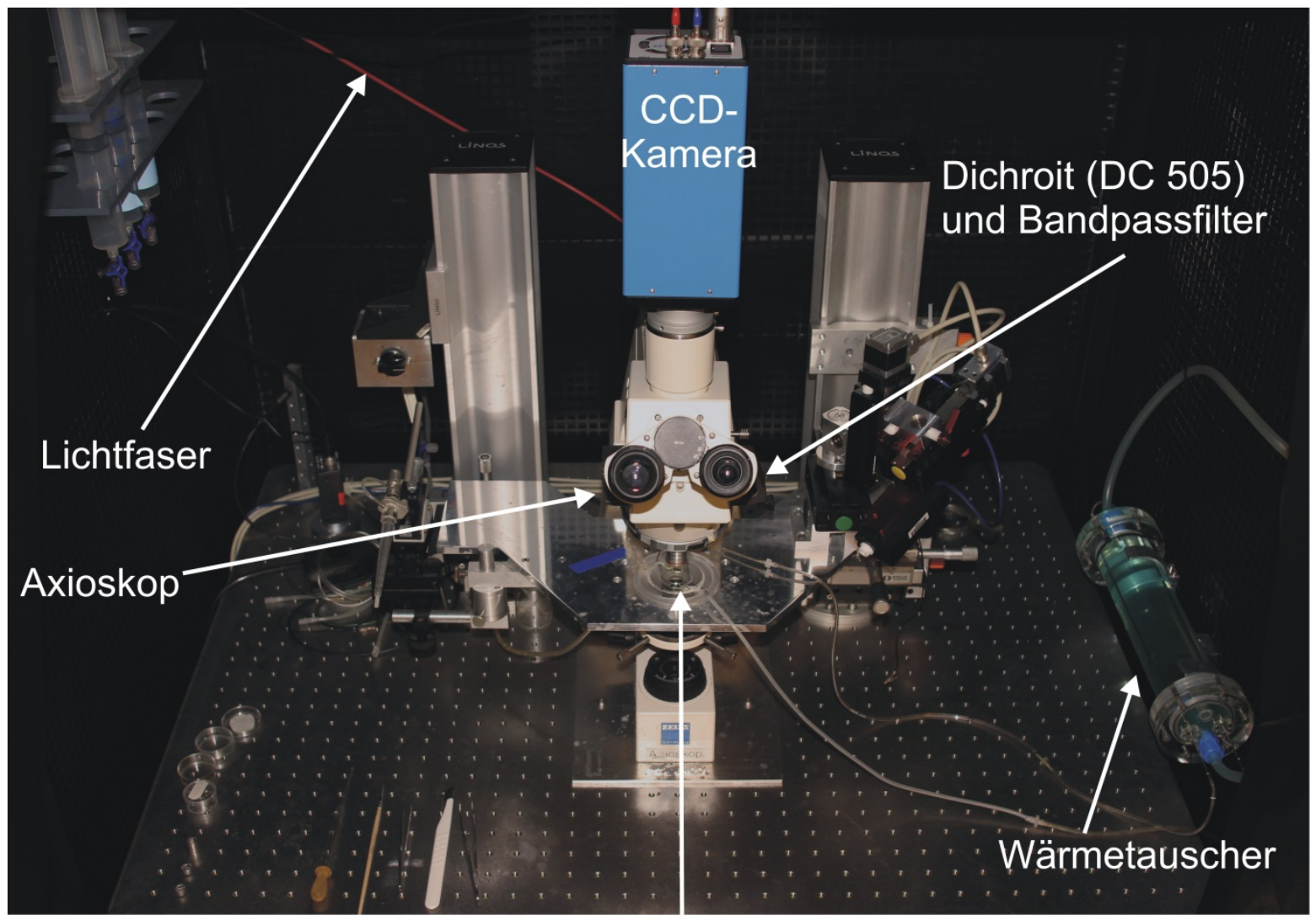

Tauchschnittkammer

\section{Abbildung 6: Messaufbau des Fluoreszenzmikroskops zur Rh123-Messung}

$\mathrm{Zu}$ sehen ist der Messaufbau des Axioskop mit CCD-Kamera und Submersionskammer. Im rechten Bildrand ist der Wärmetauscher zu erkennen. Der gesamte Messaufbau ist zur Vermeidung von Streulicht mittels antistatischer Folie abgedunkelt. Wärmebecken, Peristaltikpumpe und Polychrome stehen zur Vermeidung von Vibrationen außerhalb des eigentlichen Messaufbaus.

Das Anregungslicht wird mit einer Wellenlänge von $480 \mathrm{~nm}$ über eine Lichtfaser und den Auflichtstrahlengang des Mikroskops zum dichroiten Spiegel (DC 505) geleitet, welcher dann das einfallende Licht durch das jeweilige Objektiv auf das Präparat spiegelt. Der Dichroit ist so konzipiert, dass er kurzwelliges Licht unterhalb einer bestimmten Wellenlänge reflektiert, Licht oberhalb jener Wellenlänge jedoch passieren lässt. Dieser Spiegel ist im $45^{\circ}$ Winkel in den Strahlengang eingebracht. Da mit einer bekannten Wellenlänge angeregt wird, kann auch der Dichroit passend gewählt werden, welcher so erlaubt, dass emittiertes Licht vom Exitationslicht effizient getrennt wird und in ausreichendem Maße die CCD-Kamera erreicht.

Bei der Fluoreszenzmikroskopie wurde folgendes Prinzip angewandt (Abb. 7): Werden fluoreszierende Moleküle über eine gewisse Wellenlänge angeregt, so werden deren Elektronen kurzzeitig auf ein höheres Energieniveau angehoben. Sie 
fallen anschließend aber spontan auf ihr ursprüngliches Niveau zurück. Hierbei wird in geringem Maße Energie in Form von Lichtquanten frei, welche jedoch energieärmer sind. Folglich handelt es sich um Licht größerer Wellenlänge. Das auf diese Weise emittierte Licht passiert den dichroiten Spiegel, ohne reflektiert zu werden, und wird mittels eines Emissionsfilters (Emitter, Bandpass-Filter, BP 535/35 nm) auf den entscheidenden Wellenlängenbereich reduziert.

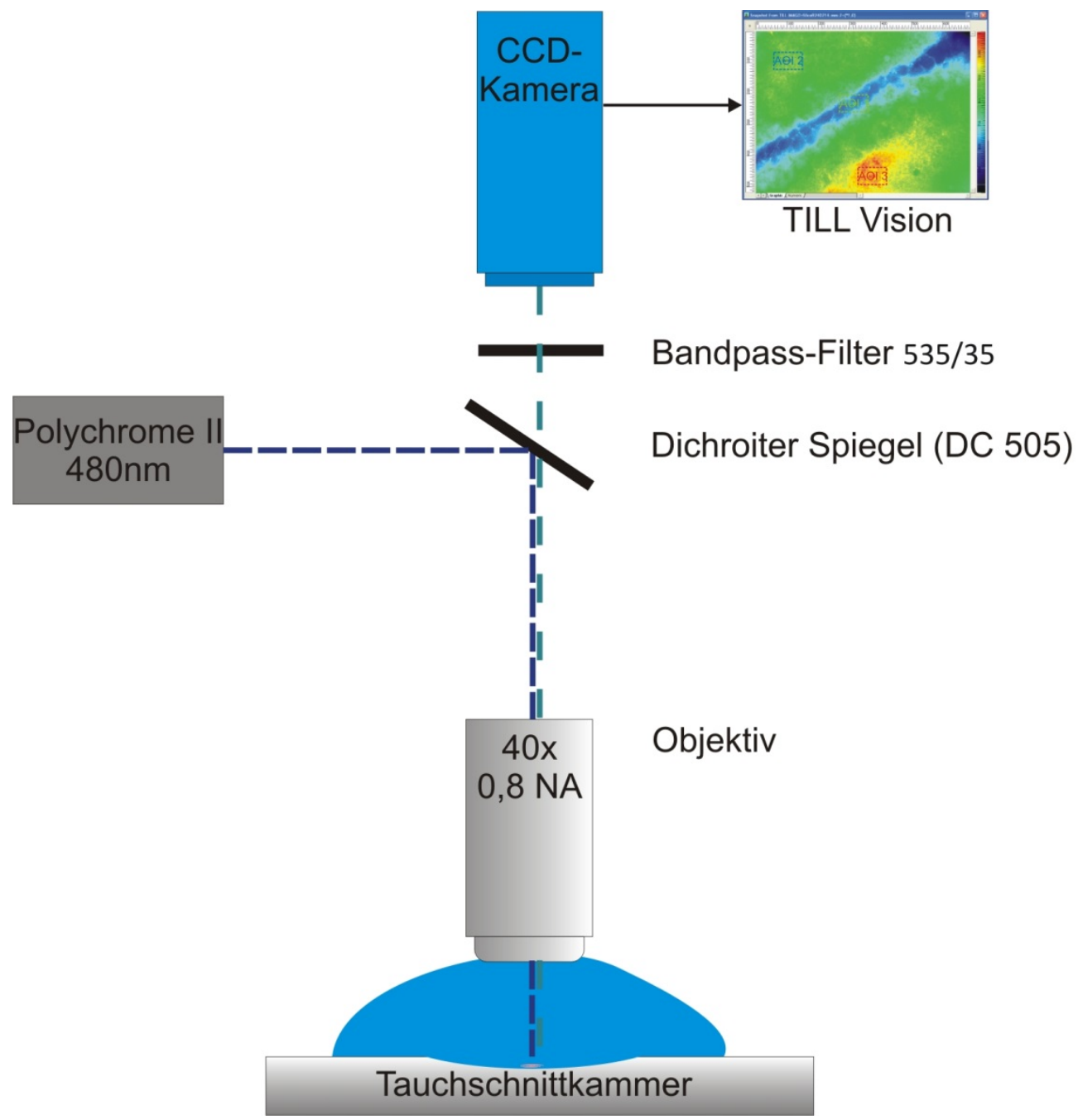

\section{Abbildung 7: Schematische Darstellung der Fluoreszenzmikroskopie}

Das von der Xenon-Hochdrucklampe des Polychroms ausgehende Licht (480 $\mathrm{nm}$ ) trifft auf den dichroiten Spiegel und wird im $45^{\circ}$ Winkel reflektiert, durch das Objektiv fokussiert und regt Rh123 innerhalb des slices an. Das emittierte Licht passiert Objektiv und dichroiten Spiegel und wird von der sensitiven CCD-Kamera erfasst. Der emissionsseitige Bandpass-Filter (Emitter) hält ungewünschte Fluoreszenzanteile zurück. Polychrome und CCD-Kamera werden über TILL Vision angesteuert. 


\subsubsection{Ablauf der Messungen}

Die akuten Hirnschnitte wurden zunächst für mindestens 60 min in der Präinkubationskammer belassen, um eine zelluläre Regeneration zu gewährleisten. Anschließend wurden die Schnitte in eine miniaturisierte Färbekammer (Funke et al. 2007) überführt. Hier fand die Färbung mittels $5 \mu \mathrm{M}$ Rh123 statt. Nach 15minütiger Inkubationszeit konnten die Hirnschnitte in die Submersionskammer gelegt und mit einer besonders angefertigten Harfe beschwert und immobilisiert werden. Die Submersionskammer wurde durchgehend mit ACSF durchspült. Diese wurde zuvor mithilfe eines Wasserbades (Haake, Thermo Scientific) auf $38^{\circ} \mathrm{C}$ erwärmt, mit Carbogen begast und über eine Peristaltikpumpe (Watson Marlow 205S, 32 U/min) der Messkammer zugeführt. Zwischengeschaltet waren außerdem ein Windkessel und ein Wärmetauscher, um die über Tygon®-Schläuche transportierte Lösung gasfrei und auf ca. $32^{\circ} \mathrm{C}$ erwärmt in die Submersionskammer zu leiten. Die Applikation der oben erwähnten Substanzen fand über dasselbe Schlauchsystem statt, sodass mit einer zeitlichen Differenz zwischen Applikationsbeginn und Wirkeintritt gerechnet werden musste ( $\sim \mathrm{min})$. Über eine Unterdruckpumpe wurde die Lösung schließlich wieder abgesaugt und verworfen.

Zur Erstellung eines Übersichtsbildes wurde ein Objektiv mit kleiner Vergrößerung gewählt (Zeiss Epiplan 5x, 0.13 NA). Für das Übersichtsbild wurde nicht das Prinzip der Fluoreszenz, sondern jenes der Transmission gewählt. Die Fokussierung des st. radiatum und die eigentliche Messung wurde mit einem 40x Wasserimmersionsobjektiv (Zeiss Achroplan, $0.8 \mathrm{NA}$ ) ausgeführt. Nachdem die CA1 Region aufgesucht war, konnte ein Übersichtsbild mit der Fluoreszenz von Rh123 zur Orientierung erfolgen. Mithilfe dieses Übersichtsbildes konnte dann die so genannte region of interest (ROI) definiert werden. In jedes stratum wurde eine ROI positioniert. Folgend wurde ein Protokoll initiiert, welches den Einstellungen des Übersichtsbildes entsprach: Die Wellenlänge des anregenden Lichtes betrug $480 \mathrm{~nm}$; die Belichtungszeit belief sich auf $5 \mathrm{~ms}$. Durch ein 2x2 binning wurden jeweils benachbarte Pixel zusammengefasst und so die Sensitivität der Fluoreszenzdetektion erhöht, wohingegen die Auflösung, die bei dieser Methode von geringerer Relevanz ist, herabgesetzt war. Dem Protokoll folgend wurde alle $5 \mathrm{~s}$ ein Bild aufgezeichnet und die durch TILL Vision (Abb. 8) berechnete Fluoreszenz gleichzeitig graphisch für jede ROI einzeln dargestellt. Es sei auch 
erwähnt, dass die farbigen Bilder von TILL Vision lediglich aus Pseudofarben (256 Farben, 8 Bit) bestehen und ausschließlich Aufschluss über die Intensität des emittierten Lichtes geben, aber keinesfalls der tatsächlichen Farbgebung entsprechen. TILL Vision lieferte außerdem ein Livebild, sodass aktuelle Veränderungen in der Fluoreszenz mit einer zeitlichen Verzögerung von 5 Sekunden beobachtet werden konnten. Nach dem Setzen der ROIs wurde dann für einige Zeit die Nivellierung abgewartet. Als graphisches Korrelat diente die stabile baseline. Sobald diese gegeben war, konnte mit der Applikation der ersten Substanz (100 $\mu \mathrm{M} \mathrm{NaCN}^{-}, 2$ min) begonnen werden. Nach jeder Substanzapplikation wurde gewartet, bis sich die baseline wieder hergestellt hatte. Dann wurde die Substanz mit höherer Konzentration (1 $\mathrm{mM} \mathrm{NaCN}^{-}, 2 \mathrm{~min}$ ) appliziert. Am Ende der Messung wurde die Atmungskette irreversibel entkoppelt ( 5 HM FCCP, 5 min), um eine maximale Rh123-Antwort zu erhalten. Der dritte Schritt diente zur späteren Berechnung des Verhältnisses. 


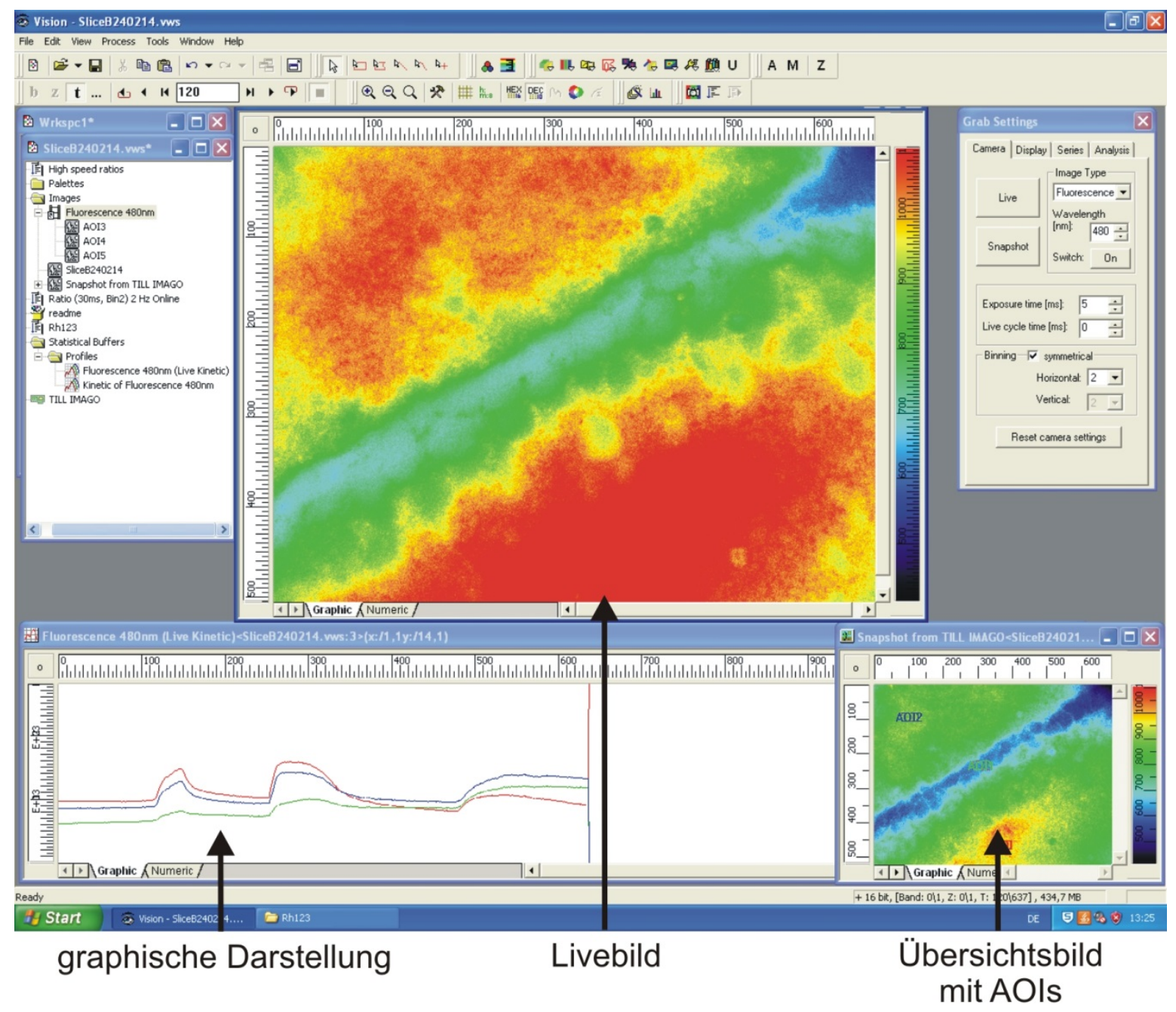

\section{Abbildung 8: Bildschirmdarstellung einer Messung-TILL Vision}

Großes Livebild mit allen drei strati. Unten Übersichtsbild sowie die graphische und zeitliche Darstellung der Intensität zu den einzelnen ROIs. Am rechten Bildrand ist das Bedienfeld für die Kamera eingeblendet.

Da bei dieser Methode die Schwierigkeit darin bestand, die fokussierte Ebene und die exakte Einstellung der Submersionskammer genau einzuhalten, wurden mehrere Maßnahmen ergriffen: Zuerst wurde die Submersionskammer für 30 min vorgewärmt, um eventuelle Temperatureinflüsse auszuschließen. Des Weiteren konnte gegebenenfalls während der Aufzeichnung der baseline nachfokussiert werden. Darüber hinaus erfolgte zusätzlich eine zweite Nachauswertung, in der die Position der ROls, unter Berücksichtigung von Artefakten, erneut gesetzt werden konnten. Die getroffenen Maßnahmen waren nur in wenigen Fällen und zumeist nur vor der Applikation des Entkopplers FCCP notwendig. 
Die detaillierte und quantitative Auswertung sowie Mittelung der Messdaten erfolgte mithilfe des Programms Microsoft Excel. Aus dem jeweiligen Antwortgipfel und der baseline wurden jeweils 5 aufeinander folgende Messdaten gemittelt, um dem baseline-Rauschen entgegenzuwirken.

\subsection{Photometrische Methoden}

Für die photometrischen Messungen, die Teil dieser Arbeit sind, wurden, sofern nicht anders erwähnt, alle Chemikalien und Assays von der Firma Sigma Aldrich bezogen.

Am Gewebe des Frontalkortex aus der Hirnschnittpräparation wurden zwei biochemische Methoden durchgeführt: Die Messungen der Lipidperoxidation (1) und der Proteincarbonylierung (2), beides Marker der zellulären oxidativen Schädigung, fanden Anwendung. Beide Tests wurden zunächst neu etabliert. So wurden für beide Methoden anhand der Herstellerprotokolle den Mess- und Versuchsbedingungen angepasste neue Protokolle entworfen, zu denen jeweils eine Verifizierung stattgefunden hat, auf die zu einem späteren Zeitpunkt eingegangen wird.

Da beide Assays photometrische Messverfahren darstellen, wird an dieser Stelle die Photometrie, speziell die Transmissionsmessung, vorgestellt: Dabei handelt es sich um eine Methode zur Konzentrationsbestimmung von zumeist in einer Lösung befindlichen Stoffen, die in Abhängigkeit von der Konzentration, dem stoffspezifischen Extinktionskoeffizienten und der Transmissionsstrecke Änderungen unterliegt. Diesen Zusammenhang beschreibt das Bouguer-Lambert-Beersche Gesetz:

$$
E_{\lambda}=\lg \left(\frac{I_{0}}{I_{1}}\right)=\varepsilon_{\lambda} \cdot c \cdot d
$$

$E_{\lambda}$ : Extinktion, also die Lichtabsorption durch das Medium

$I_{0}$ : Intensität des einfallenden Lichtes

$I_{1}$ : Intensität des gemessenen transmittierten Lichtes

$\varepsilon_{\lambda}$ : $\quad$ Stoffspezifischer Extinktionskoeffizient

$c$ : Konzentration der gemessenen Substanz

$d$ : $\quad$ Schichtdicke der Küvette (in der Regel $1 \mathrm{~cm}$ ) 
Diese Gleichung verdeutlicht das Prinzip der Photometrie: Bei bekanntem stoffspezifischem Extinktionskoeffizienten, bekannter Schichtdicke sowie bekannter und gemessener Intensität ist die Extinktion proportional der Konzentration der Lösung. So kann aus dem Ausmaß der Extinktion die Konzentration berechnet werden. Dabei muss der Extinktionskoeffizient entweder gegeben sein oder mittels einer Verdünnungsreihe (Eichkurve) bestimmt werden. Außerdem muss sichergestellt sein, dass in der Lösung keine interferierenden Substanzen vorhanden sind. Abb. 9 zeigt schematisch die Funktionsweise eines Photometers. Es ist für die Abgabe einer exakten Wellenlänge und deren Intensität sowie die genaue Messung des transmittierten Lichtes zuständig.

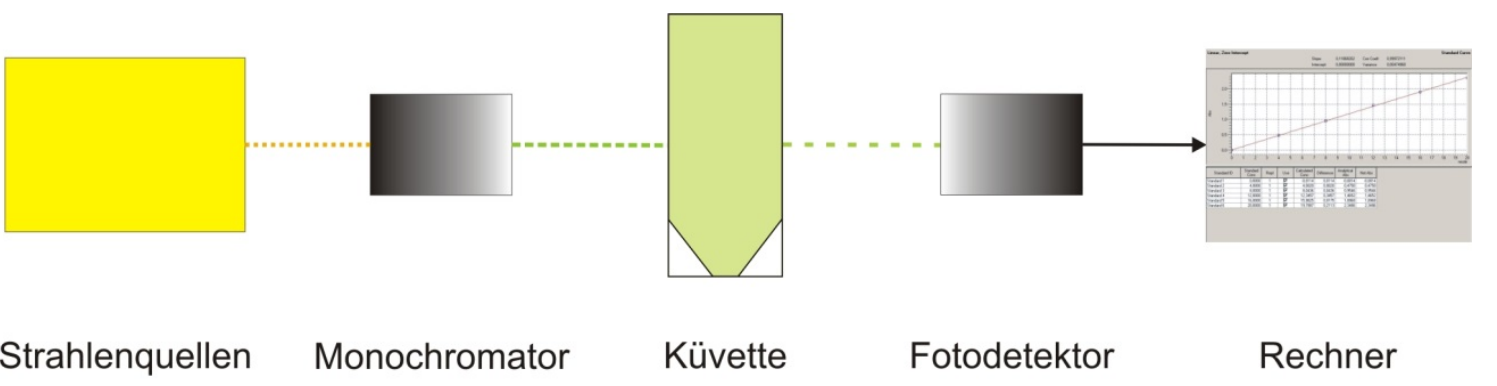

\begin{abstract}
Abbildung 9: Schematische Darstellung der Photometrie
Die eingestellte Wellenlänge wird vom Monochromator herausgefiltert und die Intensitätsabnahme bei Beleuchtung der Küvette gemessen. Anschließend werden die Daten von der Kontrollsoftware graphisch verarbeitet.
\end{abstract}

In dieser Arbeit wurden zwei verschiedene Photometer verwendet. Zum einen ein Spectrophotometer DU 800 (Beckmann Coulter) mit gleichnamiger Software und 1,5 ml Küvetten (Brand) zur Messung im sichtbaren Wellenlängenbereich. Für die Messungen im ultravioletten Bereich wurde ein Ultrospec 3000 (Pharmacia Biotech) und $70 \mu \mathrm{l}$ UV-Küvetten (Brand) genutzt. Die durchschnittliche Messzeit des Photometers war auf 0,5 s adjustiert. 


\subsubsection{Lipidperoxidation}

Die Lipidperoxide kennzeichnen den oxidativen Verfall von Lipiden und stellen somit einen Parameter für das Ausmaß des oxidativen Stresses im untersuchten Gewebe dar. Vielfach ungesättigte Fettsäuren reagieren mit freien Radikalen in einer Kettenreaktion, die zu vielfältigen Produkten führen kann, unter anderem zu Malondialdehyd (MDA). MDA bildet in einer Reaktion mit Thiobarbitursäure (TBA) ein photometrisch bestimmbares Produkt (Schmedes und Hølmer 1989, Abb. 10). Die Konzentration dieses Produktes kann in einem Photometer bei der Wellenlänge $\lambda_{532 \mathrm{~nm}}$ bestimmt werden. Erstere steht in einem linearen Verhältnis zu der Lipidperoxidation.

Abbildung 10: Die Entstehung von MDA und dessen Reaktion mit TBA

In einem ersten Schritt greift das Radikal eine Methylgruppe in direkter Beziehung zu einer Doppelbindung an. Das Produkt reagiert mit Sauerstoff zu einem Peroxylradikal (ROO`). Über Zwischenschritte entsteht dann unter diversen Möglichkeiten auch MDA, welches mit TBA zum photometrisch messbaren Produkt reagiert.
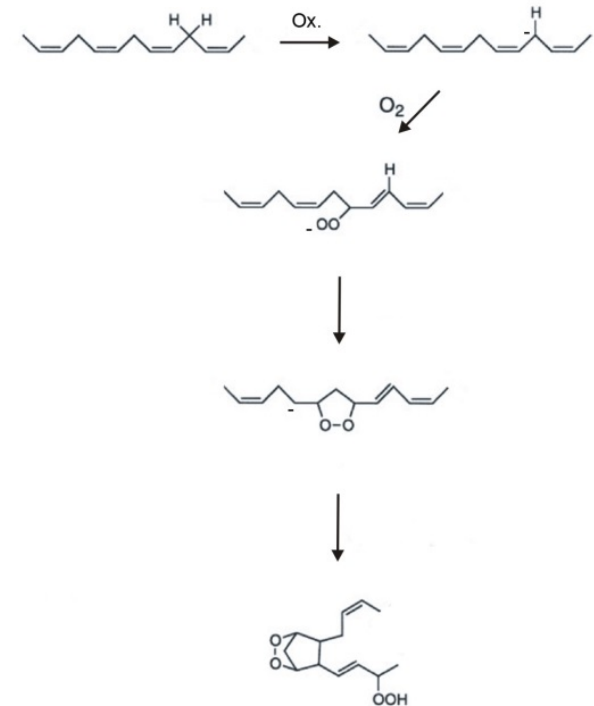

$$
\text { multiple Isoformen }
$$

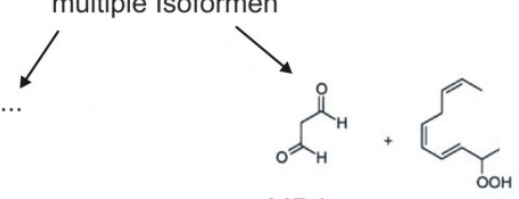

2<smiles>Oc1cc(O)nc(S)n1</smiles>

MDA

TBA

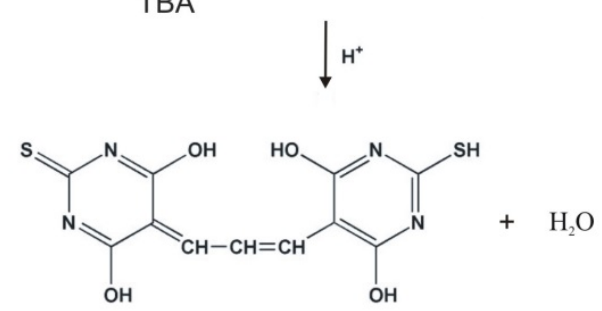


Die Messung der Lipidperoxide erfolgte mithilfe des Assay Kits Lipid Peroxidation (MAK085-1KT), welches sowohl einen photometrischen als auch einen fluoreszentrometrischen Ansatz zulässt. Wie bereits erwähnt, wurde das Protokoll des Herstellers insofern abgeändert, als es für den speziellen Fall mit Hirngewebe von Mäusen und Standardküvetten anwendbar ist.

Zuerst wurde die TBA-Lösung angesetzt. Dazu wurden die mitgelieferten TBAFläschchen mit 7,5 ml reiner Essigsäure versetzt und bis $25 \mathrm{ml} \mathrm{mit} \mathrm{H}_{2} \mathrm{O}$ aufgefüllt. Zum vollständigen Lösen des TBA-Pulvers wurde ein Ultraschallbad (USC100T, VWR International) eingesetzt. Dann erfolgte mittels MDA-Stammlösung die Erstellung einer Verdünnungsreihe mit Konzentrationen von 0 bis $20 \mathrm{nM}$. Im nächsten Schritt fand die Probenvorbereitung statt. Zu jedem untersuchten Tier erfolgte die Bewertung anhand von Doppelproben. So wurden pro Tier jeweils zwei Proben mit etwa $10 \mathrm{mg}$ Hirngewebe an einer Feinwaage eingewogen. Das tatsächliche Gewicht schwankte hierbei.

Die $10 \mathrm{mg}$ Gewebeproben wurden in $300 \mu \mathrm{l}$ MDA-Lysepuffer auf Eis mithilfe eines Ultraschall-Homogenisators (Bandelin electronics, Sonoplus GM3100 mit UW3100 Sonotrode) homogenisiert. Der Lysepuffer enthielt $3 \mu \mathrm{l}$ 100-fach Butylhydroxytoluol $(\mathrm{BHT})$, ein synthetisch hergestelltes Antioxidans. Es folgte die Zentrifugation der Proben bei 13,000 x g für 10 min (Mikro 220, Hettich Zentrifuge). Nach der Zentrifugation wurden $200 \mu$ des Überstandes in ein Mikroreaktionsgefäß überführt. Die zu diesem Zeitpunkt bereitstehenden Mikroreaktionsgefäße sowohl der Proben als auch des MDA-Standards wurden dann mit $600 \mu \mathrm{l}$ der TBA-Lösung versetzt, mithilfe eines Schüttlers durchmischt und für 60 min bei $95^{\circ} \mathrm{C}$ inkubiert (MHR 23, HLC BioTech). Anschließend kühlten die Proben im Eisbad für 10 min ab.

Da die Proben grundsätzlich eine Trübung aufwiesen - vermutlich durch Proteinpräzipitate - wurden sie nach Absprache mit dem technischen Service von Sigma Aldrich entgegen dem Herstellerprotokoll nicht gefiltert, sondern für $30 \mathrm{~s}$ bei $13,000 \times \mathrm{g}$ abzentrifugiert. $600 \mu \mathrm{l}$ des Überstandes wurden dann in Küvetten überführt und die Absorption - ein logarithmisches Verhältnis aus $I_{0}$ und $I_{1}$ - bei $\lambda_{532 n m}$ gemessen. Zuerst wurde die Standardkurve erstellt, die im Gerät hinterlegt werden konnte. Das Photometer berechnete anschließend basierend auf dieser Standardkurve die Konzentration der Proben. In der Auswertung erfolgte die Normierung auf die Menge des eingewogenen Gewebes. Außerdem wurden die 
doppelt ausgeführten Messungen gemittelt. Alle Proben wurden nach obigem Protokoll bearbeitet, sodass die Vergleichbarkeit der unterschiedlichen Probengruppen zu jeder Zeit gegeben ist.

\subsubsection{Proteincarbonylierung}

Die Proteincarbonyle werden schon seit einigen Jahren zur Bestimmung des oxidativen Stressniveaus verwendet und gelten als verlässlicher Marker (Levine et al. 1990; Dalle-Donne et al. 2003). Reaktive Sauerstoffspezies führen über Oxidation des Proteinrückgrates zur Fragmentierung und Inaktivierung der Proteine und zu Schäden an den Seitenketten. Des Weiteren können Kreuzverbindungen zwischen Proteinen auftreten. Findet eine Oxidation der Seitenketten statt, so entstehen stabile Ketone oder Aldehyde (Berlett und Stadtman 1997). Diese werden bevorzugt für die Bestimmung verwendet. Dabei wird das Nachweisreagenz 2,4-Dinitrophenylhydrazin (DNPH) verwendet. Es reagiert mit den Aldehyd- bzw. Ketogruppen der Carbonyle zu 2,4-Dinitrophenylhydrazon, welches photometrisch $\left(\lambda_{375} \mathrm{~nm}\right)$ detektiert werden kann (Abb. 11). Neben der photometrischen Bestimmung bestehen auch immunologische Nachweismethoden, die in dieser Arbeit jedoch nicht verwendet wurden. 


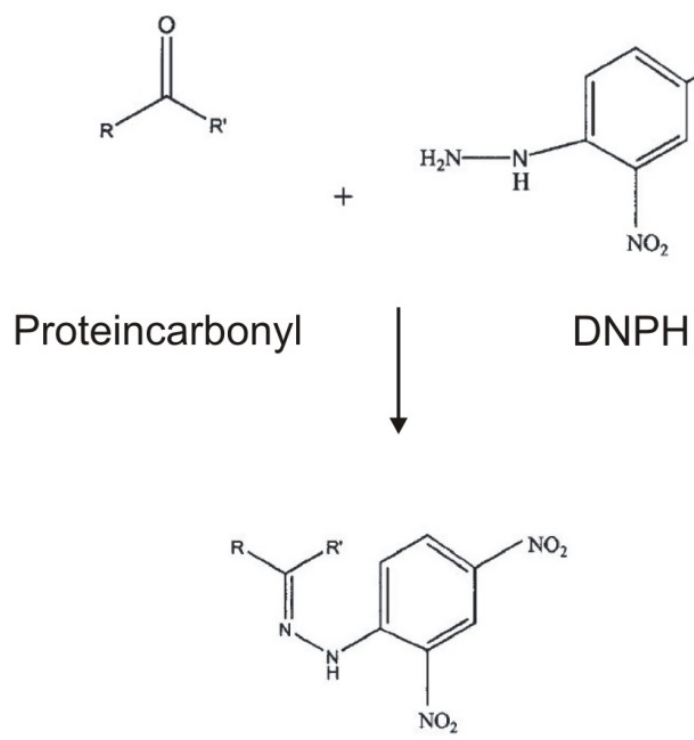

\section{Abbildung 11: Darstellung der Reaktion zwischen einem Carbonyl und DNPH}

Die Carbonylgruppe des Proteins reagiert in einer Kondensationsreaktion mit dem Nachweisreagenz unter Bildung des photometrisch bestimmbaren 2,4Dinitrophenylhydrazon $\left(\lambda_{375} \mathrm{~nm}\right)$.

Für die Bestimmung der Proteincarbonyle wurde ebenfalls ein Assay Kit (MAK094$1 \mathrm{KT}$ ) verwendet, welches ähnlich dem Lipidperoxidation-Kit auf die spezifischen Versuchsbedingungen neu abgestimmt und etabliert wurde. Außerdem fanden noch zwei weitere Assays Anwendung, da die Menge der Carbonyle auf die Gesamtproteinmenge bezogen wurde. So wurde anfangs zur Bestimmung der Proteinmenge in der Ausgangsprobe zunächst ein Bradford-Assay ausgeführt, da der Proteincarbonyl-Assay eine Ausgangskonzentration von etwa $10 \mathrm{mg} / \mathrm{ml}$ Protein erforderte. Außerdem wurde nach der Proteincarbonyl-Bestimmung der Bicinchoninic Acid (BCA) Assay (BCA1 B9643) genutzt. Dieser spezielle Assay ist erforderlich, da der üblicherweise genutzte Bradford-Assay eine Interferenz mit dem Guanidin des Proteincarbonyl-Assays zeigt. So ist hiermit nachträglich eine exakte Proteinbestimmung der bereits gemessenen Probe möglich, sodass in diesem Bezug eine genaue Normierung erfolgen kann.

Die Gewebeproben wurden in $500 \mu \mathrm{l}$ CelLytic M Medium (C2978) am UltraschallHomogenisator aufgelöst. Nach 15-minütiger Inkubationszeit wurden die Proben bei 14,000 x g für 15 min zentrifugiert, um unlösliche Fragmente zu sedimentieren. Anschließend wurde der Überstand auf zwei Aliquots aufgeteilt. An beiden Proben wurden alle drei Assays durchgeführt. Die hierbei gewonnenen Daten der 
Doppelproben wurden analog zum Lipidperoxidationsassay für jede behandelte Maus gemittelt. Außerdem wurde ein Proteinstandard mittels Bovinem Serum Albumin (BSA) von $1 \mathrm{mg} / \mathrm{ml}$ erstellt. Hiermit konnte die Messung der Standardkurven beider Proteinmengenbestimmungen erfolgen. Es wurden $50 \mathrm{mg}$ BSA-Pulver in $50 \mathrm{ml}$ CelLytic gelöst, Aliquots erstellt und bei $-80^{\circ} \mathrm{C}$ übergangsweise bis zur Verwendung gelagert.

Der Bradford-Assay wurde mit den verdünnten (1:10; 1:20) Proben und vier Standards ( $0 \mathrm{mg} / \mathrm{ml}, 0,25 \mathrm{mg} / \mathrm{ml}, 0,5 \mathrm{mg} / \mathrm{ml}, 1 \mathrm{mg} / \mathrm{ml}$ ) zur groben Einschätzung des Proteingehalts der Ausgangsprobe ausgeführt. Dazu wurde dem Herstellerprotokoll gefolgt. Es wurden $50 \mu \mathrm{l}$ Probe und 1,5 ml Bradford Reagenz zusammengeführt, durchmischt und in 1,5 ml Küvetten gemessen. Die Proben ruhten vor der Messung für mindestens $10 \mathrm{~min}$, aber nie länger als $50 \mathrm{~min}$. Die Absorption der Proben und der Standards wurde innerhalb von $10 \mathrm{~min}$ bei $\lambda_{595} \mathrm{~nm}$ bestimmt. Die vorherige Verdünnung der Ausgangsproben war notwendig, da sich der Messbereich des Bradford Reagenzes auf nur 0,1-1,4 mg/ml erstreckt, der Proteincarbonyl-Assay aber eine Konzentration von 10 mg/ml erfordert.

Es folgte nach eigens modifiziertem und etabliertem Protokoll die Bestimmung der Proteincarbonyle: Im Zuge der Etablierung fanden Kontrollen statt, die zeigen sollten, ob die Ausgangsproben eine signifikante Menge an interferierenden Nukleinsäuren enthielten. Nach Rücksprache mit dem technischen Service der Herstellerfirma wurde dazu die optische Dichte der Proben bei $\lambda_{280 \mathrm{~nm}}$ und bei $\lambda_{260 \mathrm{~nm}}$ gemessen. Das Verhältnis gab Aufschluss darüber, dass keine signifikante Menge an interferierenden Nukleinsäuren vorlag und die Behandlung der Proben mit 10\% Streptozocin somit ausgelassen werden konnte. Der Proteincarbonyl-Assay wurde deshalb folgendermaßen ausgeführt: Jede Probe (150 $\mu \mathrm{l})$ wurde mit $150 \mu \mathrm{l}$ DNPHLösung versetzt, sorgfältig durchmischt und für 10 min ruhen gelassen. Anschließend wurden $45 \mu$ l einer 100\% Trichloressigsäure (TCA) zur Präzipitation der Proteine hinzugegeben. Die Mischung wurde für 5 min auf Eis inkubiert. Die Proben wurden dann mit 13,000 x g für 2 min zentrifugiert. Das so entstandene Pellet wurde vom Überstand befreit und konnte anschließend mit Aceton von jeglichem freien DNPH gereinigt werden. $750 \mu$ leiskaltes $\left(-20^{\circ} \mathrm{C}\right)$ Aceton wurden zu jedem Pellet hinzugegeben, das Pellet mittels Ultraschallbad gelöst und anschließend für weitere $5 \mathrm{~min}$ bei $-20^{\circ} \mathrm{C}$ inkubiert. Dann wurden die Proben erneut bei $13,000 \times g$ für 2 min zentrifugiert. Der Überstand mit freiem DNPH wurde 
entfernt und der letzte Schritt der Zentrifugation wiederholt, um eine möglichst effiziente Reinigung des Pellets zu erzielen. Schlussendlich konnte das nun DNPHfreie Pellet in $330 \mu \mathrm{l} 6 \mathrm{M}$ Guanidinlösung gelöst werden. Dabei war eine Ultraschallbehandlung für $10 \mathrm{~s}$ und eine anschließende Inkubation bei $60^{\circ} \mathrm{C}$ für 20 min erforderlich. Nachdem die Proben auf Raumtemperatur abgekühlt waren, wurden $300 \mu \mathrm{l}$ in UV-gängige Küvetten überführt. Mittels $300 \mu \mathrm{l}$ Guanidin $6 \mathrm{M}$ Lösung wurde der Leerwert bereitgestellt. Die Absorption wurde bei $\lambda_{375} \mathrm{~nm}$ gemessen.

Mit dem dritten Assay (BCA Assay) wurde dann die tatsächlich noch in der Lösung befindliche Proteinmenge gemessen. $30 \mu$ des übrigen Proteincarbonyl-Assays wurden mit $600 \mu \mathrm{l}$ Reagenz zusammengeführt. Das Reagenz bestand aus zwei Komponenten - Bicinchoninicsäure und Kupfer-II-sulfat -, die am jeweiligen Versuchstag im Verhältnis 50:1 gemischt werden mussten. Auch wurde eine Standardreihe mithilfe der bereits erwähnten Albumine angefertigt. Wichtig war an dieser Stelle, dass alle Reaktionen, also sowohl die Testlösung als auch die Standardkurve, mit möglichst geringem Zeitverzug angesetzt wurden, um eine hohe Vergleichbarkeit zu garantieren. Alle Proben wurden für 30 min bei $37^{\circ} \mathrm{C}$ inkubiert und kühlten vor der Messung auf Raumtemperatur ab. Am Photometer wurde abschließend eine Standardkurve erstellt und die Proben mit Hinblick auf diese bei einer Wellenlänge von $\lambda_{562 \mathrm{~nm}}$ ausgelesen. 


\subsection{Morphologische Beurteilung durch Nissl-Färbung}

Der morphologischen Beurteilung des Gewebes mittels Nissl-Färbung liegen bereits gewonnene Erkenntnisse zur Morphologie sowohl bei Rett-Patientinnen als auch bei Mecp2 defizienten Mäusen zu Grunde. Es zeigte sich, dass sowohl die Zellsomata bei Rett-Patientinnen verkleinert sind, als auch ihre Packungsdichte erhöht ist (Bauman et al. 1995). Gleiches gilt für die MeCP2 defizienten Mäuse in der CA2-Region des Hippokampus (Chen et al. 2001). Durch unsere Arbeitsgruppe konnten diese Ergebnisse bestätigt und erweitert werden. Es wurde gezeigt, dass zusätzlich auch die CA1-Region verkleinerte Neuronen aufweist und die Gesamtgröße der Hirnschnitte im Bereich des Hippokampus gegenüber den Wildtypen verringert ist (Fischer et al. 2009).

In der oben genannten Literatur (Fischer et al. 2009) wurde zur Darstellung der Zellsomata die Nissl-Färbung mittels Thionin genutzt. Analog zu den früheren Arbeiten wurden auch im Rahmen dieser Arbeit zuerst Hirnschnitte mit Thionin gefärbt. Dabei wurde dem arbeitsgruppeninternen Protokoll gefolgt. Es stellte sich jedoch heraus, dass die Färbung in dieser Form wenig erfolgversprechend war. Deshalb wurde stattdessen der Farbstoff Kresylviolett (Cresyl Violet acetate) eingeführt (Abb. 12). Auch wurde das Protokoll der Thionin-Färbung entsprechend modifiziert, sodass nun ein zuverlässiges Protokoll für die Nissl-Färbung mit Kresylviolett vorliegt. Diesem Protokoll folgend entstanden alle der Arbeit zu Grunde liegenden Nissl-Färbungen der PFA-fixierten Hirnschnitte.
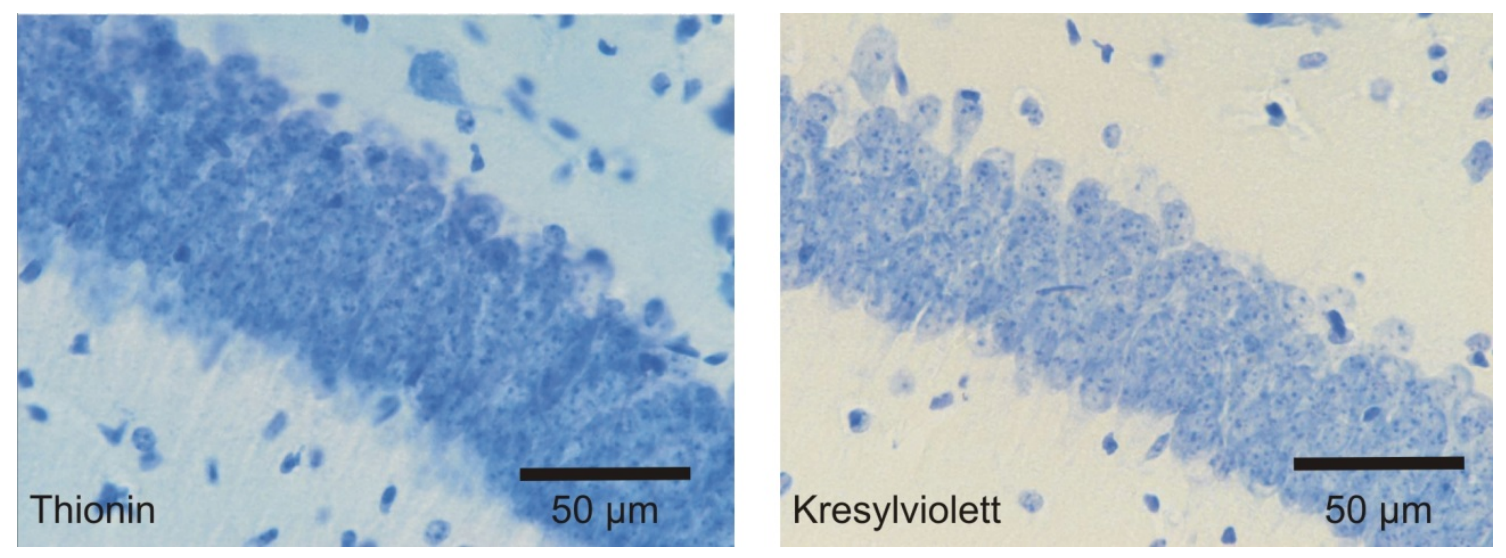

\section{Abbildung 12: Kresylviolett und Thionin im Vergleich}

Zu sehen ist das CA1-Feld des st. pyramidale einer WT-Maus. Dabei wurde ein $40 x$ Objektiv verwendet. In der rechts abgebildeten Kresylviolettfärbung konnten eine höhere Zelldifferenzierung und auch ein besserer Kontrast erreicht werden. 
Zuerst wurde die Kresylviolettlösung hergestellt. Dazu wurden 1,25 g Kresylviolettpulver mit $0,75 \mathrm{ml}$ reiner Essigsäure versetzt und anschließend auf $250 \mathrm{ml}$ mit destilliertem Wasser aufgefüllt. Mittels eines beheizten Magnetrührers wurde das Gemisch gelöst. Anschließend kühlte das Gemisch ab und Unlösliches wurde herausgefiltert. Die so entstandene Kresylviolettlösung konnte mehrfach verwendet werden. Als nächstes wurden die Gewebeschnitte, die zuvor aus PFAfixiertem Gewebe erstellt worden waren (siehe Kapitel 2.3), in einer absteigenden Alkoholreihe bewässert (95\% Ethanol für 15 min, 70\% Ethanol für 1 min, 50\% Ethanol $1 \mathrm{~min}, \mathrm{H}_{2} \mathrm{O}$ für $2 \mathrm{~min}, \mathrm{H}_{2} \mathrm{O}$ für $1 \mathrm{~min}$ ). Diese Rehydrierung war notwendig, da der Farbstoff wasserlöslich ist. Es folgte die 2-minütige Färbephase mit Kresylviolett. Der Überschuss wurde mit $\mathrm{H}_{2} \mathrm{O}$ für 1 min entfernt. Nun folgte die Entwässerung und Differenzierung: 50\% Ethanol für eine Minute, gefolgt von 70\% Ethanol, versetzt mit reiner Essigsäure (1 ml Essigsäure pro $100 \mathrm{ml}$ 70\% Ethanol). Die Essigsäure war für die Differenzierung der Färbung notwendig. Anschließend wurde die Säure mittels 95\% Ethanol für 2 min entfernt. Zum Ende erfolgte noch einmal die Entwässerung der Schnitte mit 99\% Ethanol. Der letzte Schritt war die Reinigung mit Xylol für $5 \mathrm{~min}$. Alle Schritte fanden in Färbekammern unter dem Abzug statt. Nach dem letzten Schritt trockneten die Schnitte für 15 min ebenfalls unter dem Abzug, sodass Xyloldämpfe sofort beseitigt wurden. Schließlich konnten die Schnitte mit einem Deckmedium (Eukitt quick-hardening mounting medium) beträufelt und mit Deckgläsern eingedeckt werden. Das Deckmedium härtete über Nacht unter dem Abzug aus.

Die Auswertung der nach Nissl gefärbten Schnitte erfolgte an einem Digitalmikroskop (Nikon Coolscope), welches mit einem Computer auf Basis der Software NIS-Elements (Version 3.22.13, Laboratory Imaging) kommunizierte. Hiermit wurde zuerst mit einem 2x Objektiv ein Übersichtsbild aufgenommen (Abb. 13). In dem Übersichtsbild wurden die Hemisphärengröße, die Hippokampusgröße und die Schichtstärke des Kortex bestimmt. Mit einem 40x Objektiv erfolgten dann die Vermessung der Somatagrößen und der Schichtdicke des st. pyramidale. Für jedes Tier wurden drei Hirnschnitte anhand eindeutiger Kriterien ausgewählt. Mithilfe des Allen Brain Atlas für Mäuse fand eine genaue Orientierung der rostrokaudalen Achse statt. Dabei waren drei Kriterien ausschlaggebend: Zuerst wurde darauf geachtet, dass, der rostro-kaudalen Achse folgend, die Zellsomata des Hippokampus rechtwinklig angeschnitten waren. Außerdem wurde die Größe der 
Hirnventrikel beurteilt. Diese sollten möglichst gering angeschnitten sein und in direkter Beziehung zu den jeweiligen Hippokampi liegen. Zuletzt lag das Augenmerk auf den medialen habenulae. Diese stellen eine makroskopisch gut beurteilbare Hirnregion dar und eignen sich deshalb zur Orientierung in der rostrokaudalen Achse.

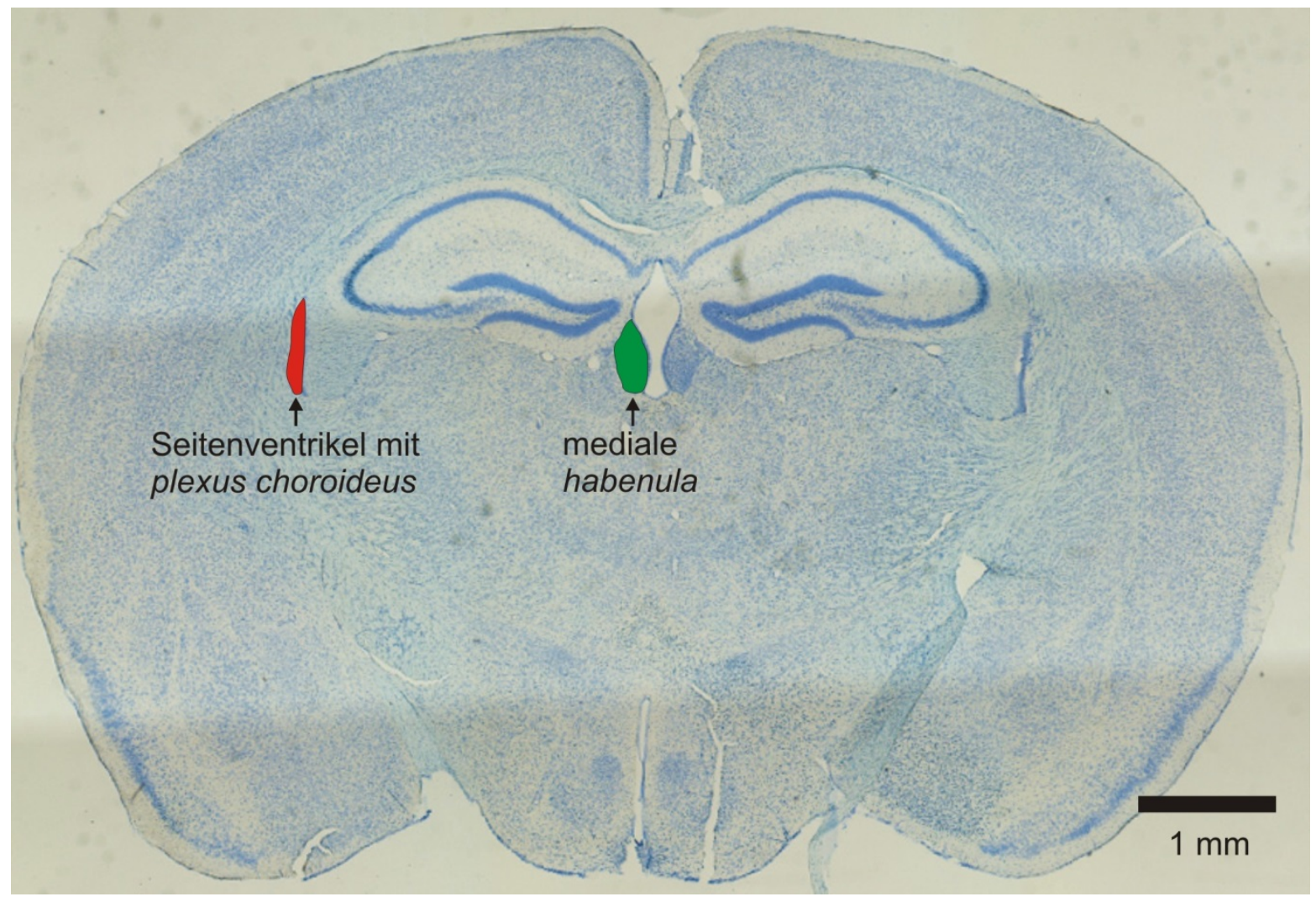

\section{Abbildung 13: Rostro-kaudale Orientierung der Hirnschnitte}

Abgebildet ist ein Nissl gefärbter Hirnschnitt einer WT-Maus. Rot gekennzeichnet befindet sich in nächster Nähe zum Hippokampus der Seitenventrikel. Die stärker gefärbte Struktur an gleicher Position auf der rechten Hemisphäre stellt den plexus choroideus dar. Grün eingefärbt ist die mediale habenula der linken Hemisphäre, die in dieser Schnittebene eine besonders große Konstellation aufweist. Die sichtbare horizontale Streifung kommt dadurch zu Stande, dass diese Gesamtübersicht am digitalen Mikroskop aus mehreren Einzelbildern zusammengesetzt wurde. 


\subsection{Statistik}

Die Daten, die dieser Dissertation zu Grunde liegen, wurden im Rahmen einer umfangreichen präklinischen Studie erhoben. Deshalb konnte aus organisatorischen und zeitlichen Gründen nicht immer jeder Versuch an jedem Tier ausgeführt werden. Dennoch wurde die Nutzung des Gewebes maximal gehalten, da die Tiere, sowie andere Abschnitte der Gehirne, ebenfalls von einer Kollegin für andere Fragestellungen im Rahmen ihrer Dissertation genutzt wurden (Janc 2015).

Die Anzahl (n) bezieht sich auf die Anzahl der Tiere oder der Hirnschnitte, die genutzt wurden. Die Ergebnisse sind immer als Mittelwert \pm Standardabweichung angegeben.

Die quantitative und statistische Auswertung der erhobenen Daten erfolgte mit Microsoft Excel. Die Signifikanz wurde mit einem zweiseitigen Student T-Test errechnet. Die Niveaus der Signifikanz sind für das 5\%-Niveau $(p<0,05)$ mit einem Sternchen (*), für das 1\%-Niveau $(p<0,01)$ mit zwei Sternchen $\left(^{* *}\right)$ und für das 0,1\%-Niveau $(p<0,001)$ mit drei Sternchen $\left(^{\star \star \star}\right)$ gekennzeichnet. Solange nicht anders erwähnt, bezieht sich die Signifikanz immer auf den direkten Vergleich zwischen Wildtyp und Mecp2 $2^{-/ y}$ einer Farbe.

Bei beiden biochemischen Methoden - also die Proteincarbonylbestimmung und die Lipidperoxidationsmessung - wurden zu jedem Tier Doppelproben erhoben und anschließend diese beiden Werte gemittelt. Bei der morphologischen Beurteilung durch Nissl-Färbung wurden für jedes Tier drei Hirnschnitte vermessen und die Daten für jedes Tier separat gemittelt. Außerdem wurden für jedes Tier 15 Zellen im st. pyramidale vermessen und gemittelt. 


\section{Ergebnisse}

Ziel dieser Arbeit ist die präklinische Beurteilung eines mit dem Radikalfänger Trolox in vivo behandelten Mausmodells des Rett-Syndroms. Alle Daten wurden an etwa 45 Tage alten Tieren erhoben. Im Ergebnisteil wird neben dem Vergleich zwischen Mecp $^{-/ y}$ und Wildtyp ebenso ein Vergleich innerhalb der verschiedenen Behandlungsgruppen dargestellt. Die Methodik lässt Schlüsse zu verschiedenen Bereichen der Neurowissenschaften zu und zeigt eine breit aufgestellte Begutachtung der Erkrankung sowie der potentiellen Vor- und/oder Nachteile einer systemischen, chronischen Trolox-Behandlung am Mausmodell des Rett-Syndroms unter der Zielsetzung eines möglichen therapeutischen Ansatzes. Da diese Arbeit einen Teil eines größer angelegten Projektes darstellt, ist eine Gesamtschau der Ergebnisse sämtlicher an den behandelten Tieren durchgeführter Versuche unerlässlich.

Die Tiere wurden je nach Behandlung in drei verschiedene Gruppen eingeteilt. Es wurden sowohl Mecp2 defiziente Mäuse als auch Wildtypen verwendet. Die Einteilung innerhalb der verblindeten Studie erfolgte farbcodiert. Die rote Gruppe steht für die mit PBS behandelten Tiere der Kontrollgruppe. Die grüne Gruppe spiegelt die mit niedriger Troloxdosierung (10 mg/kg KG) behandelten Tiere wieder. Die blaue Gruppe zeigt jene Tiere mit hoher Troloxdosierung (40 mg/kg KG). Diese Farbcodierung wird für den Ergebnisteil beibehalten. Die Anzahl der untersuchten Tiere findet sich in den Diagrammen wieder. Solange nicht anders erwähnt, beziehen sich statistische Signifikanzen immer auf den Vergleich innerhalb einer Behandlungsgruppe, beispielsweise also den Vergleich zwischen Wildtyp und $M_{\text {ecp }} 2^{-/ y}$ der roten Gruppe. Die anderen Vergleichsformen werden durch entsprechende Verbindungsklammern verdeutlicht.

Alle erhobenen Daten sind Teil einer Blindstudie. Die vorliegende Arbeit stellt dabei insbesondere eine Erweiterung der bisherigen Methodik dar. Es wurde ein Verhaltenstest (Hole Board) sowie eine optische Messmethode zur Bestimmung der Mitochondrienfunktion und deren Hypoxieempfindlichkeit durchgeführt (Rhodamin123 Fluoreszenz). Zusätzlich wurden biochemische Analysen - die Bestimmung der Proteincarbonyle und der Lipidperoxidation - genutzt, um die Behandlung auf molekularer Ebene verfolgen zu können. Unter Zuhilfenahme der 
Nissl-Färbung konnten zudem morphologische Analysen der Gewebestruktur angestellt werden.

\subsection{Beurteilung des explorativen Verhaltens}

Mittels Hole Board-Test wurden die Umweltexplorativität, die Motorik und das Aktivitätsniveau der Mäuse untersucht. Der Hole Board-Test wird vielfach bei der medikamentösen Therapie von Tiermodellen genutzt (Nolan und Parkes 1973). Hierbei wurden die Mäuse für $5 \mathrm{~min}$ im Versuchsfeld belassen und die mittlere Laufgeschwindigkeit, die Laufdistanz, der prozentuale Anteil der Zeit, in der die Tiere unbeweglich verweilten, und die Anzahl der vertikalen explorativen Aktionen in Form von Erkundungen der Löcher (head dippings) aufgezeichnet und verglichen. Die Ergebnisse sind in Tabelle 1 zusammengefasst.

Bekannt ist in diesem Zusammenhang, dass Rett-Patientinnen eine verminderte Lokomotion, motorische Probleme sowie vermindertes Umweltinteresse aufweisen (Chahrour und Zoghbi 2007). Mecp2 ${ }^{-/ y}$ Mäuse zeigen ebenso verminderte Aktivitäten (Stearns et al. 2007). Der Hole Board-Test lässt in der gewählten Durchführungsart Aussagen über die Explorativität und die Motilität der Tiere zu. Dabei waren zwei Tiere auffällig, die aufgrund ihres besonders ausgeprägten Phänotyps und ihrer eingeschränkten Bewegung (Ruhezeiten von mehr als 66\%) nicht für diese Art von motorisch-explorativem Verhaltenstest geeignet waren und deshalb von der Messung ausgeschlossen wurden. 


\begin{tabular}{|c|c|c|c|}
\hline & Behandlungsgruppe & WT & Mecp2 $^{-/ y}$ \\
\hline \multirow{2}{*}{\begin{tabular}{c} 
head dippingsl \\
\multirow{2}{*}{$\mathbf{5}$ min }
\end{tabular}} & PBS & $90,9 \pm 22,0$ & $42,0 \pm 17,4$ \\
\cline { 2 - 4 } & $10 \mathrm{mg} / \mathrm{kg}$ Trolox & $81,6 \pm 25,2$ & $43,3 \pm 20,6$ \\
\cline { 2 - 4 } & $40 \mathrm{mg} / \mathrm{kg}$ Trolox & $74,9 \pm 24,4$ & $67,8 \pm 12,0$ \\
\hline
\end{tabular}

\begin{tabular}{|c|c|c|c|}
\hline \multirow{2}{*}{ Distanz [m]/5 min } & PBS & $20,8 \pm 3,8$ & $10,7 \pm 4,6$ \\
\cline { 2 - 4 } & $10 \mathrm{mg} / \mathrm{kg}$ Trolox & $21,6 \pm 3,8$ & $12,1 \pm 5,3$ \\
\cline { 2 - 4 } & $40 \mathrm{mg} / \mathrm{kg}$ Trolox & $20,4 \pm 3,0$ & $15,0 \pm 6,0$ \\
\hline
\end{tabular}

\begin{tabular}{|c|c|c|c|}
\hline Mittlere & PBS & $6,9 \pm 1,2$ & $3,6 \pm 1,5$ \\
\cline { 2 - 4 } Geschwindigkeit & $10 \mathrm{mg} / \mathrm{kg}$ Trolox & $7,2 \pm 1,3$ & $4,0 \pm 1,8$ \\
\cline { 2 - 4 } [cm/s] & $40 \mathrm{mg} / \mathrm{kg}$ Trolox & $6,8 \pm 1,0$ & $5,0 \pm 1,8$ \\
\hline
\end{tabular}

\begin{tabular}{|c|c|c|c|}
\hline \multirow{3}{*}{ Ruhezeiten [\%] } & PBS & $14,3 \pm 3,7$ & $38,4 \pm 13,3$ \\
\cline { 2 - 4 } & $10 \mathrm{mg} / \mathrm{kg}$ Trolox & $13,3 \pm 5,5$ & $37,1 \pm 17,1$ \\
\cline { 2 - 4 } & $40 \mathrm{mg} / \mathrm{kg}$ Trolox & $14,8 \pm 6,5$ & $26,7 \pm 8,1$ \\
\hline
\end{tabular}

Tabelle 1: Ergebnisse des Hole Board-Verhaltenstests in tabellarischer Darstellung

In Abbildung 14 (A) ist zu sehen, dass die 10 mg/kg Körpergewicht (KG)Behandlungsgruppe und die Kontrollgruppe im Vergleich zwischen Wildtyp und Mecp2 $^{-/ y}$ signifikant mehr Erkundungen der Löcher aufweisen. Der Unterschied in der Kontrollgruppe beläuft sich für den Parameter der head dippings auf $\sim 53,8 \%$. In der 10 mg/kg KG-Gruppe liegt der Unterschied mit 46,9\% noch ähnlich hoch. Dieser ist in der 40 mg/kg KG-Behandlungsgruppe jedoch kaum mehr zu erkennen. In Letzterer liegt der Unterschied bei 9,5\%. Die Gruppe der 40 mg/kg KG Trolox behandelten Mecp2 $2^{-/ y}$ Tiere erreicht mit im Schnitt ca. 68 head dippings ca. 20 dippings mehr als die Mecp2 $2^{-/ y}$ Tiere beider anderer Gruppen (jeweils $p<0,01$ ). Erwähnenswert ist ebenfalls die Tendenz der gesamten Gruppe der Wildtypen, die mit höherer Trolox Dosierung weniger dippings aufweist.

Für die Distanz (Abb. 14, B) ergibt sich ein ähnliches Muster. Der prozentuale Unterschied der Kontrollgruppe beläuft sich zwischen Wildtyp und $M e c p 2^{-/ y}$ auf 48,6\%. In der 40 mg/kg KG-Gruppe zeigt sich lediglich ein Unterschied von nur noch $26,5 \%$. 
$\begin{array}{lll}\text { WT PBS } & \text { WT } 10 \mathrm{mg} / \mathrm{kg} & \text { WT } 40 \mathrm{mg} / \mathrm{kg}\end{array}$

$\square$ Mecp $^{-/ y}$ PBS $\square$ Mecp $^{-/ y} 10 \mathrm{mg} / \mathrm{kg} \quad \square M e c p 2^{-/ y} 40 \mathrm{mg} / \mathrm{kg}$

$\mathbf{A}$

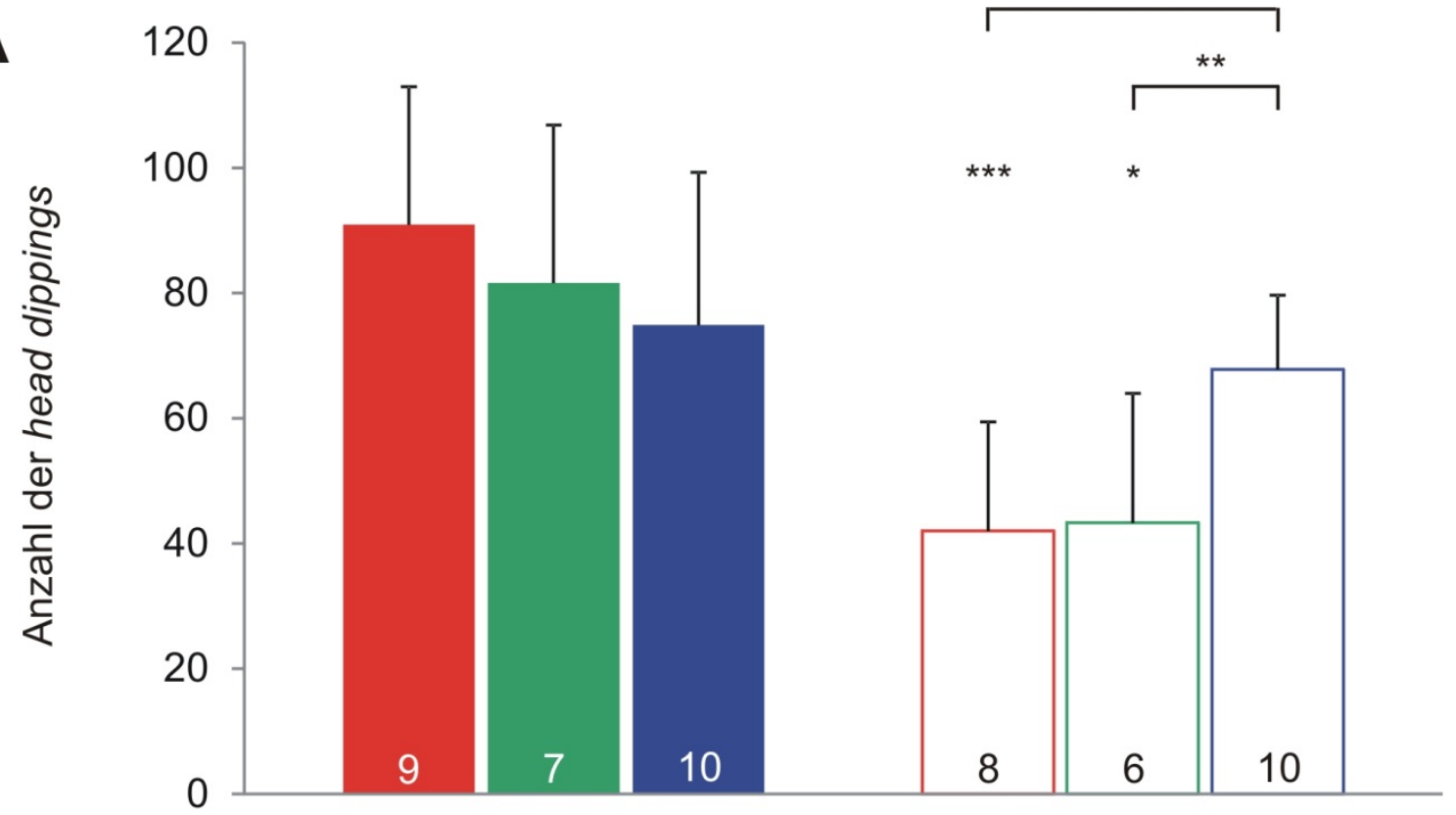

B

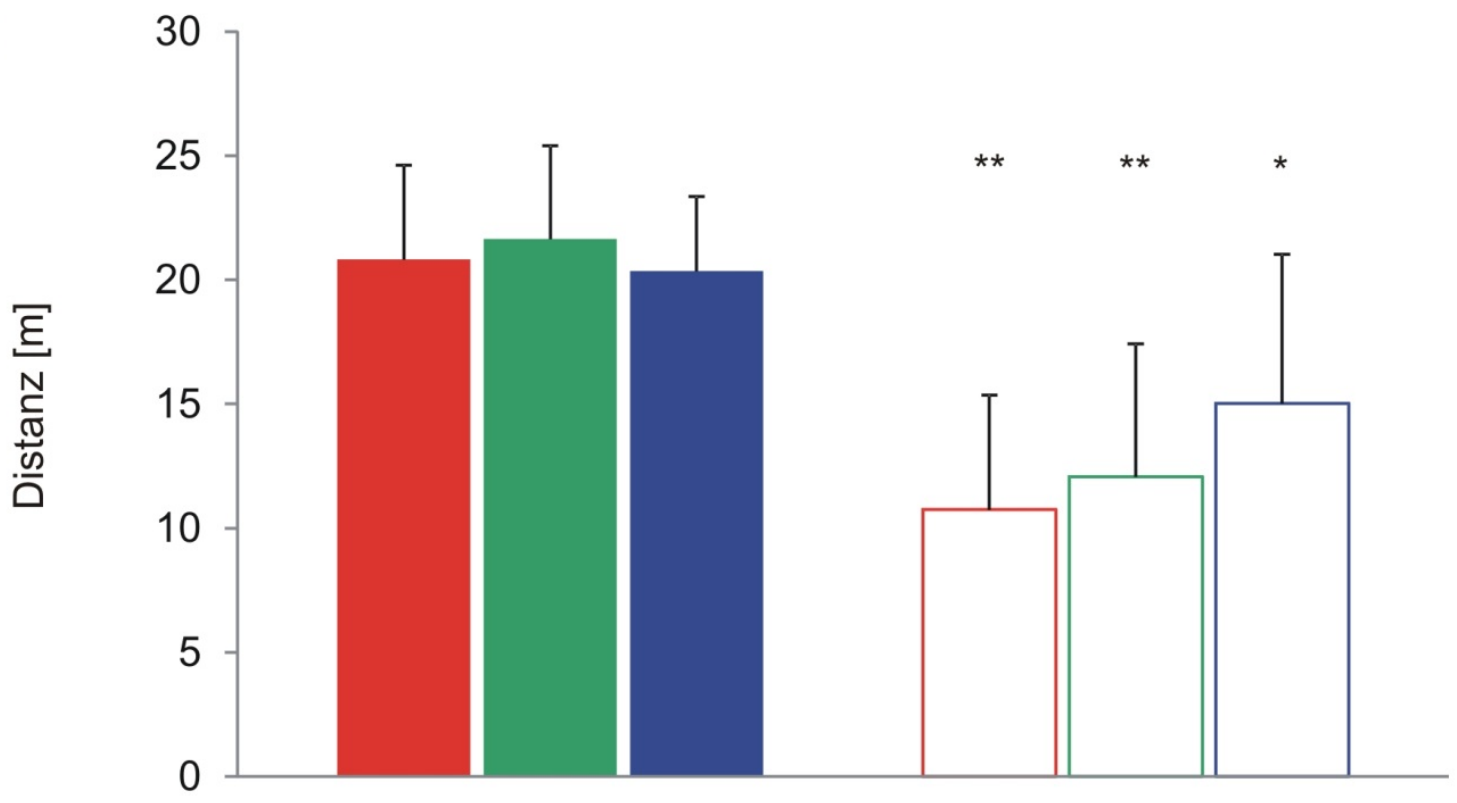

Abbildung 14: Anzahl der head dippings und zurückgelegten Gesamtdistanz im Hole Board-Verhaltenstest

A) Die Abbildung zeigt die sechs Gruppen im direkten Vergleich der Anzahl vertikal explorativer Aktionen (head dippings). Außerdem ist an der Basis des Balkendiagramms die Anzahl (n) der untersuchten Tiere eingezeichnet. Diese Zahlen gelten für die gesamte Methodik Hole Board. B) Hier ist die Gesamtdistanz, die die Tiere innerhalb der 5 min zurückgelegt haben, angegeben. Auch sind in beiden Graphen die Fehlerbalken als Ausdruck der Standardabweichung und die Signifikanzniveaus (Sternchen) verzeichnet. 
Die in Abbildung 15 dargestellte mittlere Geschwindigkeit ergibt vergleichbare Ergebnisse. Fallen die Signifikanzen in der Kontrollgruppe und $10 \mathrm{mg} / \mathrm{kg} \mathrm{KG-}$ Gruppe noch eindeutig aus $(\mathrm{p}<0,01)$, ist in der $40 \mathrm{mg} / \mathrm{kg} \mathrm{KG-Gruppe} \mathrm{eine} \mathrm{geringere}$ Signifikanz $(p<0,05)$ zu erkennen. Die $M e c p 2^{-1 y}$ Tiere der Kontrollgruppe sind im Mittel 39\% langsamer, als jene Mecp2 ${ }^{-/ y}$ Tiere der $40 \mathrm{mg} / \mathrm{kg}$ KG-Gruppe. Die dargestellte Ruhezeit (Abb. 15, B) der untersuchten Tiere ergibt in allen drei Gruppen signifikante Unterschiede, allerdings nimmt das Niveau der Signifikanz von der Kontrollgruppe zur $40 \mathrm{mg} / \mathrm{kg}$ KG-Gruppe hin dezent ab. Besteht der prozentuale Unterschied der Ruhezeit in der Kontrollgruppe noch bei $169 \%$ mehr Ruhezeit bei den Mecp2 $^{-1 /}$ Mäusen als bei den WT, so ist dieser in der $40 \mathrm{mg} / \mathrm{kg}$ KG-Gruppe bei nunmehr noch $80 \%$ auf mehr als die Hälfte reduziert.

Im Vergleich aller Wildtypen ist kein signifikanter Unterschied zu erkennen. Der Vergleich der $M e c p 2^{-1 y}$ Tiere zeigt einen signifikanten Unterschied $(p<0,05)$ zwischen der Kontrollgruppe und der $40 \mathrm{mg} / \mathrm{kg}$ KG-Gruppe. Die Mecp2 ${ }^{-/ y}$ Tiere der

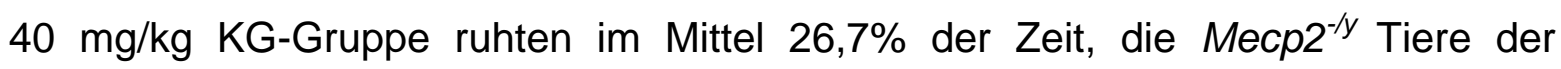
Kontrollgruppe ca. $38 \%$. 


$\begin{array}{lll}\text { WT PBS } & \text { WT } 10 \mathrm{mg} / \mathrm{kg} & \text { WT } 40 \mathrm{mg} / \mathrm{kg} \\ \square \text { Mecp2 }^{-/ y} \text { PBS } & \square{\text { Mecp2 } 2^{-1 /} 10 \mathrm{mg} / \mathrm{kg}}\end{array}$

A

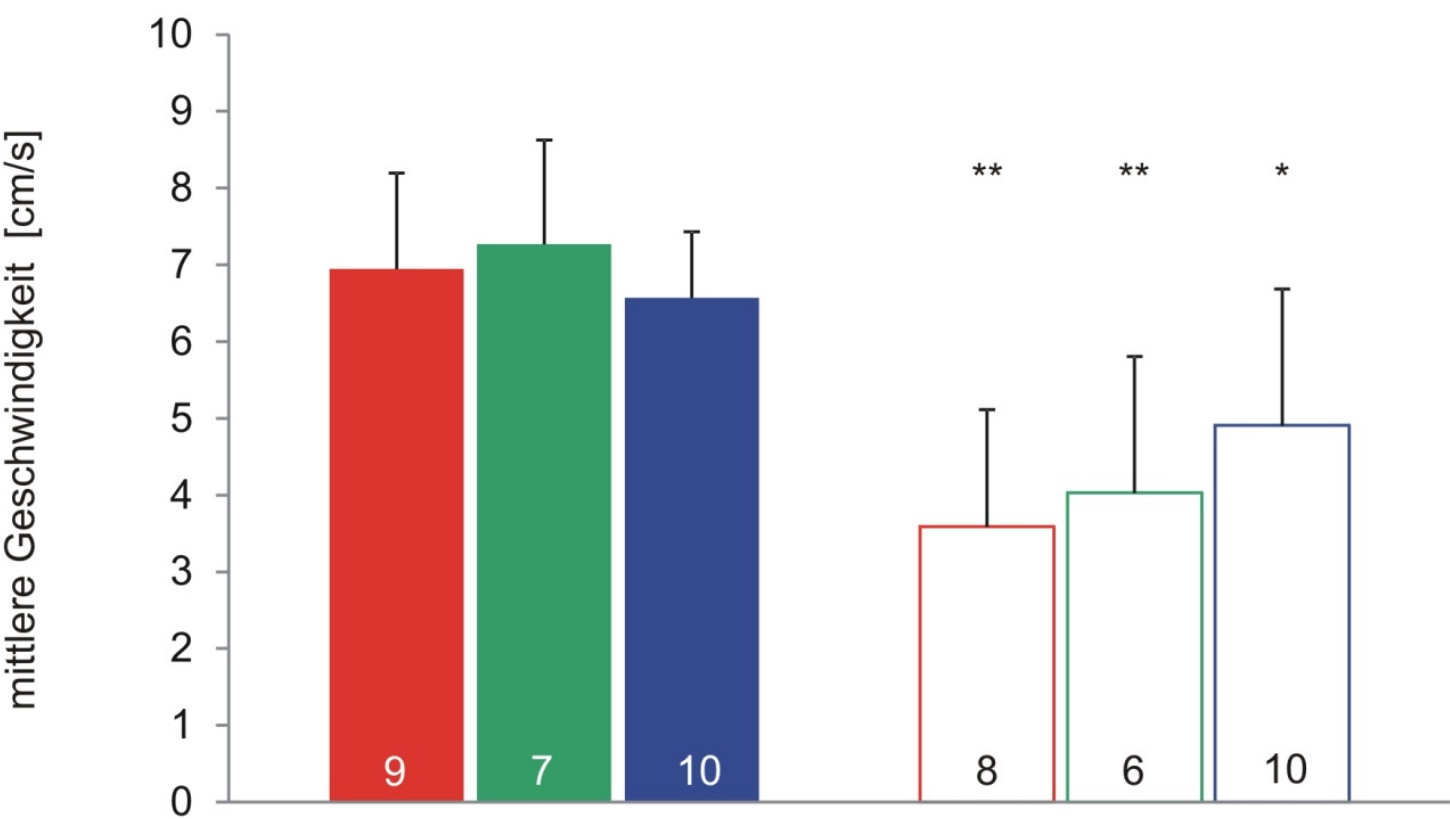

B

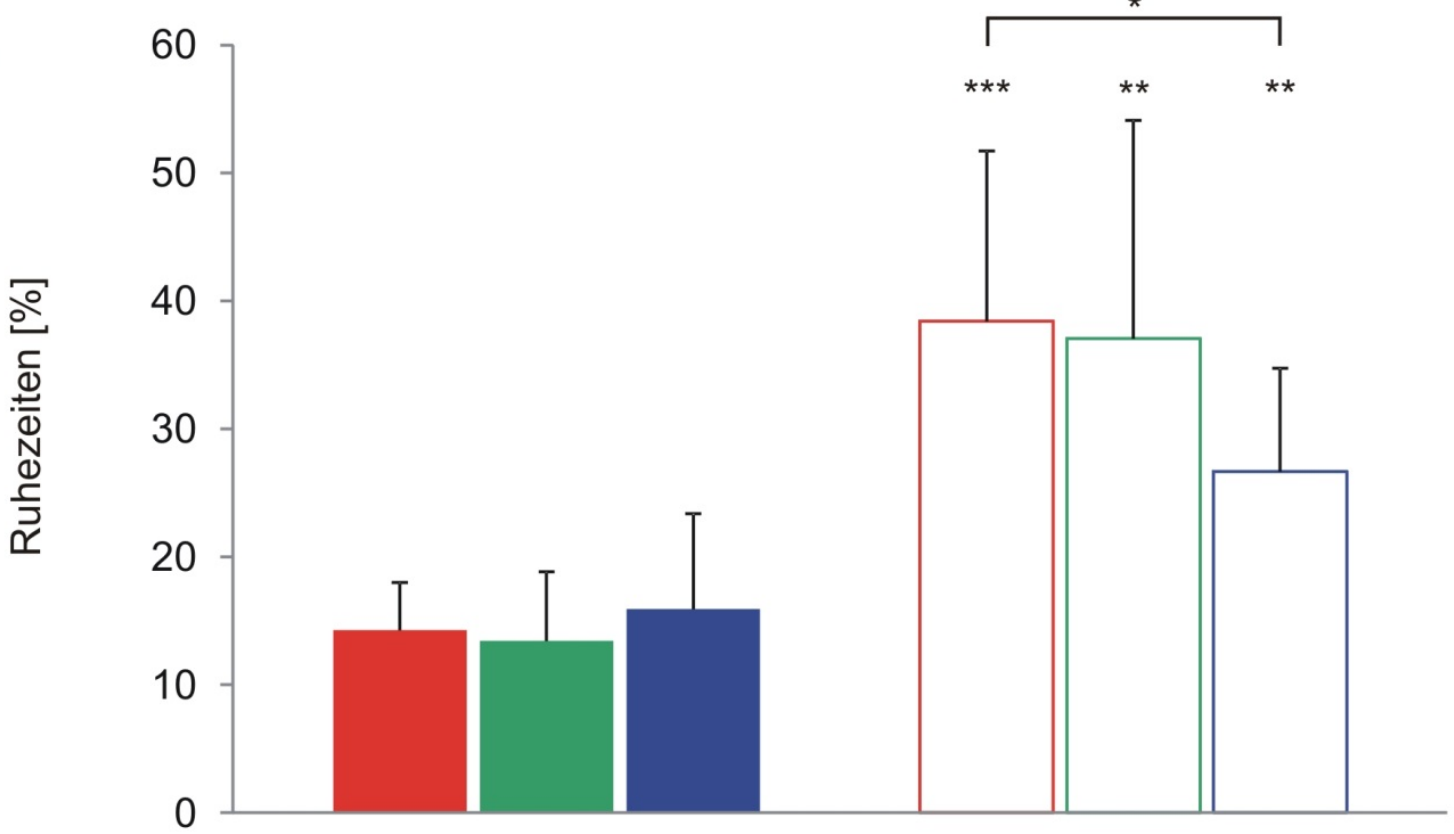

Abbildung 15: Mittlere Geschwindigkeit und Ruhezeiten im Hole BoardVerhaltenstest

A) Das Diagramm zeigt die mittlere Geschwindigkeit in $\mathrm{cm} / \mathrm{s}$. Zu erkennen ist, dass alle Mecp2 $^{-1 y}$ Gruppen eine geringere Geschwindigkeit als die WT erreichen. B) Dargestellt ist der prozentuale Anteil der Zeit, in dem die Tiere sich nicht bewegten. Entsprechend sind hier im Vergleich zu den Wildtypen die Ruhezeiten der $M e c p 2^{-/ y}$ Tiere deutlich erhöht. Signifikanzniveaus sind mit Sternchen gekennzeichnet. 


\subsection{Optische Messungen zur Mitochondrienfunktion}

Um zu überprüfen, inwieweit die in vivo-Behandlung mit Trolox einen Einfluss auf den mitochondrialen Metabolismus hat, wurden Versuche zur Mitochondrienfunktion mittels Fluoreszenzfarbstoff Rh123 und dem chemischem Induktor einer Hypoxie - Zyanid sowie dem Atmungskettenentkoppler FCCP - durchgeführt. Die Fluoreszenz von Rh123 zeigt die Änderung der mitochondrialen Polarisation an. Auch gibt der Bezug zur baseline der Rh123-Messung Aufschluss über die relative Änderung $(\Delta \psi \mathrm{m})$ der Potentialdifferenz der inneren Mitochondrienmembran (Emaus et al. 1986; Duchen 1999). Unter der Gabe der Substanzen - in diesem Fall Zyanid in zweierlei Dosen und FCCP - kann die Veränderung nach Hypoxieinduktion bzw. mitochondrialer Entkopplung beobachtet werden. Zyanid induziert durch Hemmung der Zytochrom-c-Oxidase (Komplex IV der Atmungskette) die Hypoxie, da der vorhandene Sauerstoff nicht mehr genutzt werden kann. Der Protonengradient über der inneren Mitochondrienmembran kann nicht aufrechterhalten werden. Allerdings ist die Hemmung reversibel. FCCP ist ein Atmungskettenentkoppler und sorgt für Protonenlecks in der inneren Mitochondrienmembran, die irreversibel sind. So kommt es zum Zusammenbruch des mitochondrialen Potentials und die Fluoreszenz von Rh123 steigt maximal an. Weiterhin wird im Zuge der Aufrechterhaltung des Protonengradienten reaktiv die Atmungskette maximal stimuliert.

Die hier dargestellten mikroskopischen Versuche wurden im CA1-Feld des Hippokampus an akut gewonnenen Hirnschnitten durchgeführt. Die Auswertung beschränkt sich aus Gründen der Übersichtlichkeit auf das st. radiatum, an dem auch vorherige Versuche der Arbeitsgruppe durchgeführt wurden. Vergleichend wird die maximale Antwort - generiert durch FCCP - und die jeweilige Reaktion gegenüber Zyanid graphisch dargestellt (Abb. 16-18). Die Werte sind teils im Bezug zur jeweiligen baseline teils im Bezug zur Maximalantwort normalisiert.

In der gesamten Methodik der Rh123-Messung können innerhalb der Gruppen keine signifikanten Unterschiede ausgemacht werden. Ein Augenmerk sollte darauf gerichtet werden, dass unter Substitution von hohen Dosen Zyanid die mit 40 mg/kg KG Trolox behandelten Wildtypen in der Tendenz eine stärkere Reaktion zeigen. 

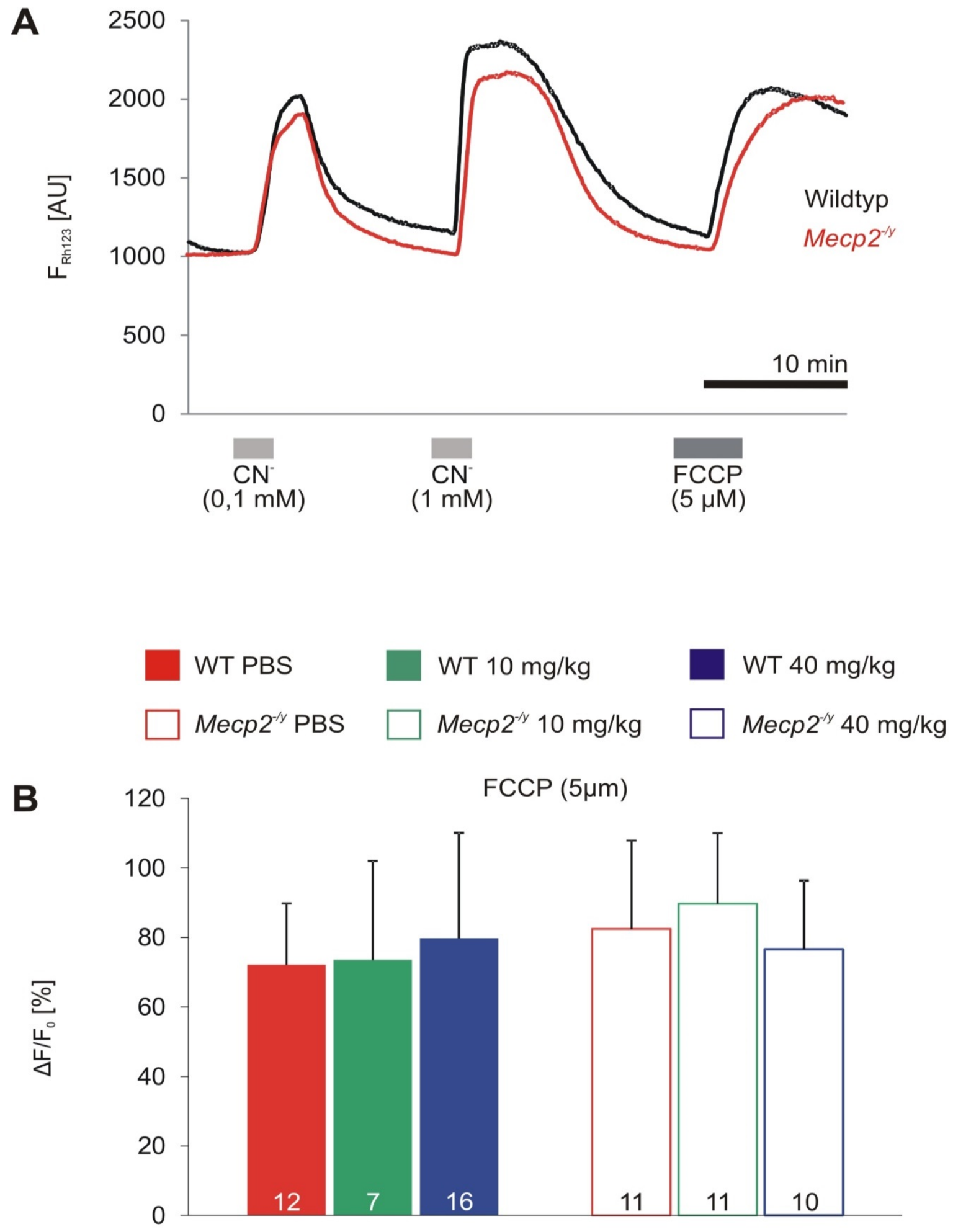

\section{Abbildung 16: Beispielspur einer Messung und Reaktion auf FCCP}

A) Gezeigt ist beispielhaft der Ablauf einer Messung der PBS behandelten Gruppe (Placebo) sowohl für WT als auch für Mecp2 $2^{-/ y}$. Auf der Ordinate sind Absolutintensitäten der Rh123-Fluoreszenz aufgetragen. An der Abszisse ist die Gabe der Modulanzien verzeichnet. B) Zusammenfassende Darstellung der maximalen Rh123-Fluoreszenzänderung bei vollständiger Entkopplung der Atmungskette durch FCCP. Genotypische Unterschiede oder ein Einfluss der jeweiligen Behandlung auf die FCCP-Antwort sind nicht zu beobachten. 


WT PBS $\begin{array}{ll}\text { WT } 10 \mathrm{mg} / \mathrm{kg} & \text { WT } 40 \mathrm{mg} / \mathrm{kg} \\ \square \text { Mecp2 }^{-/ y} \text { PBS } & \square \text { Mecp2 }^{-/ y} 10 \mathrm{mg} / \mathrm{kg}\end{array}$ Mecp2 $^{-/ y} 40 \mathrm{mg} / \mathrm{kg}$
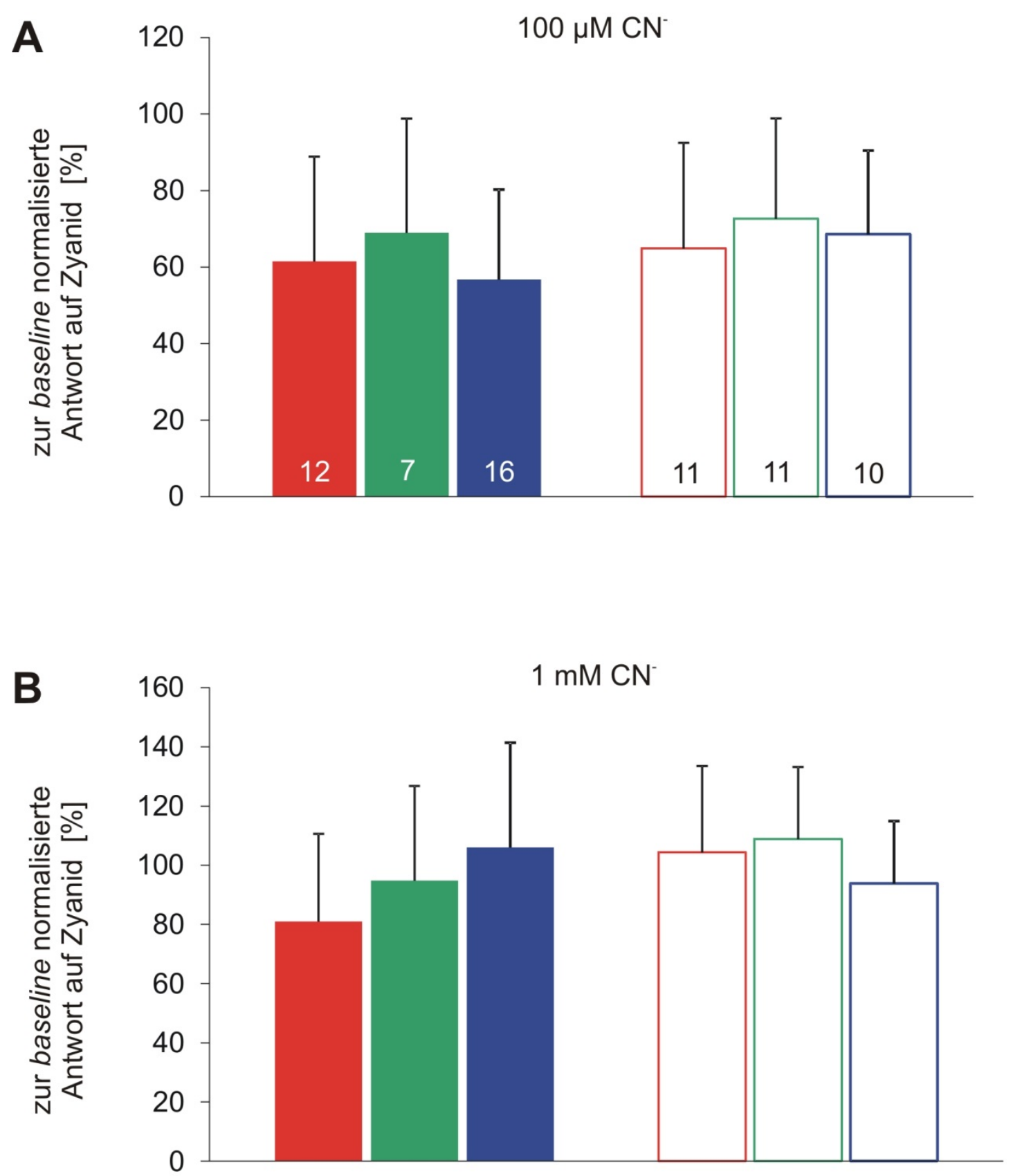

Abbildung 17: Darstellung der auf die baseline normalisierten Rh123-Antworten auf Zyanid

A) Gezeigt ist die Antwort der jeweiligen Gruppe auf 0,1 $\mathrm{mM}$ Zyanidgabe. Der Antwortbereich ist auf die baseline normalisiert und in Prozent angegeben. B) Hier ist Zyanid in hoher Dosis ( $1 \mathrm{mM})$ ebenfalls normalisiert abgebildet. Auch hier sind bei beiden Graphen unabhängig von der jeweiligen ZyanidKonzentration keine Änderungen zu verzeichnen. 

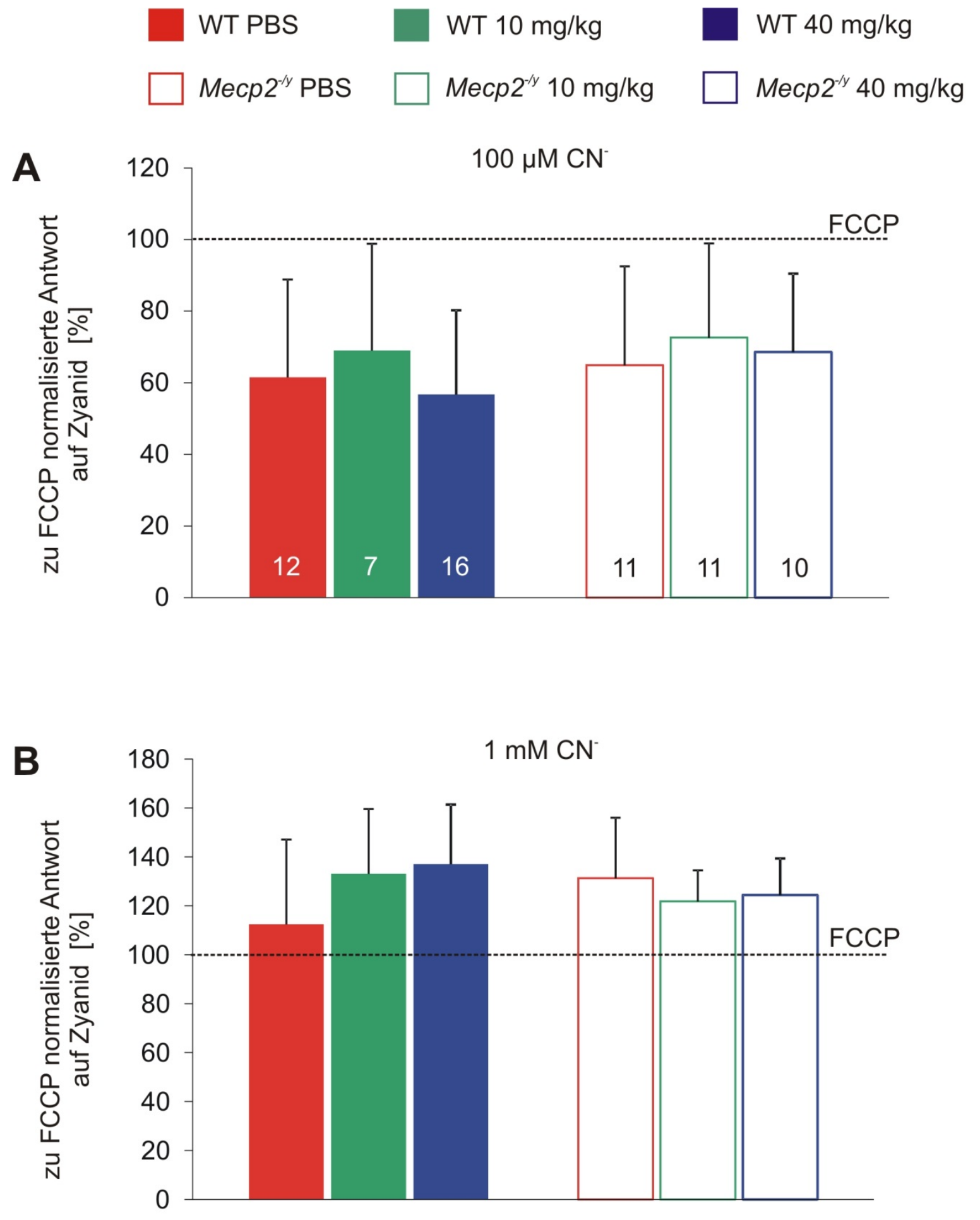

\section{Abbildung 18: Zur Maximalantwort (FCCP) normalisierte Reaktion auf Zyanid}

A) Gemittelte Antwort auf die niedrige Dosis Zyanid $(0,1 \mathrm{mM})$. Unterschiede sind hierbei nicht zu erkennen. B) Rh123-Antworten auf hohe Dosis Zyanid. Die Werte sind jeweils auf die FCCP-induzierte Maximalantwort normalisiert und entsprechend in Prozenten angegeben. Auf diese Weise kann festgestellt werden, mit wieviel Prozent der Maximalantwort die mitochondriale Reaktion ausfällt. Auch hier sind in beiden Graphen keine zyanid-abhängigen Änderungen zu verzeichnen. 


\subsection{Oxidative Veränderungen auf Gewebeebene}

Zur Überprüfung von potentiellen Effekten der chronischen Trolox-Behandlung auf Gewebeebene wurden zwei biochemische Assays eingeführt, die auf photometrischen Messungen beruhen. Die vorliegenden Ergebnisse der Messungen wurden an isoliertem kryokonserviertem Hirngewebe durchgeführt. Dabei wurde speziell der Frontalkortex verwendet, da die Anzahl der Tiere limitiert war und die Hippokampi in anderen Teilaspekten der präklinischen Studie genutzt wurden (Janc 2015).

Die Lipidperoxidation stellt eine repräsentative Messgröße für oxidativen Stress dar und dieser Parameter ist bei Rett-Patientinnen im Blut teils erhöht (Sierra et al. 2001). Auch im Hirngewebe von Mecp2 defizienten Mäusen konnten Hinweise auf erhöhte Peroxide - speziell der Arachidonsäure - nachgewiesen werden (De Felice et al. 2014). Bei der im Zuge dieser Arbeit verwendeten Methode wurde das photometrisch bestimmbare Malondialdehyd als Lipidperoxidationsmarker genutzt.

Die Proteincarbonylierung ist als ein Indikator für oxidative Schäden an zelleigenen Makromolekülen mit der Lipidperoxidation vergleichbar. Allerdings stellt sie ein Äquivalent für den oxidativen Schaden an Proteinen dar. Auch für diese Messgröße bestehen Hinweise auf erhöhte Spiegel im Blut von Rett-Patientinnen (De Felice et al. 2009). Die erhöhten Spiegel von oxidativen Proteinmarkern konnten in der genannten Untersuchung mithilfe von 4-Hydroxy-2-nonenal (4-HNE) für Hirngewebe von Mäusen für den Genotypen Mecp2 $2^{308 / y}$ nachgewiesen werden.

Zur Validierung beider nachfolgend beschriebener photometrischer Methoden fanden Positivkontrollen mit tert-Butylhydroperoxid (TBHP), einem starken Oxidationsmittel, statt. Diese Validierung war notwendig, da das Herstellerprotokoll an die Gegebenheiten des Labors und größere Probenvolumina angepasst werden musste. Zur Verifizierung wurde im Hirngewebe von jeweils drei Tieren die Proteincarbonylierung sowie die Lipidperoxidation vor in vitro-Behandlung mit TBHP und nach Behandlung mit $500 \mu \mathrm{M}$ TBHP bestimmt. Für jedes Tier erfolgte auch hier eine zweifache Bestimmung in Doppelproben, die anschließend gemittelt wurden. Die photometrisch-biochemischen Methoden erlauben die Beurteilung einiger in der Arbeitsgruppe bisher nicht betrachteter Aspekte des Mausmodells 
und bewerten im Speziellen den potentiellen Einfluss einer intraperitonealen Behandlung mit Trolox auf die oxidative Schädigung auf Gewebeebene.

Sowohl für die Validierung der Lipidperoxidation als auch der Proteincarbonylierung mit TBHP konnte bei einer Anzahl an Proben ( $n=3)$ und genotypischer Unterschiede ein signifikanter Unterschied $(p<0,05)$ festgestellt und die jeweilige Methode auf diese Weise bestätigt werden (Tabelle 2, Abb. 19). Im Detail steigerte TBHP die Lipidperoxidation im Mittel um 57\%. Die Oxidation der Proteine wurde durch TBHP um 80\% gesteigert.

\begin{tabular}{|c|c|c|c|}
\hline $\begin{array}{c}\text { Genotypl } \\
\text { Behandlung }\end{array}$ & $\begin{array}{c}\text { ohne } \\
\text { TBHP }\end{array}$ & $\begin{array}{c}\text { mit TBHP } \\
(500 \mu \mathrm{M})\end{array}$ & $\begin{array}{c}\text { Verhältnis } \\
\text { TBHPIACSF }\end{array}$ \\
\hline
\end{tabular}

\begin{tabular}{|c|c|c|c|c|}
\hline \multirow{2}{*}{$\begin{array}{c}\text { Lipidperoxidation } \\
\text { MDA [nmol/ } \mathrm{\mu g} \\
\text { Gewebe] }\end{array}$} & $\begin{array}{c}10 \mathrm{mg} / \mathrm{kg} \\
\text { Trolox }\end{array}$ & 178,6 & 268,0 & 1,5 \\
\cline { 2 - 5 } & $\begin{array}{c}40 \mathrm{mg} / \mathrm{kg} \\
\text { Trolox }\end{array}$ & 177,6 & 290,7 & 1,6 \\
\hline
\end{tabular}

\begin{tabular}{|c|c|c|c|c|}
\hline \multirow{3}{*}{$\begin{array}{l}\text { Proteincarbonylie- } \\
\text { rung } \\
\text { DNP [nmol/mg } \\
\text { Protein] }\end{array}$} & PBS & 16,4 & 27,1 & 1,6 \\
\hline & $\begin{array}{c}10 \mathrm{mg} / \mathrm{kg} \\
\text { Trolox }\end{array}$ & 13,9 & 24,6 & 1,8 \\
\hline & $\begin{array}{c}40 \mathrm{mg} / \mathrm{kg} \\
\text { Trolox }\end{array}$ & 10,3 & 20,3 & 2,0 \\
\hline
\end{tabular}

Tabelle 2: Validierung beider biochemischer Methoden - Darstellung der Einzelwerte

Die angegebenen Werte bilden die Mittelwerte des jeweiligen Tieres mit und ohne TBHP-Behandlung an gleichem Gewebe ab. In der letzten Spalte ist ergänzend das Verhältnis zwischen behandeltem und unbehandeltem (TBHP) Gewebe des jeweiligen Tieres genannt. Da es sich hierbei um die Verifizierung des jeweiligen Assays handelt, wurde jeweils nur ein Tier pro Behandlungsgruppe analysiert, sodass für jeden Assay Gewebe von insgesamt drei verschiedenen Tieren in Doppelproben untersucht wurde. 

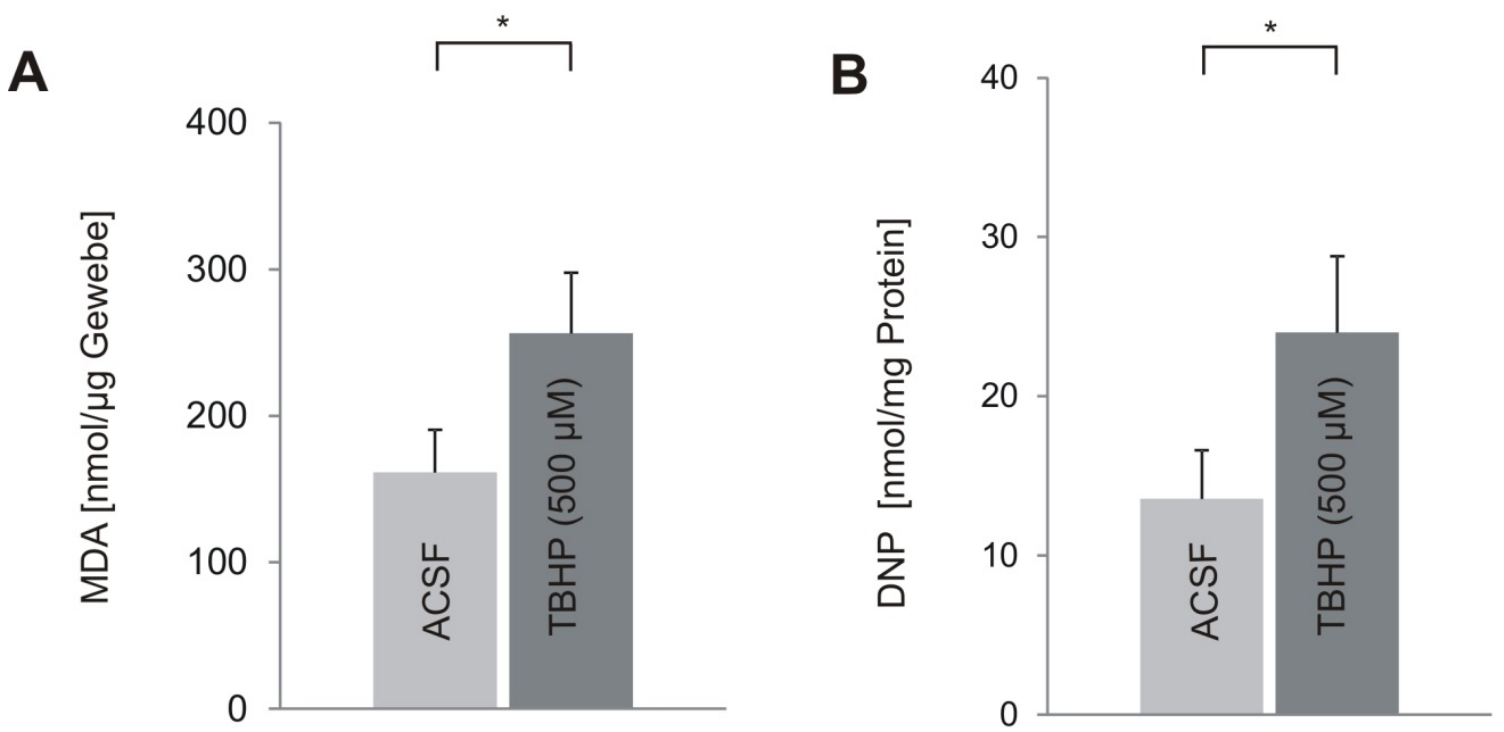

\section{Abbildung 19: Zusammenfassende Darstellung der Verifizierung beider Messmethoden}

A) Gemittelte Validierung zur Messmethode der Lipidperoxide. Dabei wurden die kortikalen Gewebeproben der drei in der Tabelle genannten Tiere gemittelt und gegeneinander aufgetragen. B) Abgebildet ist hier das gleiche Vorgehen zur Proteincarbonylierung. In beiden Graphen ist die mit TBHP (500 $\mu \mathrm{M}, 5 \mathrm{~min}$ ) inkubierte Gruppe in dunkelgrau dargestellt. Ebenfalls gilt, dass der Unterschied in beiden Gruppen bei einer Anzahl von $n=3$ signifikant $(p<0,05)$ ausfällt. Die Inkubation der kortikalen Gewebeproben wurde für beide Tests mit 5 min angesetzt. Beide Tests zeigen einen deutlichen Anstieg, der für die Proteincarbonylierung mit einem Anstieg von $80 \%$ noch deutlicher ausfällt, als bei der Lipidperoxidation (57\%).

Nach erfolgreicher Validierung wurden nun die eigentlichen kortikalen Gewebeproben der trolox- und placebobehandelten Tiere untersucht (Tabelle 3, Abb. 20). Es scheint eine große Variabilität $\mathrm{zu}$ bestehen. Weiterhin ist kein Unterschied zwischen den Wildtypen und Mecp2-/y Tieren der Kontrollgruppe zu sehen. Auffällig ist die etwas geringere Lipidperoxidation der gesamten $40 \mathrm{mg} / \mathrm{kg}$ KG-Gruppe und gerade auch der $M e c p 2^{-/ y}$ Tiere eben jener Gruppe. Im direkten Vergleich zwischen Mecp2-ly Tieren der PBS-Gruppe und Mecp2 $2^{-/ y}$ Tieren der 40 $\mathrm{mg} / \mathrm{kg}$ KG-Gruppe zeigt sich eine signifikante Verringerung der Lipidperoxidation $(p<0,05)$. Innerhalb der Behandlungsgruppen sind keine Signifikanzen auszumachen. 


\begin{tabular}{|c|c|c|c|}
\hline & $\begin{array}{c}\text { Behandlungs- } \\
\text { gruppe }\end{array}$ & WT & Mecp2 $^{-/ y}$ \\
\hline $\begin{array}{c}\text { Lipidperoxidation } \\
\text { MDA [nmol/pg } \\
\text { Gewebe] }\end{array}$ & PBS & $158,1 \pm 50,3$ & $164,8 \pm 33,9$ \\
\cline { 2 - 4 } & $10 \mathrm{mg} / \mathrm{kg}$ Trolox & $164,7 \pm 41,2$ & $156,4 \pm 33,9$ \\
\cline { 2 - 4 } & $40 \mathrm{mg} / \mathrm{kg}$ Trolox & $147,9 \pm 46,2$ & $123,0 \pm 44,4$ \\
\hline
\end{tabular}

Tabelle 3: Darstellung der Messergebnisse zur Lipidperoxidation

Die Ergebnisse sind in nmol MDA/ $\mu \mathrm{g}$ Gewebe angegeben und der jeweiligen Behandlungsgruppe zugeordnet. Dargestellt sind die Mittelwerte plus/minus die Standardabweichung.

\begin{tabular}{|c|c|c|}
\hline WT PBS & WT $10 \mathrm{mg} / \mathrm{kg}$ & WT $40 \mathrm{mg} / \mathrm{kg}$ \\
\hline$M e c p 2^{-1 y}$ PBS & $M e c p 2^{-1 / y} 10 \mathrm{mg} / \mathrm{kg}$ & $\mathrm{Mecp}^{-/ y} 40 \mathrm{mg} / \mathrm{kg}$ \\
\hline
\end{tabular}

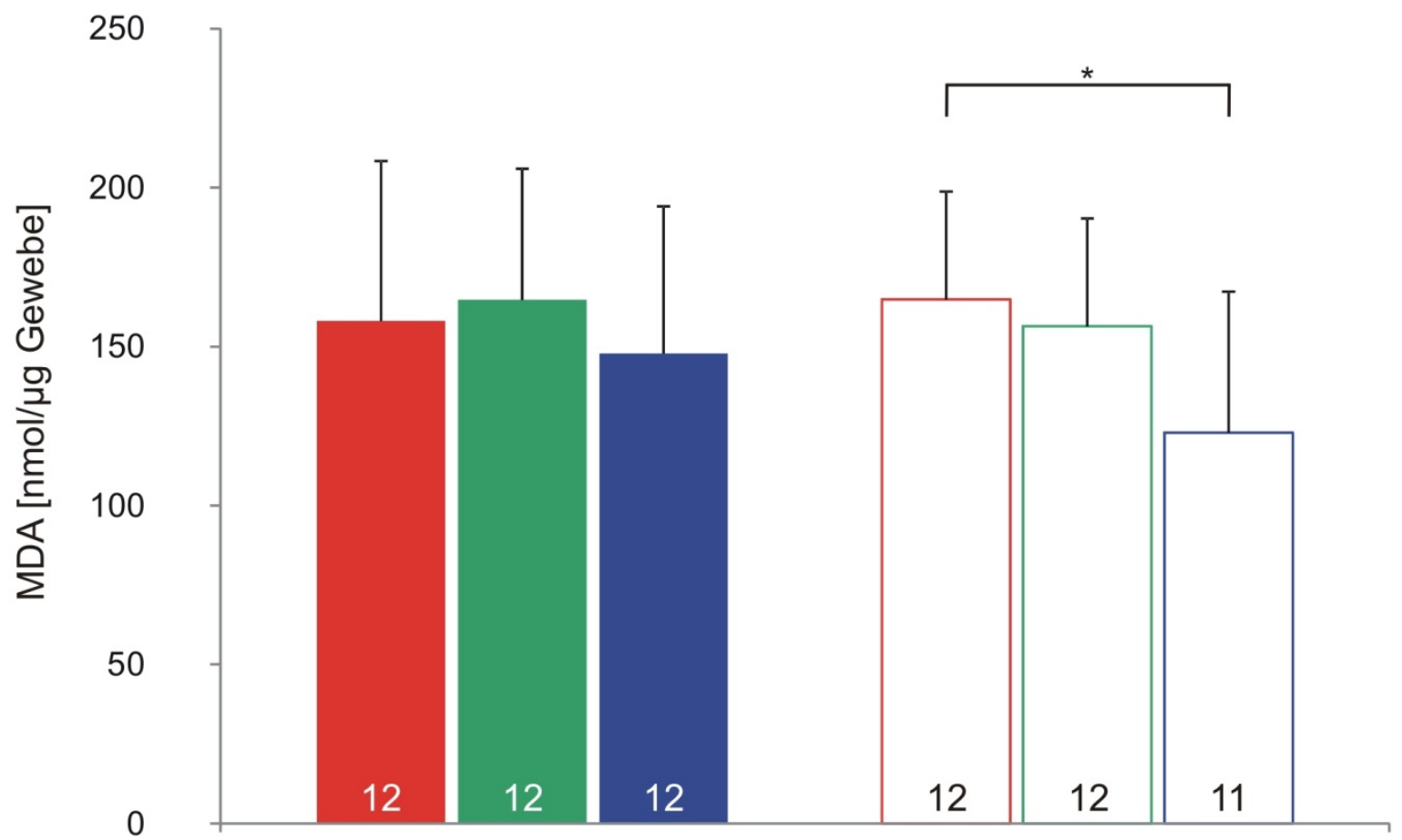

\section{Abbildung 20: Graphische Zusammenfassung der Lipidperoxidation}

Im direkten Vergleich innerhalb der einzelnen Behandlungsgruppen sind keine signifikanten Unterschiede erkennbar. Lediglich in der Tendenz fällt auf, dass vor allem die mit hohen Dosen Trolox behandelten Mecp2-/y Tiere eine geringere Lipidperoxidation aufweisen. Vergleicht man die PBS Mecp2 $2^{-/ y}$ Tieren

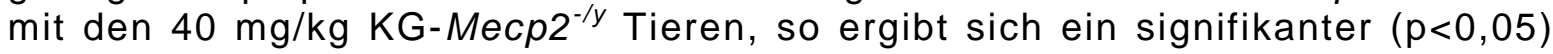
Unterschied. 
Die Ergebnisse zur Proteincarbonylierung (Tabelle 4, Abb. 21) werden nach der Berechnung in nmol 2,4-Dinitrophenylhydrazon (DNP) pro mg Protein angegeben. Innerhalb der Behandlungsgruppen lassen sich keine Unterschiede feststellen. Auch im direkten Vergleich der Behandlungsgruppen sind keine signifikanten Unterschiede zu erkennen. Auffällig ist die hohe Standardabweichung und damit die große Variabilität, die sich über alle Gruppen erstreckt.

\begin{tabular}{|c|c|c|c|}
\hline & $\begin{array}{c}\text { Behandlungs- } \\
\text { gruppe }\end{array}$ & WT & Mecp2 $^{-/ y}$ \\
\hline $\begin{array}{c}\text { Proteincarbonylierung } \\
\text { DNP [nmol/mg }\end{array}$ & PBS & $12,5 \pm 4,5$ & $13,4 \pm 4,7$ \\
\cline { 2 - 4 } Protein] & $10 \mathrm{mg} / \mathrm{kg}$ Trolox & $13,0 \pm 4,0$ & $11,7 \pm 4,2$ \\
\cline { 2 - 4 } & $40 \mathrm{mg} / \mathrm{kg}$ Trolox & $11,4 \pm 3,5$ & $12,9 \pm 4,1$ \\
\hline
\end{tabular}

Tabelle 4: Ausmaß der Proteincarbonylierung der kortikalen Gewebeproben

Die Ergebnisse sind in $\mathrm{nmol} / \mathrm{mg}$ Protein dargestellt und der jeweiligen Gruppe zugeordnet. Angegeben sind die Mittelwerte plus/minus die Standardabweichung. 


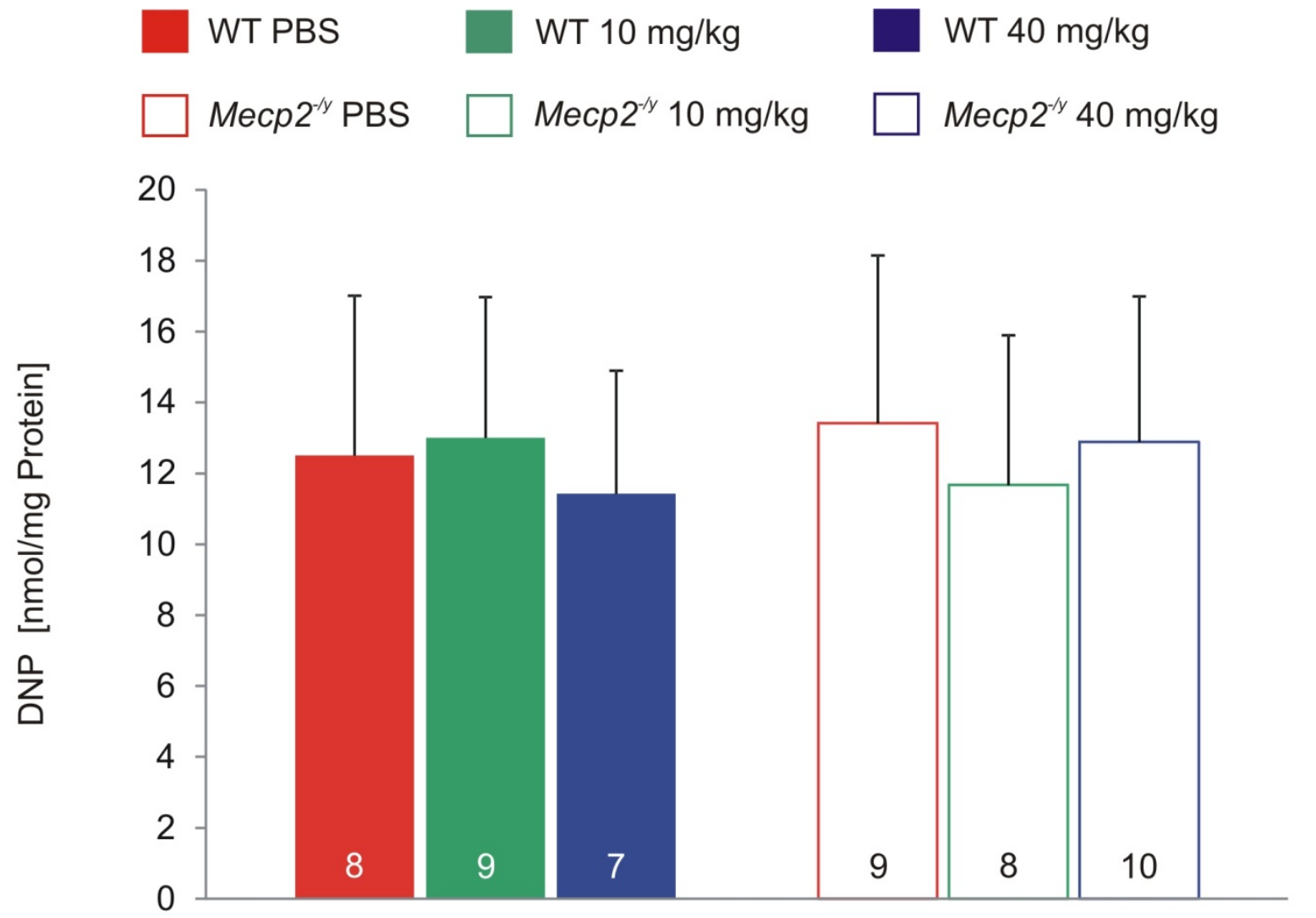

\section{Abbildung 21: Bewertung der Proteincarbonylierung in kortikalen Gewebeproben}

Das gemessene Produkt (DNP) ist in $\mathrm{nmol} / \mathrm{mg}$ Protein aufgetragen. Die Fehlerbalken repräsentieren die Standardabweichung. Nahe der x-Achse ist die Anzahl der jeweilig pro Gruppe analysierten Tiere eingetragen. Das ermittelte Ausmaß der Proteincarbonylierung liegt teilweise weit auseinander, sodass sich eine große Variabilität sowohl zwischen als auch innerhalb der Gruppen ergibt. 


\subsection{Morphologische Gewebeanalyse}

Die Nissl-Färbung ermöglicht eine morphologische Beurteilung der Gewebestruktur von Hirnschnitten sowohl auf mikroskopischer als auch auf makroskopischer Ebene. Die Auswertung mittels digitalen Mikroskops ermöglicht hierbei quantifizierbare und reproduzierbare Ergebnisse mit aussagekräftiger Vergleichbarkeit.

Zur Bewertung möglicher Gewebeveränderungen durch die Trolox-Behandlung wurden in jeder Behandlungsgruppe vier bis sechs Tiere transkardial perfundiert, fixiert, geschnitten, gefärbt und ausgewertet.

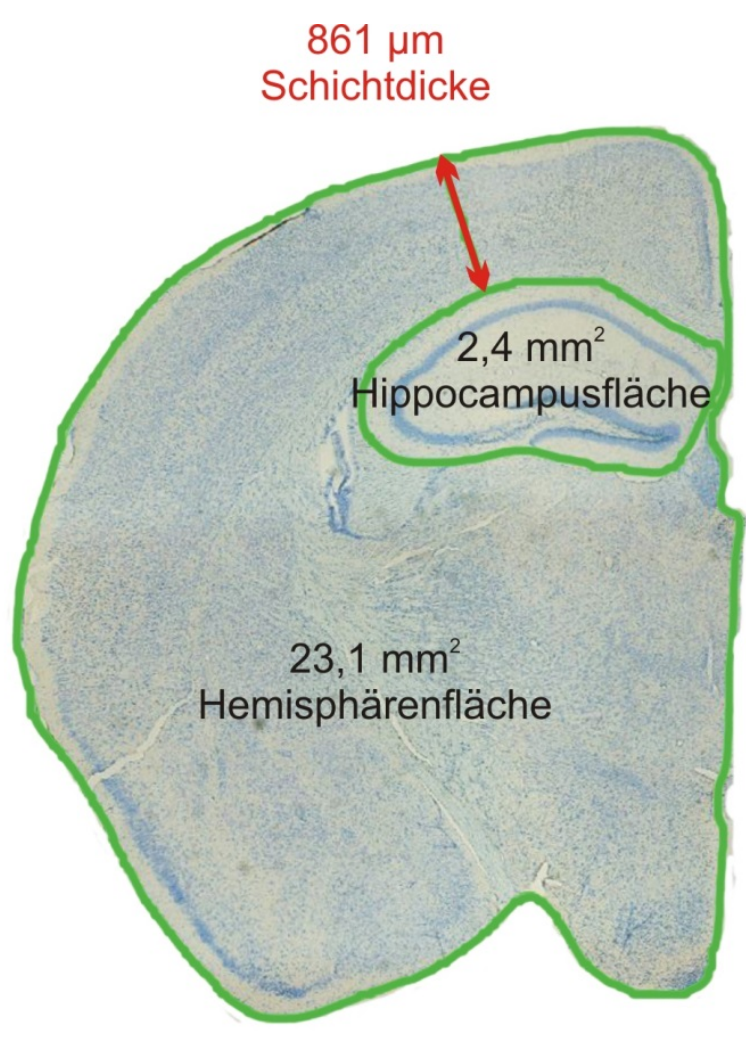

$\operatorname{Mecp}^{-1 / y}$

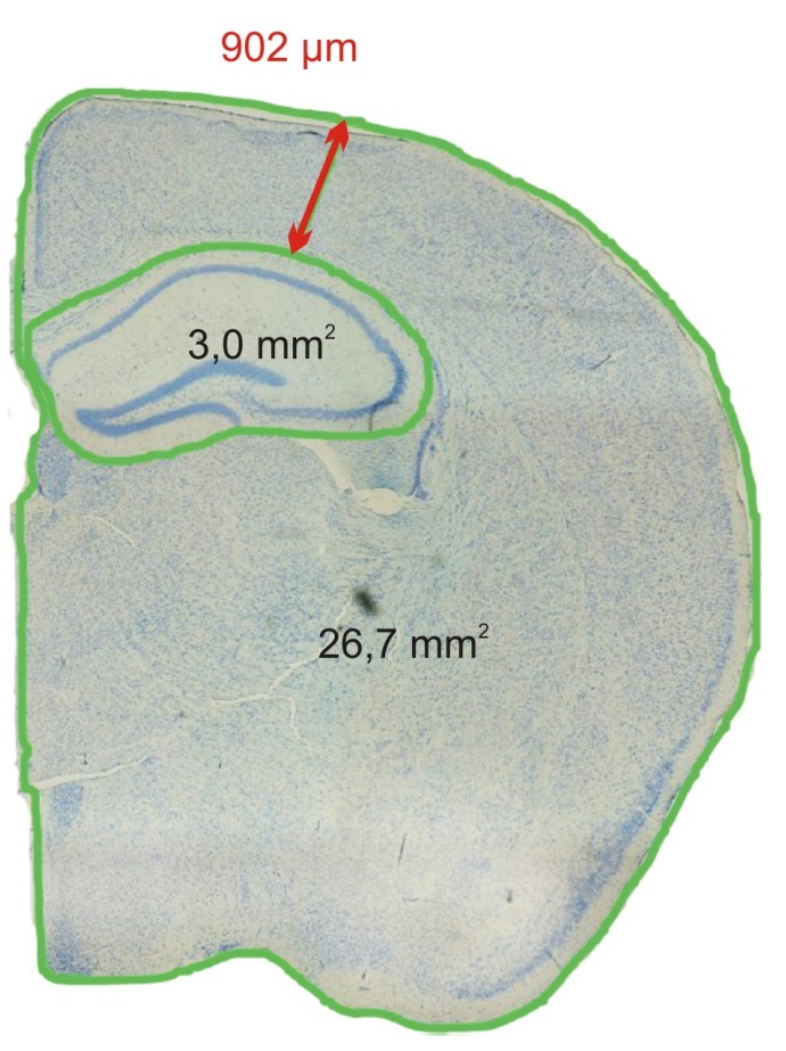

Wildtyp

$1 \mathrm{~mm}$

Abbildung 22: Direkter Vergleich zwischen $M^{-1 y} 2^{-/ y}$ und Wildtyp der Kontrollgruppe (PBS)

Die exemplarischen Daten entstammen direkt der Bildanalysesoftware des Digitalmikroskops und entsprechen den hier dargestellten Schnitten. 
Die Ergebnisse der Nissl-Färbung bestätigen zum Teil bereits gewonnene Erkenntnisse. So ist seit Langem bekannt, dass in Bezug auf das verwendete RettMausmodell, aber auch auf Patientinnen, die Somatagröße der Zellen in der Hippokampusformation vermindert ist (Bauman et al. 1995; Chen et al. 2001). Auch die verminderte Gesamtgröße der Mäusehirne ist ein bekannter Parameter auf dem Feld der Rett-Forschung, zu welchem vergleichbare Messungen aus früheren Studien der Arbeitsgruppe vorliegen (Fischer et al. 2009).

Im Rahmen der hier dargestellten Analysen wurden fünf verschiedene Parameter erhoben: Für jedes Tier wurden je drei Hirnschnitte vermessen und gemittelt. Zuerst wurden die nach bereits beschriebenen Kriterien selektierten Hirnschnitte in der Gesamtfläche der Hemisphäre vermessen. Auch wurde die Gesamtfläche der Hippokampusformation bestimmt, ebenso die Schichtdicke des Kortex. In höherer Vergrößerung (40x Objektiv) erfolgte dann zu jedem Hirnschnitt die exakte exemplarische Vermessung von fünf Neuronen. Außerdem wurden für jeden Schnitt drei gemittelte Messungen der Schichtdicke des st. pyramidale angefertigt (siehe Tabelle 5).

In den Kategorien der Abbildung 22 bestätigen sich die in früheren Studien der Arbeitsgruppe gewonnenen Ergebnisse, die jedoch an gänzlich unbehandelten Tieren gewonnen wurden. Die Hemisphärengrößen zeigen innerhalb jeder Behandlungsgruppe (d.h. beim Vergleich WT/Mecp2 ${ }^{-1 / y}$ ) eindeutig signifikante Unterschiede. Ebenso sind in der Kategorie kortikale Schichtdicke signifikante Unterschiede zwischen Wildtyp und Mecp2 ${ }^{-/ y}$ jeder Gruppe zu verzeichnen. Einzig die Größe der Hippokampusformation zeigt für die PBS-Gruppe im Vergleich Wildtyp zu Meсp2-ly keinen signifikanten Unterschied, allerdings für die beiden anderen mit Trolox behandelten Gruppen. Innerhalb der Genotypengruppen finden sich keine signifikanten Unterschiede. 


\begin{tabular}{|c|c|c|c|}
\hline & Behandlungsgruppe & WT & Mecp2 $^{-/ y}$ \\
\hline \multirow{2}{*}{\begin{tabular}{c} 
Hemisphärenfläche \\
\multirow{2}{*}{$\begin{array}{c}{\left[\mathrm{mm}^{2}\right]} \\
n\end{array}$}
\end{tabular}} & PBS & $26,3 \pm 0,7$ & $23,8 \pm 0,4$ \\
\cline { 2 - 4 } & $10 \mathrm{mg} / \mathrm{kg}$ Trolox & $27,0 \pm 0,9$ & $22,6 \pm 1,7$ \\
\cline { 2 - 4 } & $40 \mathrm{mg} / \mathrm{kg}$ Trolox & $27,0 \pm 0,8$ & $23,8 \pm 0,8$ \\
\hline
\end{tabular}

\begin{tabular}{|c|c|c|c|}
\hline Fläche der & PBS & $2,7 \pm 0,1$ & $2,5 \pm 0,3$ \\
\hline Hippokampusformation & 10 mg/kg Trolox & $2,8 \pm 0,1$ & $2,4 \pm 0,3$ \\
\hline$\left[\mathrm{mm}^{2}\right]$ & $40 \mathrm{mg} / \mathrm{kg}$ Trolox & $2,8 \pm 0,1$ & $2,5 \pm 0,1$ \\
\hline
\end{tabular}

\begin{tabular}{|c|c|c|c|}
\hline \multirow{2}{*}{\begin{tabular}{c} 
kortikale Schichtdicke \\
\multirow{2}{*}{$\begin{array}{c}{[\mu \mathrm{m}]} \\
\end{array}$}
\end{tabular}} & PBS & $927,0 \pm 23,3$ & $842,0 \pm 29,7$ \\
\cline { 2 - 4 } & $10 \mathrm{mg} / \mathrm{kg}$ Trolox & $971,0 \pm 36,8$ & $822,0 \pm 16,0$ \\
\cline { 2 - 4 } & $40 \mathrm{mg} / \mathrm{kg}$ Trolox & $962,0 \pm 42,7$ & $845,0 \pm 49,1$ \\
\hline
\end{tabular}

\begin{tabular}{|l|c|c|c|}
\hline \multirow{2}{*}{$\begin{array}{l}\text { Schichtdicke st. } \\
\text { pyramidale }[\mu \mathrm{m}]\end{array}$} & PBS & $70,2 \pm 6,1$ & $67,7 \pm 8,4$ \\
\cline { 2 - 4 } & $10 \mathrm{mg} / \mathrm{kg}$ Trolox & $70,7 \pm 7,5$ & $65,8 \pm 8,2$ \\
\cline { 2 - 4 } & $40 \mathrm{mg} / \mathrm{kg}$ Trolox & $69,1 \pm 7,4$ & $68,8 \pm 6,4$ \\
\hline
\end{tabular}

\begin{tabular}{|c|c|c|c|}
\hline \multirow{2}{*}{ Zellgröße $\left[\mathrm{\mu m}^{2}\right]$} & PBS & $136,8 \pm 25,5$ & $124,9 \pm 24,6$ \\
\cline { 2 - 4 } & $10 \mathrm{mg} / \mathrm{kg}$ Trolox & $131,8 \pm 21,4$ & $120,0 \pm 25,9$ \\
\cline { 2 - 4 } & $40 \mathrm{mg} / \mathrm{kg}$ Trolox & $142,9 \pm 22,3$ & $128,3 \pm 18,4$ \\
\hline
\end{tabular}

Tabelle 5: Zusammenfassung der im Rahmen der Nissl-Färbung erhobenen morphologischen Gewebeparameter

Dargestellt sind die Absolutzahlen aller fünf erhobener Parameter. Die Reihenfolge spiegelt die Datenanordnung in den Abb. 22-23 wieder. Angaben zur Anzahl der untersuchten Tiere sind dem jeweilig ersten Graphen zu entnehmen. Die Schichtdicke des st. pyramidale und die Zellgröße sind in der CA1-Region des Hippokampus vermessen worden. 
WT PBS

$\square$ Mecp2 $2^{-1 y}$ PBS
WT $10 \mathrm{mg} / \mathrm{kg}$

$M e c p 2^{-1 / y} 10 \mathrm{mg} / \mathrm{kg}$
WT $40 \mathrm{mg} / \mathrm{kg}$

$M e c p 2^{-1 / y} 40 \mathrm{mg} / \mathrm{kg}$

A

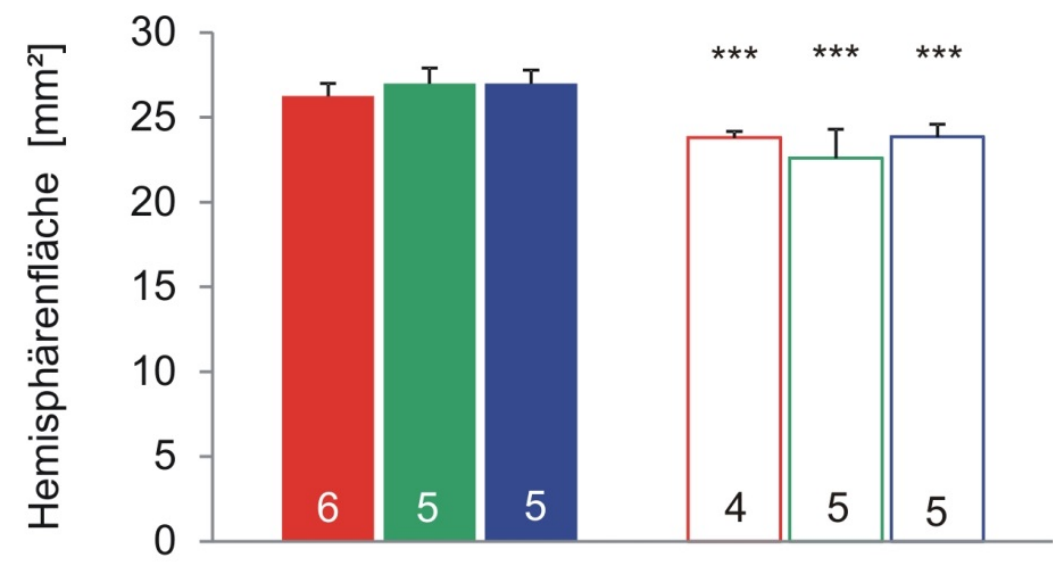

B

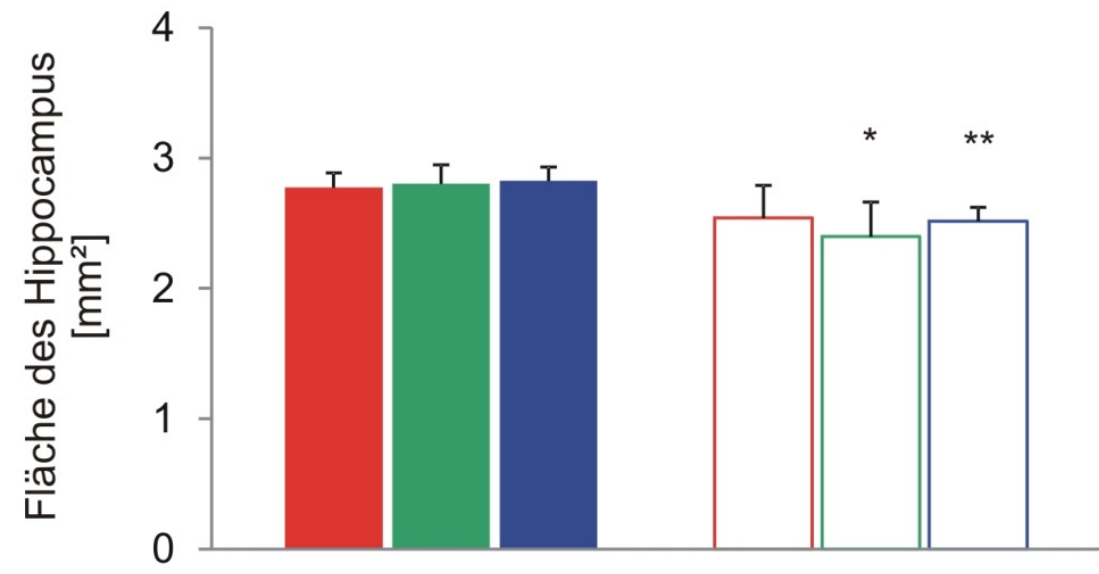

C

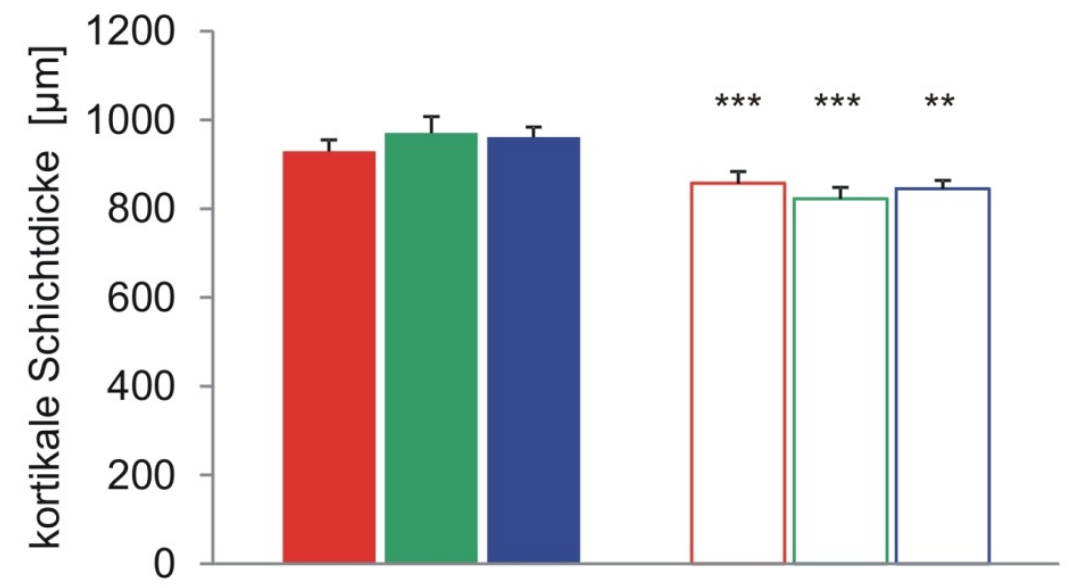

\section{Abbildung 22: Ergebnisse - Nissl-Färbung}

A) Die Flächenvermessung der Hemisphären in $\mathrm{mm}^{2}$ gezeigt. B) Dargestellt ist die Fläche der Hippocampi ebenfalls in $\mathrm{mm}^{2}$. C) Gezeigt ist die kortikale Schichtdicke in $\mu \mathrm{m}$. Die verschiedenen Signifikanzniveaus sind als Sternchen dargestellt. Dabei bezieht sich der statistische Vergleich immer auf den Vergleich WT/Mecp2 ${ }^{-1 /}$ innerhalb einer Behandlungsgruppe. 
Die in mittlerer Vergrößerung (40x Objektiv) entstandenen Messungen der Zellsomatagröße stimmen mit den früheren oben genannten Ergebnissen, die jedoch von nicht injizierten Tieren stammen, überein. Die in Abbildung 23 unter A) gezeigte Schichtdicke des st. pyramidale, die pro Schnitt dreifach vermessen und gemittelt wurde, zeigt intragenotypisch keine Unterschiede. Für die in B) zu sehende Größe der Zellsomata ist in allen drei Gruppen ein teils hochsignifikanter Unterschied zu erkennen. Innerhalb der Gruppe der $M e c p^{2 /-y}$ Tiere ergeben sich keine signifikanten Unterschiede.

\begin{tabular}{|c|c|c|}
\hline WT PBS & WT 10 mg/kg & WT $40 \mathrm{mg} / \mathrm{kg}$ \\
\hline $\mathrm{Mecp}^{-1 /} \mathrm{PBS}$ & $\operatorname{Mecp}^{-1 /} 10 \mathrm{mg} / \mathrm{kg}$ & $\operatorname{Mecp2}^{-1 /} 40 \mathrm{mg} /$ \\
\hline
\end{tabular}

A

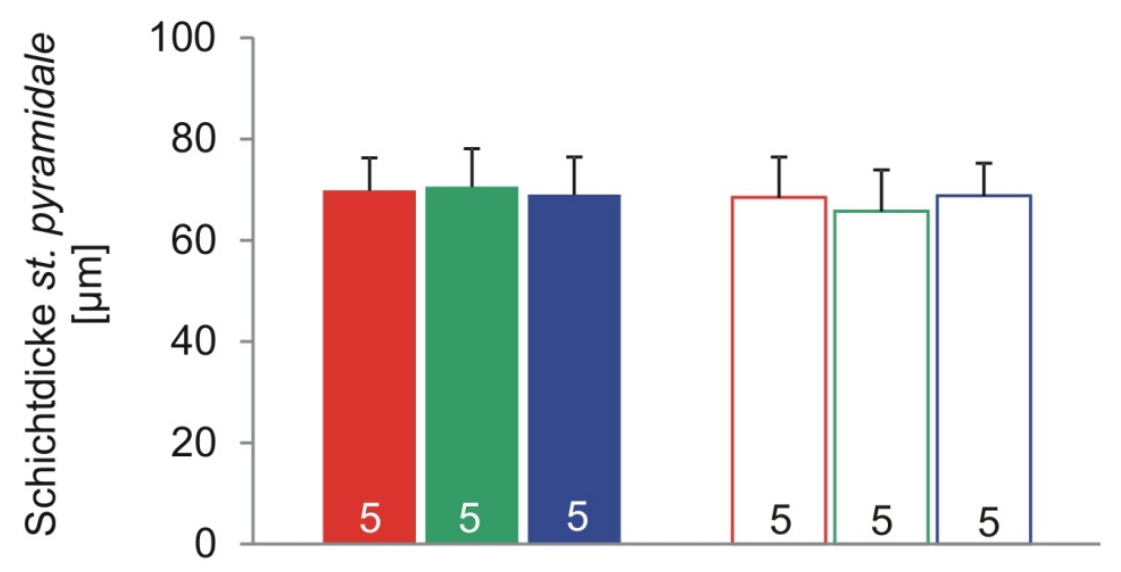

B

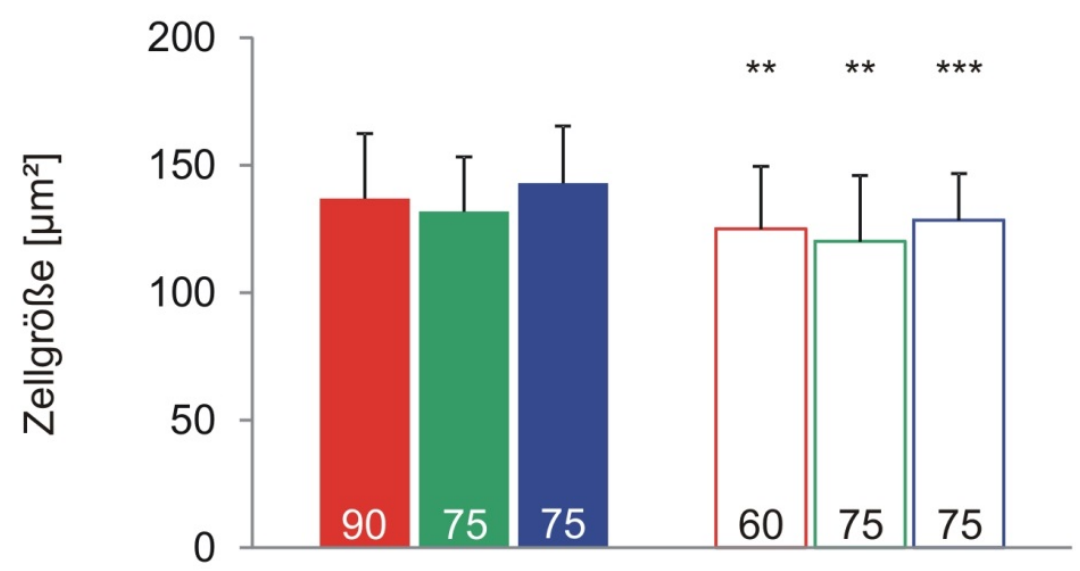

Abbildung 23: Darstellung der zellulären Parameter in der CA1-Region des Hippokampus

A) Gezeigt ist die Schichtdicke des st. pyramidale (CA1) in $\mu \mathrm{m}$. B) Hier ist die Größe der einzeln vermessenen Pyramidenzellsomata in $\mu m^{2}$ dargestellt. Pro Tier wurden dabei 15 Zellen vermessen. 


\section{Diskussion}

Im Rahmen dieser Arbeit wurde der potentielle Benefit eines mit dem wasserlöslichen Vitamin E-Derivat Trolox in vivo behandelten Mausmodells der Rett-Erkrankung untersucht. Dabei stellt diese Arbeit partielle Ergebnisse einer größer angelegten präklinischen Studie dar. Die Zielsetzung war die präklinische Beurteilung des genannten Radikalfängers sowie die Identifikation möglicher beeinflussbarer Parameter. In der vorliegenden Arbeit wurden dabei Parameter erhoben, welche hier nun einer an den Versuchen gegliederten Beurteilung unterliegen.

Bislang konnten in der Arbeitsgruppe Müller erhöhte oxidative Redoxbedingungen in hippokampalem Gewebe bei $M e c p 2^{-/ y}$ Tiere festgestellt werden (Großer et al. 2012). Auch konnte die Arbeitsgruppe in diesem Zusammenhang den mitochondrialen Metabolismus juveniler Tiere (p7-10) charakterisieren und feststellen, dass es bereits frühjuvenil Hinweise auf ein zur Oxidation verschobenes Redox-Gleichgewicht gibt (Großer et al. 2012). Somit kann angenommen werden, dass das Redox-Gleichgewicht schon in sehr frühen Stadien, in denen phänotypisch noch kein eindeutiger Krankheitsprogress anhand charakteristischer Symptomatik beobachtet werden kann, verschoben ist (Müller und Can 2014). Weiter ist für das genutzte Mausmodell bekannt, dass die innere Mitochondrienmembran eine gewisse Durchlässigkeit in Form von Protonenlecks aufweist, und der mitochondriale Sauerstoffverbrauch sowie die Respirationsraten erhöht zu sein scheinen (Kriaucionis et al. 2006; Menzfeld et al. 2014). Auf diesen Erkenntnissen aufbauend fand in der Arbeitsgruppe zunächst die in vitroBehandlung akuter hippokampaler Schnitte mit Trolox statt, die ebenfalls vielversprechende Ergebnisse mit sich brachte und so den Grundstein zur nachfolgenden präklinischen Erprobung mittels i.p.-Behandlung legte. Dabei konnte gezeigt werden, dass Trolox an akuten hippokampalen Hirnschnitten Mecp2 defizienter und bereits symptomatischer Mäuse spezifisch die erhöhte neuronale Erregbarkeit dämpft, die synaptische Kurz- und Langzeitplastizität verbessert und die Hypoxietoleranz erhöht (Janc und Müller 2014).

Auch in Bezug auf Rett-Patientinnen scheint dieser Ansatz plausibel. Längst ist bekannt, dass bei Patientinnen ein verminderter Spiegel des Antioxidans Vitamin E - gemessen im Blut - vorherrscht (Formichi et al. 1998). Ebenso wurden erhöhte 
Proteincarbonyl- und Lipidperoxidationsspiegel, beides Marker für erhöhten oxidativen Stress, im Blut von Patientinnen nachgewiesen. Gleichzeitig sind die Superoxiddismutase und das Tocopherol (Vitamin E) vermindert (Sierra et al. 2001; Formichi et al. 1998; De Felice et al. 2009). Übertragen auf $M e c p 2^{-/ y}$ Mäuse ist ein erhöhter oxidativer Schaden in Form erhöhter Lipidperoxidation in Mäusehirnen nachgewiesen worden (De Felice 2014).

Im Bezug zum Rett-Syndrom erfolgt aktuell eine Phase II Studie mit dem Vitamin EDerivat EPI 743 (http://edisonpharma.com/wp-content/files_mf/1409757666RettSyn dromepressrelease140903.pdf). Auch andere erfolgversprechende Therapien bestätigen durchaus positive Effekte einer gezielten Verringerung erhöhten oxidativen Stresses. So wurde beispielsweise nach der Behandlung der Patientinnen mit $\omega-3$ PUFAs (engl. polyunsaturated fatty acids: mehrfach ungesättigte Fettsäuren) eine Verbesserung der Motorik, der nonverbalen Kommunikation und der Atemregelmäßigkeit festgestellt (De Felice et al. 2012; Maffei et al. 2014).

Inzwischen gilt als gesichert, dass das zentrale Nervensystem eines der Organe mit der höchsten Vulnerabilität für oxidative Schäden darstellt und ein RedoxUngleichgewicht ernsthafte Folgen nach sich ziehen kann (Uttara et al. 2009). Gleichzeitig ist das Hirn auch eines der Organe mit der höchsten Stoffwechselrate, ergo mit der größten ROS-Produktion. So ist auch für andere Erkrankungen wie zum Beispiel die Alzheimersche Krankheit oder Morbus Parkinson (Castegna et al. 2003; Jenner 2003; Uttara et al. 2009) eine Beteiligung reaktiver Sauerstoffspezies bekannt.

Die antioxidative Therapie stellt in den genannten Erkrankungen einen vielversprechenden Ansatz dar. Dennoch sollte nicht unerwähnt bleiben, dass verschiedene Studien zu unterschiedlichen Ergebnissen gelangen. Der genaue Funktionsmechanismus einer antioxidativen Therapie ist nach wie vor nicht endgültig geklärt, was wiederum die Ursache für konträre Ergebnisse sein könnte. Eine mögliche Fehlerquelle ist hierbei die häufig schwierige Dosierung der jeweiligen Substanz. Prinzipiell bestehen im Redox-Gleichgewicht der Patientinnen Unterschiede, die eine personalisierte Dosierung voraussetzen. Unterschiede bestehen auch innerhalb des Gewebes sogar zwischen „gesunden“ und MeCP2 defizienten Zellen desselben Zelltyps (siehe die in der Einleitung beschriebene 
zufällige X-Inaktivierung und das resultierende genetische Mosaik). Zu einer Überoder Unterdosierung mit Antioxidantien ist bekannt, dass ROS vielfältige Aufgaben, wie die Signaltransduktion, erfüllen (Serrano und Klann 2005) und gerade das Redox-Gleichgewicht den entscheidenden Aspekt darstellt. So ist es vorstellbar, dass eine zu hoch gewählte Dosierung den physiologischen Signalcharakter von ROS negativ beeinflusst. Im Gegensatz hierzu steht die Ausscheidung von $\alpha$ Tocopherol. a-Tocopherol ist aus der Gruppe Vitamin E jenes mit der höchsten biologischen Aktivität und wird bei zu hoher Dosierung mit dem Urin ausgeschieden (Brigelius-Flohé und Traber 1999). Dabei möglicherweise entstehende osmotische Nebeneffekte können nicht mit Sicherheit ausgeschlossen werden.

In der vorliegenden Arbeit wurde die Substanz Trolox - ein Vitamin E-Derivat untersucht. Trolox ist als wasserlösliches Derivat gut zu handhaben und besitzt hohe antioxidative Eigenschaften (Alberto et al. 2013). Trolox wird aufgrund seiner Eigenschaften zum Beispiel auch im TEAC-Test verwendet. Dabei wird die antioxidative Kapazität einer Probe bestimmt. Trolox dient dann als Referenzsubstanz (Miller et al. 1993). Weiterhin liegen viele Erfahrungswerte der Arbeitsgruppe vor, auf die Bezug genommen werden kann.

Vitamin $E$ ist in der Behandlung vieler neurologischer Erkrankungen erforscht worden. Ein Mangel an Vitamin $E$ geht mit vielfältigen neurologischen Fehlfunktionen wie beispielweise einer Ataxie einher (Ouahchi et al. 1995). Es ist im Speziellen als lipophiles Molekül am Schutz der Membranen beteiligt. Vitamin C hingegen ist weniger an der direkten antioxidativen Funktion beteiligt, sondern dient als wasserlösliches Molekül eher dazu, verschiedene Antioxidantien - unter anderem Vitamin E - nach Verbrauch zu regenerieren (Buettner 1993; Traber und Stevens 2011) und ist damit nicht gut steuerbar. Die Tatsache, dass Vitamin E nicht verbraucht wird, könnte dessen Effizienz weiter steigern. Dieser Zusammenhang schließt nachteilige Effekte jedoch nicht aus. Es stellt sich die Frage, ob jederzeit ein ausreichend hoher Spiegel an Vitamin $E$ in reduzierter Form vorliegt. Ist singulär der Spiegel von Vitamin $E$ erhöht, die mit Vitamin $E$ in Interaktion stehenden weiteren Substanzen aber nicht, könnten sich nicht überschaubare Nebenwirkungen ergeben. Selbst die als paradox beschriebene diuretische Wirksamkeit von Vitamin E (Becker-Freyseng 1951) könnte Auswirkungen auf den Gesamtorganismus zeigen. Ebenso ist eine Überladung des Organismus mit Vitamin $\mathrm{E}$ denkbar. Trolox wurde in der vorliegenden Arbeit in unterschiedlich 
hohen Dosen verabreicht, wobei die Dosierung mit $40 \mathrm{mg} / \mathrm{kg} \mathrm{KG}$ die höchst mögliche Dosierung darstellt, da Trolox in höheren Dosen nicht mehr wasserlöslich ist. Gleichzeitig wird die Letaldosis weit unterschritten. Die LD50 Dosis für Mäuse wird oral mit $1630 \mathrm{mg} / \mathrm{kg} \mathrm{KG}$ angegeben (chemisches Sicherheitsdatenblatt der Anbieter, z.B.: Acros Organics). Die Verwendung von zusätzlichen Lösungsmitteln wurde in diesem Zusammenhang bewusst umgangen, sodass nachgewiesene Effekte ausschließlich auf die Applikation von Trolox selbst zurückzuführen sind.

\subsection{Exploratives Verhalten nach Trolox-Behandlung}

Eines vieler klinischer Erscheinungsbilder bei Rett-Patientinnen ist die eingeschränkte motorische Aktivität in Form von partiellem Verlust der Handmotorik sowie bereits erlernter motorischer Fähigkeiten (Chahrour und Zoghbi 2007). Im Hole Board-Verhaltenstest wird ein Augenmerk auf die motorische, aber auch auf die explorative Eigenschaft der Mäuse gelegt. Der Hole Board-Test stellt einen vielfach in der Erprobung medikamentöser Therapien angewandten Verhaltenstest dar (Nolan und Parkes 1973).

Der durchgeführte Hole Board-Verhaltenstest liefert eindeutige Ergebnisse. In der Anzahl der Erkundungen von Löchern (head dippings) zeigen die mit PBS behandelten Wildtypen einen signifikant höheren Wert als die $M e c p 2^{-/ y}$ Tiere. Das Ergebnis der Versuchsreihe zeigt, dass für jeden im Hole Board erhobenen Parameter der signifikante oder sogar hochsignifikante Unterschied, der in der Kontrollgruppe herrscht, in der 10 mg/kg KG-Gruppe geringer ausfällt, und in der 40 mg/kg KG-Gruppe teilweise keine bis nur geringe Signifikanz besteht. Im direkten

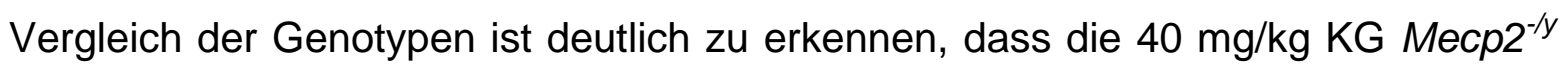
Gruppen Werte erreichen, die näher an denen der Wildtypen liegen. Betrachtet man die Gruppe der Wildtypen, so ist ein inverser Effekt zu bemerken. An dem Parameter der head dippings ist im Vergleich der PBS-behandelten und der mit 40 $\mathrm{mg} / \mathrm{kg} \mathrm{KG}$ behandelten Wildtypen eine Tendenz feststellbar, die zeigt, dass Trolox bei gesunden Tieren unter Umständen einen inversen Effekt hervorruft.

Trolox nimmt nach den hier durchgeführten Versuchen erkennbar Einfluss auf alle beschriebenen Parameter des Hole Board-Tests. Hierbei ergeben sich für die Mecp2 $2^{-/ y}$ Mäuse analog der jeweils gewählten Dosierung erheblich verbesserte 
Leistungswerte. Umgekehrt reduzieren sich die Leistungen der Wildtypen ebenfalls entsprechend der Dosis.

Für jedes Tier war die Hole Board-Umgebung neu und mit Stress verbunden. Dabei stellt sich die Frage, ob Wildtyp und Mecp $2^{-/ y}$ Tiere gleichermaßen auf Stress reagieren. Tolerieren gesunde Tiere ein vermeintlich höheres Stressniveau oder reagieren erkrankte Tiere mit Resignation und schütten weniger Stresshormone aus? Diese Fragen sind nicht endgültig zu klären.

Genau wie $M e c p 2^{-/ y}$ Tiere zeigen Rett-Patientinnen eine verminderte Aktivität (Guy et al. 2001), was zunächst bei Beobachtung der Kontrollgruppe im Mausmodell bestätigt wird und auch im Einklang mit den Ergebnissen eines weiteren Verhaltenstests (open field) im Rahmen des Projektes steht (Janc 2015). Die vorliegenden Untersuchungen haben gezeigt, dass hohe Dosen Trolox einen inversen Effekt auf Wildtyptiere haben können. Dafür spricht, dass das RedoxGleichgewicht ein sensibler Parameter ist, der, wie einleitend erwähnt, einer genauen Dosierung bedarf. ROS wirken als Signalmoleküle (Dröge 2002; Valko et al. 2007) und sind auch für die synaptische Plastizität unerlässlich (Knapp und Klann 2002; Massaad und Klann 2011). Geht man davon aus, dass gesunde Tiere ein optimales Redox-Gleichgewicht aufweisen sollten, so ist jede Form von Supplementierung überschüssig und könnte den inversen beobachteten Effekt erklären (Abb. 24).

Weiterhin sollte erwähnt werden, dass im Zuge der umfassenden Gesamtstudie auch die Blutzuckerwerte der Tiere erhoben wurden. Dabei ist der in der PBS behandelten Gruppe vorerst hochsignifikante Unterschied in der $40 \mathrm{mg} / \mathrm{kg} \mathrm{KG}$ Gruppe zur Gänze ausgelöscht und die Blutglukosewerte sind bei den $M e c p 2^{-/ y}$ Tieren, die mit hohen Dosen Trolox behandelt wurden, bis auf Normalniveau angehoben (Janc 2015). Die Glukoseverfügbarkeit steht in direktem Verhältnis zur

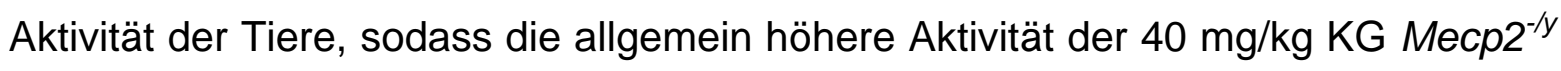
Gruppe mit dem wiederhergestellten Blutzuckerspiegel in Verbindung gebracht werden könnte. 


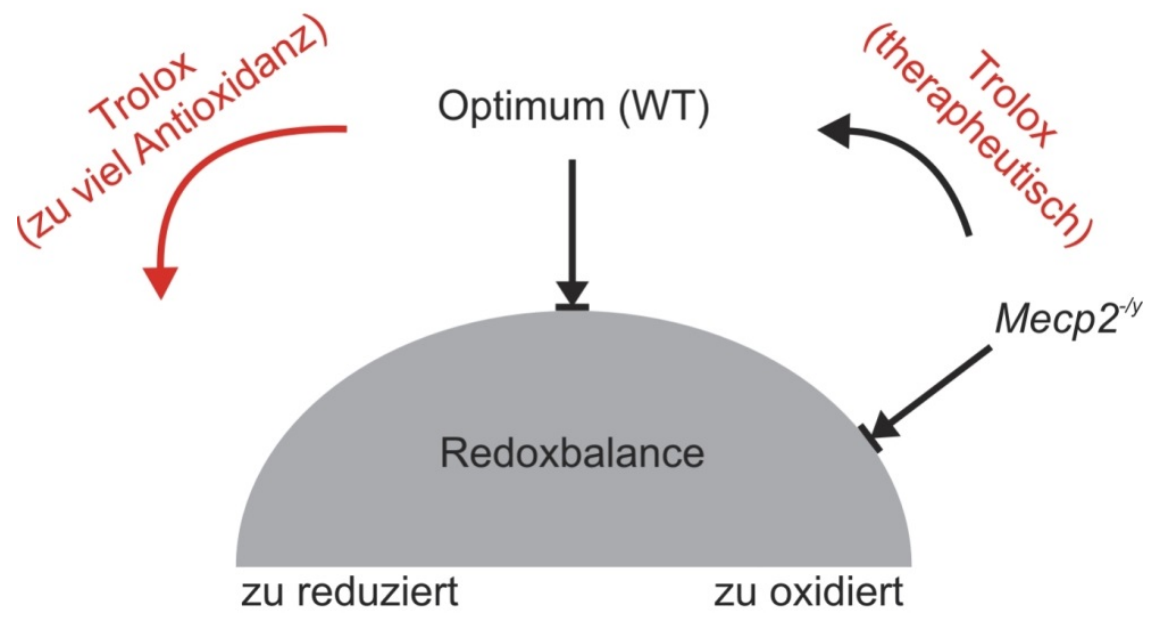

\section{Abbildung 24: Schematische Darstellung der Redoxbalance und deren Beeinflussung}

In der Abbildung ist die Redoxbalance als äußerst vulnerables Gleichgewicht dargestellt. Eine nur geringe Beeinflussung zur einen oder anderen Seite bringt das System potentiell aus dem Gleichgewicht. Diesen Effekt der „Überpufferung“ könnte Trolox an Wildtyptieren verursachen. Die zur Seite der vermehrten Oxidation verschobenen Mecp $2^{-/ y}$ Tiere können durch Trolox dem wohl balancierten Optimum angenähert werden.

Schlussendlich bleibt festzuhalten, dass Trolox entweder einen direkten Einfluss auf die Aktivität der Tiere ausübt oder die erhöhte Aktivität der behandelten Gruppen über den Umweg der erhöhten Blutzuckerkonzentration zu erklären ist. Spekulativ bleibt, warum gesunde Tiere in ihrer Aktivität und vor allem Explorativität von Trolox beeinflusst werden. Vorzustellen ist, dass eine Beeinflussung des Redox-Gleichgewichts hin zur übermäßigen Reduktion nachteilige Effekte birgt.

\subsection{Mitochondrienpotential - Rhodamin123}

Der mitochondriale Metabolismus stellt die größte Quelle der ROS dar (Boveris und Chance 1973; Adam-Vizi 2005). Gleichzeitig sind Mitochondrien aber auch von oxidativem Schaden betroffen und reagieren mit morphologischen und funktionellen Alterationen (Petronilli et al. 1994; Gerich et al. 2009; Qi et al. 2011; Lenaz und Genova 2012).

Die Zytochrom-c-Oxidase oxidiert Zytochrom-c und reduziert Sauerstoff zu Wasser. Damit stellt sie das Enzym dar, welches maßgeblich am Sauerstoffverbrauch der Mitochondrien beteiligt ist. Eine Hemmung dieses Enzyms durch Zyanid kommt 
folglich einer chemisch induzierten Hypoxie gleich. FCCP ist ein Protonophor, also ein Molekül, welches Ionen über eine Membran befördert. Es zählt zu den CarrierIonophoren (Benz und McLaughlin 1983) und wurde als vollständiger Atmungskettenentkoppler genutzt.

In früheren Versuchen der Arbeitsgruppe konnte gezeigt werden, dass die Mitochondrien in der besonders hypoxieanfälligen CA1-Region des Hippokampus (Schmidt-Kastner und Freund 1991; Wilde et al. 1997; Wang et al. 2007) Mecp2-/y defizienter adulter Mäuse weniger stark polarisiert sind (Großer et al. 2012; Janc und Müller 2014). Die ATP Level im adulten Hippokampus der Rett-Mäuse hingegen scheinen sich nicht zu unterscheiden (Fischer et al. 2009) und sogar neonatal höher zu sein (Toloe et al. 2014), was zu der Annahme leitet, dass die Mitochondrien auf einem dauerhaft erhöhten Niveau arbeiten und so gleichzeitig auch mehr ROS generieren, was seinerseits zu einer erhöhten oxidativen Belastung führt. Die in vitro-Behandlung mit Trolox zeigt bei der FAD/NADH Messung, die in früheren Arbeiten an unbehandeltem Gewebe Unterschiede zwischen Wildtyp und Mecp2-/y aufwies (Großer et al. 2012), keine signifikanten Ergebnisse. Die inhibitorischen Effekte von niedrig- und hochdosiertem Zyanid hingegen konnten durch Trolox abgeschwächt werden. Ebenso konnte der vorher signifikante Unterschied der Genotypen in der Antwort auf FCCP verringert werden (Janc und Müller 2014). Der Redoxstatus - gemessen mithilfe des Redoxindikators roGFP - hingegen konnte durch in vitro-Behandlung mit Trolox verbessert werden (Großer et al. 2012).

Nicht alle früheren Ergebnisse der Arbeitsgruppe (Großer et al. 2012; Janc und Müller 2014) waren in den systemisch behandelten Tieren hier so zu reproduzieren. In den Behandlungsgruppen finden sich zwischen Wildtyp und Mecp2-ly in der vorliegenden Untersuchung keine signifikanten Unterschiede. Auch in der PBS behandelten Kontrollgruppe bleiben Unterschiede aus. Zu diesem Ergebnis war bezüglich der Autofluoreszenz von FAD/NADH auch die Arbeitsgruppe gelangt (Janc 2015).

Dieses könnte bedeuten, dass die Membranpotentialänderungen $(\Delta \psi \mathrm{m})$ der Tiere tatsächlich sehr ähnlich sind. Allerdings gibt der fehlende Unterschied in der Kontrollgruppe Anlass zu der Annahme, dass Rh123 als membrangängiges Kation über den häufig langen Versuchszeitraum und die dauerhafte Umspülung der 
Schnitte mit ACSF zunächst partiell ausgewaschen oder geblichen sein könnte. Insbesondere die Gabe von hohen Dosen Zyanid führt zum Ausstrom der Rhodaminkationen, die dann aus dem Gewebe ausgespült und umverteilt werden können. Die damit zuletzt durchgeführte Entkopplung der Atmungskette könnte somit zu gering ausgefallen sein und gegebenenfalls einen genotypischen Unterschied teilweise maskieren. Denkbar ist auch, dass die FCCP-induzierte Entkopplung durch die noch funktionstüchtigen Komplexe der Zytochrom-c-Oxidase teilweise kompensiert wurden. Schlussendlich ist die geringer ausgefallene Antwort der FCCP-Entkopplung sowohl durch einen Verlust an Rhodamin-Kationen, als auch über eine Teilkompensierung zu erklären.

In der Hemmung der Zytochrom-c-Oxidase mittels Zyanid bestehen keine Unterschiede. Offensichtlich reagieren Wildtypen und Mecp2-/y aller Gruppen mit ähnlichen Potentialverhältnisänderungen. Wie bereits beschrieben, ist davon auszugehen, dass die Zytochrom-c-Oxidase im Rett-Syndrom in verminderter Form vorliegt (Dotti et al. 1993; Coker und Melnyk 1991). Es sollte in Betracht gezogen werden, dass bei gleichem mitochondrialem Membranpotential die Hemmung der Zytochrom-c-Oxidase nicht wesentlich unterschiedlich ausfallen sollte. Lediglich die Erholung des Membranpotentials dürfte im Sinne eines kompensatorischen Profils schneller erfolgen.

Eine endgültige Aussage über die Auswirkung einer in vivo-Behandlung mit Trolox auf die mitochondrialen Potentialverhältnisse und deren Vulnerabilität gegenüber einer chemisch induzierten Hypoxie kann nur teilweise getroffen werden. Die sehr ähnlichen Potentialverhältnisse der Mitochondrienmembran unterliegen durch Trolox offensichtlich keinem negativen Effekt. Zuletzt weisen die Tiere innerhalb der Gruppen Unterschiede auf, die unter Umständen einer biologischen Individualität und Variabilität, zuletzt auch des Rett-Phänotypen, geschuldet sind. Weiterhin sollte nicht außer Acht gelassen werden, dass die Tiere im Zweitagesrhythmus intraperitoneal behandelt und dazu aus dem Käfig genommen wurden. Einerseits könnte die intraperitoneale Behandlung und häufige Handhabung durchaus als Stressereignis (Ryabini et al. 1999) wahrgenommen werden und so zu einer vermehrten Stresshormonfreisetzung der Tiere führen. Andererseits könnte die dauerhafte Handhabung der Mäuse auch positive Effekte (Bereicherung der Umwelt) mit sich bringen (Rampon et al. 2000). Weiterhin bleibt ungeklärt, ob Wildtypen und Rett-Mäuse in unterschiedlicher Weise auf Stress reagieren. 
Die gerade beschriebenen Aspekte erweisen sich nicht nur in Bezug zur Rhodamin123-Messung als diskutabel, sondern stellen vielmehr die grundsätzliche Problematik der repetitiven in vivo-Behandlung und vor allem der häufigen Injektionen dar.

\subsection{Biochemische Analysen}

Die photometrischen Methoden erfassen das Ausmaß des oxidativen Stresses auf molekularer Ebene. Dabei stellt die Lipidperoxidation den oxidativen Schaden an Lipiden dar, die Proteincarbonylierung jenen an Proteinen. Zu beiden Methoden fand eine Anpassung des Herstellerprotokolls an die Gegebenheiten des Labors statt, sodass diese Anpassung validiert werden musste. So wurde beispielsweise die photometrische Messung nicht dem Herstellerprotokoll folgend in 96-well microplates durchgeführt, sondern mithilfe von deutlich großvolumigeren Standardküvetten. Folglich mussten auch die Gewebemengen angepasst werden. Die Validierung der Methoden erfolgte durch eine in vitro-Behandlung des Hirngewebes mit $500 \mu \mathrm{M}$ TBHP, einem Oxidationsmittel. Für beide Tests konnte die jeweilige Methode erfolgreich validiert werden. Trotz der für die Validierung genotypisch inhomogen gewählten Gruppen und der geringen Anzahl an Proben $(n=3)$ sind für beide Methoden eindeutig signifikante Unterschiede zwischen Kontrollgruppe und TBHP-Gruppe $(p<0,05)$ gefunden worden. In diesem Zusammenhang ist zu erwähnen, dass TBHP ein starkes Oxidationsmittel ist und dass der Unterschied zwischen TBHP-behandelt und unbehandelt sicherlich auch von der relativ hohen Konzentration des TBHPs profitierte. Betrachtet man diese Gegebenheiten, so ist der Unterschied der Validierung als relativ moderat zu bezeichnen: So wurde die Lipidperoxidation um $57 \%$, die Proteincarbonylierung um $80 \%$ gesteigert. Dies suggeriert, dass die angewandten Assays nur eine relativ geringe Sensitivität aufweisen.

Die photometrischen Methoden stellen eine in der Arbeitsgruppe bisher nicht angewandte Untersuchungsmethodik dar. Die Methoden basieren auf bereits bekannten Ergebnissen zur molekularen Auswirkung von ROS. Seit einiger Zeit ist der oxidative Schaden an Lipiden beziehungsweise die Abnormität von Lipiden in den Vordergrund der Rett-Forschung gelangt (Buchovecky et al. 2013; Felice et al. 
2013; Sticozzi et al. 2013; De Felice et al. 2014). Auch die Proteincarbonylierung scheint in einem anderen - in dieser Arbeit nicht verwendeten - Mausmodell $\left(M e c p 2^{308 / y}\right)$ für das Rett-Syndrom erhöhte Werte aufzuweisen (De Felice et al. 2014).

Zur Lipidperoxidation ist festzuhalten, dass die gesamte Gruppe der Wildtypen unabhängig von der erhaltenen Behandlung keine signifikanten Unterschiede aufweist. In der Gruppe der $M e c p 2^{-1 / y}$ Tiere hingegen liegt bei der $40 \mathrm{mg} / \mathrm{kg} \mathrm{KG-}$ Gruppe ein signifikant geringerer Lipidperoxidationsspiegel $(p<0,05)$ als bei der Kontrollgruppe vor. Erkennbar ist, dass die PBS-Kontrollgruppe zwischen Wildtyp und $M e c p 2^{-1 y}$ Tieren keine Unterschiede zeigt. Dennoch scheint Trolox-Einfluss auf die Lipidperoxidation zu nehmen. Allerdings ist der Einfluss verhältnismäßig gering. Hier muss in Frage gestellt werden, ob die Modifikation des vom Hersteller ausgegebenen Protokolls Einfluss auf die Ergebnisse nimmt. Die Validierung hierzu ist positiv verlaufen. Da die Validierung mit recht hohen Konzentrationen an Oxidantien erfolgte, kann eine geringe Sensitivität der Methodik angenommen werden. Auch die relativ hohe Variabilität der Werte spricht dafür.

Weiterhin sollte in Betracht gezogen werden, dass Trolox die Blut-Hirn-Schranke überwinden muss, um eine zentrale Wirkung zu entfalten. Trolox ist ein wasserlösliches Molekül und braucht für die Überwindung der Blut-Hirn-Schranke einen Transporter oder Kanal. Vitamin E als lipophiler Stoff benötigt Lipoproteine, um seinen Bestimmungsort zu erreichen. Dies ist das high density lipoprotein. In gesunden Organismen gelangt Vitamin E auf diese Weise zur Blut-Hirn-Schranke und wird dort unter anderem von dem SRBI-Rezeptor in Empfang genommen und zur intrazellulären Seite transportiert (Kaempf-Rotzoll et al. 2003).

Dieser Rezeptor scheint allerdings beim Rett-Syndrom in nur stark verminderter Form vorhanden zu sein (Sticozzi et al. 2013). Das spricht neben einem absoluten (Formichi et al. 1998) auch für einen relativen Vitamin E-Mangel. Sollte auch Trolox als Derivat dieselben Transporter benötigen, wäre eine uneingeschränkte Wirksamkeit von Trolox fraglich. Letztendlich bleibt zu klären, in welchem Umfang Trolox eine zentrale Wirksamkeit erreicht. Es ist jedenfalls davon auszugehen, dass hohe Dosen Trolox eine verminderte Lipidperoxidation bewirken.

In der Messung der Proteincarbonylierung sind keine Unterschiede feststellbar, jedoch ist hier die Variabilität und dementsprechend die Standardabweichung 
relativ hoch. Bedenkt man, dass das Rett-Syndrom vor allem mit einem Mangel an Vitamin E in Zusammenhang gebracht wird und dass Vitamin E im Speziellen für den antioxidativen Schutz von Lipiden zuständig ist, so ist dieses zu erklären. Zwar hat die Etablierung der Methodik in Absprache mit dem Hersteller stattgefunden, allerdings sind interferierende Proteinpräzipitate nicht auszuschließen. Die Validierung ist eindeutig positiv verlaufen, zeigt aber einen verhältnismäßig moderaten Effekt. $\mathrm{Zu}$ bedenken ist in diesem Zusammenhang, dass das Gehirn eine relativ geringe Menge an Proteinen im Verhältnis zu Lipiden aufweist, sodass geringe Unterschiede nicht unumgänglich festgehalten werden müssen. Vorherige Arbeiten zeigen zu dem in dieser Arbeit verwendetem Mausmodell auch keine erhöhten Carbonylspiegel, sondern berichten diese lediglich im Mausmodell Mecp2 ${ }^{308 / y}$ (De Felice et al. 2014).

\subsection{Morphologische Gewebeanalysen}

Die morphologische Beurteilung des Hirngewebes beruht auf Publikationen über verminderte Hirngrößen bei Rett-Mäusen (Belichenko et al. 2008). Auch in Bezug auf Patientinnen ist bekannt, dass sowohl die Zellsomata des Hippokampus verkleinert sind, als auch die Packungsdichte erhöht ist (Bauman et al. 1995; Chen et al. 2001). Die Arbeitsgruppe hat in Vorversuchen diese Gegebenheiten, die vorerst nur für die CA2-Region des Hippokampus beschrieben war, für die CA1Region an Tieren bestätigen und damit erweitern können (Fischer et al. 2009). Auch die vorliegende Arbeit bezieht Teile der Messungen auf die CA1-Region des Hippokampus. Allerdings sind diese Messungen nicht wie in den Vorversuchen mit Thionin, sondern mit Kresylviolett entstanden. Mit der Färbung und morphologischen Beurteilung kann ein weiterer Aspekt der Erkrankung erfasst und ein potentieller Einfluss von Trolox evaluiert werden.

Wie bereits erwähnt, können zu den systemisch behandelten Tieren die oben genannten Gegebenheiten teilweise bestätigt werden. In der Vermessung der Hemisphärengröße ergeben sich zwischen Wildtyp und Mecp2-/y Tieren teils hochsignifikante Unterschiede. In der Gruppe der $M e c p 2^{-/ y}$ Mäuse hingegen ergeben sich keine signifikanten Unterschiede, sodass davon ausgegangen werden kann, dass Trolox diese Parameter des zerebralen Wachstums und der 
Entwicklung nicht messbar beeinflusst. Allerdings ist aber auch kein nachteiliger Effekt der Trolox-Behandlung morphologisch zu beobachten. Gleichsam verhält es sich für die Vermessung der kortikalen Schichtdicken. Da das Rett-Syndrom keine neurodegenerative Erkrankung darstellt, wären grundsätzliche massive morphologische Alterationen auch unerwartet. Eine dünnere Kortexschichtdicke ist aber dennoch typisch für das Rett-Syndrom. Hierbei ist nicht erklärbar, weshalb die Messung der Hippokampusformation in der $10 \mathrm{mg} / \mathrm{kg} \mathrm{KG-Gruppe} \mathrm{und} 40 \mathrm{mg} / \mathrm{kg}$ KG-Gruppe signifikante Unterschiede $(p<0,05$; $p<0,01)$ zeigt, in der PBS-Gruppe jedoch nur eindeutige Tendenzen. Dieses ist noch am ehesten damit zu begründen, dass einerseits die Gesamtzahl der Tiere relativ gering war und andererseits die Orientierung an der rostro-kaudalen Achse zwar verifiziert wurde, aber auch einer natürlichen Alteration unterliegt. Diese Tatsache ist in den genannten Quellen teils nachrangig behandelt und gestattet somit kaum Vergleichbarkeit. Für die Vermessung von Zellsomata mag dieser Aspekt wenig relevant sein, aber gerade bei der Vermessung der Hemisphärengröße und der Hippokampusformation ist er entscheidend am Resultat der Methodik beteiligt.

In dieser Arbeit können durch Untersuchungen der Zellsomatagröße und Schichtdicke des st. pyramidale oben genannte Ergebnisse, die an unbehandelten Tieren gewonnen wurden, teilweise reproduziert werden. Es wurden pro Tier 15 Zellen vermessen. Jeder Schnitt wurde seinerseits gemittelt. Warum gerade die Schichtdicke in Mecp2 ${ }^{-/ y}$ Tieren die gleiche Größe aufweisen wie in Wildtyptieren, ist unklar. Möglicherweise ist eine stressinduzierte Verringerung der Wildtyptiere hier ursächlich. Der Vergleich der Absolutzahlen, bezogen auf die Zellsomatagröße, wirft Fragen auf: In Vorexperimenten wurde die Zellgröße der Wildtyptiere mit $152 \pm$ $29 \mu \mathrm{m}^{2}$ angegeben (Fischer et al. 2009). Im Ergebnis dieser Arbeit erreichen die Wildtypen der Kontrollgruppe jedoch nur Werte von 136,8 $\pm 25,5 \mu \mathrm{m}^{2}$. Gleichzeitig erreichen die $M e c p 2^{-/ y}$ Tiere der Kontrollgruppe wesentlich höhere Werte als jene Tiere der Voruntersuchung (Fischer et al. 2009). Dieser Vergleich leitet zu der Annahme, dass die in Voruntersuchungen zu findenden stärkeren Unterschiede hier besonders durch die stressinduzierende Behandlung maskiert werden. Es kann nur unter Vorbehalt auf einen potentiellen Effekt verwiesen werden, der durch das repetitive Handhaben und die i.p.-Behandlung der Tiere entsteht. Jedenfalls ergibt die Trolox-Behandlung für die gewählten Parameter keinen nachteiligen Effekt. 


\subsection{Resümee}

In der Tat übt Trolox auf einige Parameter des komplexen Rett-Phänotyps einen positiven Effekt aus. Dieses gilt insbesondere für die Lipidperoxidation und das Verhalten (Hole Board-Verhaltenstest).

In vielerlei Hinsicht können bereits bestehende Ergebnisse zum Rett-Syndrom verifiziert werden. Andererseits sind auch Ergebnisse gegeben, die selbst in der Kontrollgruppe früher erhobene Parameter nur teilweise bestätigen können. Dabei ist zu bedenken, dass die Tiere im Zuge der Behandlung jeden zweiten Tag intraperitoneal behandelt wurden und dementsprechend sicherlich einem gewissen Handhabungseffekt unterliegen. Welchen Einfluss dieser Effekt letztlich ausübt, kann nur gemutmaßt werden.

Im Vordergrund steht der Hole Board-Test, der signifikante Unterschiede für die Behandlung mit Trolox zeigt. Gleiches gilt für die Lipidperoxidation und damit den oxidativen Schaden an Lipiden. Für Proteine kann die antioxidative Funktion von Trolox nicht bestätigt werden. Weiterhin ist das Ergebnis dieser Arbeit, dass Trolox für einige Parameter einen inversen Effekt hervorruft und Trolox behandelte Wildtyptiere teils signifikante Veränderungen gegenüber der Kontrollgruppe aufweisen. Diese Tatsache ist am ehesten mit dem sensiblen Redox-Gleichgewicht zu begründen, das eine Verschiebung in die eine oder andere Richtung schlecht toleriert. Weiterhin ist ein teils großer Unterschied bezüglich verschiedener Parameter auffällig, der genotypisch nicht unbedingt erklärbar ist.

Im Vordergrund der Diskussion steht besonders der Handhabungseffekt, der über eine repetitive Stressinduktion möglicherweise einige genotypische Unterschiede maskiert. Bis jetzt ist nicht sicher geklärt, welches der exakte Wirkmechanismus einer antioxidativen Therapie ist und welche Nebeneffekte dabei auftreten können. Für das in dieser Arbeit verwendete Antioxidans konnte in Zellkulturen ein hoher antioxidativer Effekt beschrieben werden (Forrest et al. 1994). Zuletzt verbleibt die detaillierte Gängigkeit von Trolox für die Blut-Hirn-Schranke unsicher. Dennoch hat Trolox in Test an Ratten einen Effekt auf die sauerstoffinduzierte Retinopathie und damit einem zentralen Pathomechanismus - ausgeübt (Forrest et al. 1994; Dorfman et al. 2006). Auffällig ist in Bezug zur vorliegenden Arbeit, dass die direkt am Hirn durchgeführten Tests häufig nur geringe Unterschiede aufweisen, der 
Hole Board-Verhaltenstest aber - als ein den Gesamtorganismus und damit auch die Peripherie betrachtender Test - wesentlich deutlichere Ergebnisse liefert. Dieses legt einen starken peripheren und milden zentralen Effekt von Trolox nahe, der zuletzt auch durch die Wiederherstellung der Blutglukosespiegel bestätigt werden konnte (Janc 2015).

Trolox scheint in der Lage, einige Symptome des Rett-Syndroms auch bei systematischer Applikation zu mildern. Das zeigt, dass das Konzept der frühen Antioxidantienbehandlung im Rett-Syndrom durchaus Potential aufweist, das jetzt näher zu analysieren ist. Kombinationen verschiedenster Antioxidantien und Substanzen mit besserer Blut-Hirn-Schranken-Gängigkeit könnten hier demnach noch vielversprechendere Ergebnisse liefern. 


\section{Zusammenfassung und Ausblick}

Das Ziel der vorliegenden Arbeit war die präklinische Beurteilung eines mit dem Radikalfänger Trolox in vivo behandelten Mausmodells des Rett-Syndroms. Die Erkrankung stellt eine postnatal progressiv verlaufende neurologische Entwicklungsstörung dar.

Seit Langem ist bekannt, dass Rett-Patientinnen im Blut verminderte Vitamin ESpiegel aufweisen (Formichi et al. 1998). Auch ist bekannt, dass das ROSGleichgewicht einen entscheidend betroffenen Aspekt der Erkrankung darstellt (Großer et al. 2012; Müller und Can 2014). Die in vivo-Vitamin E-Supplementierung durch Trolox als Antioxidans stellt dabei einen plausiblen therapeutischen Ansatz dar, welcher in in vitro-Tests am Mausmodell bereits erfolgreiche Ergebnisse erzielen konnte (Janc und Müller 2014).

Die in dieser Arbeit durchgeführten Untersuchungen beleuchten zum Teil eine in der Arbeitsgruppe bisher nicht angewandte Untersuchungsmethodik und erlauben die ausgiebige Erweiterung einer größer angelegten präklinischen Studie. Dabei ist die Gesamtschau aller im Rahmen des Projektes durchgeführter Versuche von Bedeutung.

Besonders im Vordergrund stand die Etablierung zweier biochemischer Methoden der Proteincarbonylierungs- und der Lipidperoxidationsmessung. Außerdem wurde photometrisch die Reagibilität der Mitochondrienmembran untersucht, das Verhalten der Tiere getestet sowie die morphologischen Alterationen mittels NisslFärbung analysiert.

Nach der Supplementierung von Trolox konnten in einigen Versuchsreihen deutliche Änderungen detektiert werden. Besonders im Fokus stehen hierbei die Absenkung der Lipidperoxidation und die Verbesserung der explorativen Aktivität der Mecp $2^{-/ y}$ Tiere. Trolox weist in einigen Parametern einen inversen Effekt auf die Wildtyptiere auf, was ein äußerst sensibles Redox-Gleichgewicht nahe legt und auf die Wichtigkeit einer exakten Dosierung der Antioxidantien hinweist.

Weiterhin gibt es deutliche Hinweise auf Handhabungseffekte, denen die Tiere im Rahmen der mehrwöchigen systemischen Behandlung unterliegen. Dieser Frage könnte in Zukunft mit einer Optimierung des Studiendesigns nachgekommen 
werden. Beispielsweise könnte über die Applikation der Substanz über die Nahrung nachgedacht werden. Zwar ist so keine exakte Dosierung gegeben, Handhabungseffekte könnten jedoch sicher ausgeschlossen werden. Auch sollte weiter die exakte Blut-Hirn-Schranken-Gängigkeit von Trolox geklärt werden und wie diese molekular erfolgt. Weiter ist über eine kombinierte Therapie - zum Beispiel mit Vitamin C - nachzudenken, da der Metabolismus von Vitamin $E$ in direktem Zusammenhang mit Vitamin C steht (Buettner 1993; Traber und Stevens 2011).

In der Arbeitsgruppe ist kürzlich eine neue Mauslinie generiert worden, die mittels des Redox-Indikators roGFP eine Überprüfung des Redox-Status in Echtzeit erlaubt (Wagener et al. 2016). Diese Mauslinie könnte in Zukunft mit Mecp2-/y Tieren verpaart werden, um den Einfluss von Trolox detaillierter in verschiedenen Hirnarealen zu evaluieren und Redox-Änderungen mit dem Krankheitsverlauf zu korrelieren.

Insgesamt ist festzuhalten, dass Trolox viele Parameter beeinflusst, hierbei die tatsächlichen molekularen Prozesse aber noch nicht überschaubar sind. Trolox als Vitamin E-Derivat ist eine potentiell therapeutische Substanz, bedarf aber weiterer Untersuchungen, um einen eindeutigen Effekt nachzuweisen. Weiterhin sollten ROS im Vordergrund der Rett-Forschung stehen und der exakte Einfluss auf den Progress der Erkrankung ergründet werden. Dabei sollte vor allem der Gedanke des Redox-Gleichgewichts im Fokus stehen. 


\section{Anhang}

\subsection{Abkürzungsverzeichnis}

4-HNE

Abb.

ACSF

ATP

BCA

BHT

BSA

C57BL/6J

CA

$\mathrm{CaCl}_{2}$

CCD

CDKL5

$\mathrm{CN}^{-}$

$\mathrm{CO}_{2}$

CpG

DC

DNA

DNP/DNPH

FAD

FCCP

FOXG1

$\mathrm{H}_{2} \mathrm{O}_{2}$
4-Hydroxy-2-nonenal

Abbildung

artifizielle zerebrospinale Flüssigkeit

Adenosintriphosphat

Bicinchoninicsäure

Butylhydroytoluol

Bovines Serumalbumin

verbreiteter Inzucht-Mausstamm

cornu ammonis

Calciumchlorid

charged-coupled device

cyclin-dependet kinase-like 5

Zyanid

Kohlenstoffdioxid

Cytosin-phosphatidyl-Guanin

Dichroit

Desoxyribonukleinsäure

2,4-Dinitrophenylhydrazin/2,4-

Dinitrophenylhydrazon

Flavin-Adenin-Dinokleotid

Carbonylzyanid-p-trifluoromethoxyphenylhydrazon

forkhead box 1 Gen

Wasserstoffperoxid 
i.p.

IR

$\mathrm{KCl}$

KG

MDA

MeCP2

Mecp2 (Maus)

MECP2 (Mensch)

$\mathrm{MgSO}_{4}$

$\mathrm{N}_{2}$

NA

$\mathrm{NaCl}$

$\mathrm{NADH}$

$\mathrm{NaH}_{2} \mathrm{PO}_{4}$

NO

$\mathrm{O}_{2}$

$\mathrm{p}$

PBS

PFA

PUFAs

Rh123

RNA

rOGFP

$\mathrm{ROO}^{-}$

ROS

SOD

st.

TBA intraperitoneal

Infrarot

Kaliumchlorid

Körpergewicht

Malondialdehyd

Methyl CpG binding protein 2, exprimiertes Protein

Methyl CpG binding protein 2, kodierendes Gen

Methyl CpG binding protein 2, kodierendes Gen

Magnesiumsulfat

Stickstoff

numerische Apertur

Natriumchlorid

Nicotinamidadenindinukleotid

Natriumhydrogenphosphat

Stickstoffmonoxid

Sauerstoff

postnatal

phosphatgepufferte Salzlösung

Paraformaldehyd

mehrfach ungesättigte Fettsäuren

Rhodamin 123

Ribonukleinsäure

redoxsensitives grün fluoreszierendes Protein

Peroxylradikal

reaktive Sauerstoffspezies

Superoxiddismutase

stratum

Thiobarbitursäure 
TCA

Uqcrc1

UV

WT
Trichloressigsäure

ubiquinol-cytochrome $\mathrm{c}$ reductase core protein 1

Ultraviolett

Wildtyp

\subsection{Tabellenverzeichnis}

Tabelle 1: Ergebnisse des Hole Board-Verhaltenstests in tabellarischer

Darstellung $45-$

Tabelle 2: Validierung beider biochemischer Methoden - Darstellung der

Einzelwerte $-54-$

Tabelle 3: Darstellung der Messergebnisse zur Lipidperoxidation. $-56-$

Tabelle 4: Ausmaß der Proteincarbonylierung der kortikalen Gewebeproben... 57 Tabelle 5: Zusammenfassung der im Rahmen der Nissl-Färbung erhobenen morphologischen Gewebeparameter $61-$

\subsection{Abbildungsverzeichnis}

Abbildung 1: Schematische Darstellung der therapeutischen Angriffspunkte...- 15 Abbildung 2: Schematische Darstellung der Versuche ................................... 20 Abbildung 3: Schema der Trolox-Behandlung ................................................ 21 Abbildung 4: Versuchsaufbau Hole Board ................................................ 22 -

Abbildung 5: Leica VT1200S Vibratom .................................................... 24 -

Abbildung 6: Messaufbau des Fluoreszenzmikroskops zur Rh123-Messung ...- 26 Abbildung 7: Schematische Darstellung der Fluoreszenzmikroskopie............... 27 Abbildung 8: Bildschirmdarstellung einer Messung-TILL Vision ...................... 30 Abbildung 9: Schematische Darstellung der Photometrie................................ 32 Abbildung 10: Die Entstehung von MDA und dessen Reaktion mit TBA .......... 33 - 
Abbildung 11: Darstellung der Reaktion zwischen einem Carbonyl und DNPH- 36 -

Abbildung 12: Kresylviolett und Thionin im Vergleich $39-$

Abbildung 13: Rostro-kaudale Orientierung der Hirnschnitte..... $-41$

Abbildung 14: Anzahl der head dippings und zurückgelegten Gesamtdistanz im Hole Board-Verhaltenstest. $46-$

Abbildung 15: Mittlere Geschwindigkeit und Ruhezeiten im Hole BoardVerhaltenstest $48-$

Abbildung 16: Beispielspur einer Messung und Reaktion auf FCCP $50-$

Abbildung 17: Darstellung der auf die baseline normalisierten Rh123Antworten auf Zyanid.

Abbildung 18: Zur Maximalantwort (FCCP) normalisierte Reaktion auf Zyanid - 52 Abbildung 19: Zusammenfassende Darstellung der Verifizierung beider Messmethoden $-55-$

Abbildung 20: Graphische Zusammenfassung der Lipidperoxidation $-56-$

Abbildung 21: Bewertung der Proteincarbonylierung in kortikalen Gewebeproben $58-$

Abbildung 22: Ergebnisse - Nissl-Färbung $62-$

Abbildung 23: Darstellung der zellulären Parameter in der CA1-Region des Hippokampus $63-$

Abbildung 24: Schematische Darstellung der Redoxbalance und deren Beeinflussung $69-$ 


\section{$7 \quad$ Literaturverzeichnis}

Adam-Vizi V (2005): Production of reactive oxygen species in brain mitochondria: contribution by electron transport chain and non-electron transport chain sources. Antioxid Redox Signal ㄱ, 1140-1149

Alberto ME, Russo N, Grand A, Galano A (2013): A physicochemical examination of the free radical scavenging activity of Trolox: mechanism, kinetics and influence of the environment. Phys Chem Chem Phys $\underline{15}$, 4642-4650

Amir RE, Van den Veyver IB, Wan M, Tran CQ, Francke U, Zoghbi HY (1999): Rett syndrome is caused by mutations in X-linked MECP2, encoding methyl-CpG-binding protein 2. Nat Genet $\underline{23}, 185-188$

Anderson A, Wong K, Jacoby P, Downs J, Leonard H (2014): Twenty years of surveillance in Rett syndrome: what does this tell us? Orphanet J Rare Dis $\underline{9}, 87$

Ariani F, Hayek G, Rondinella D, Artuso R, Mencarelli MA, Spanhol-Rosseto A, Pollazzon M, Buoni S, Spiga O, Ricciardi S (2008): FOXG1 is responsible for the congenital variant of Rett syndrome. Am J Hum Genet 83, 89-93

Bauman ML, Kemper TL, Arin DM (1995): Pervasive neuroanatomic abnormalities of the brain in three cases of Rett's syndrome. Neurology $\underline{45}, 1581-1586$

Becker-Freyseng $H$ (1951): The diuretic and antidiuretic effect of single doses of vitamin E. Klin Wochenschr 29, 649-650

Belichenko NP, Belichenko PV, Li HH, Mobley WC, Francke U (2008): Comparative study of brain morphology in Mecp2 mutant mouse models of Rett syndrome. J Comp Neurol $\underline{508}, 184-195$

Belichenko PV, Wright EE, Belichenko NP, Masliah E, Li HH, Mobley WC, Francke U (2009): Widespread changes in dendritic and axonal morphology in Mecp2-mutant mouse models of Rett syndrome: evidence for disruption of neuronal networks. J Comp Neurol 514, 240-258

Benz R, McLaughlin S (1983): The molecular mechanism of action of the proton ionophore FCCP (carbonylce p-trifluoromethoxyphenylhydrazone). Biophys $\mathrm{J} \underline{41}$, 381-398

Berlett BS, Stadtman ER (1997): Protein oxidation in aging, disease, and oxidative stress. J Biol Chem 272, 20313-20316

Boveris A, Chance B (1973): The mitochondrial generation of hydrogen peroxide. General properties and effect of hyperbaric oxygen. Biochem J $\underline{134}$, 707-716

Boveris A, Cadenas E, Stoppani AOM (1975): Role of Ubiquinone in the Mitochdonrial Generation of Hydrogen Peroxide. Biochem J $\underline{156}$, 435-444 
Brendel C, Belakhov V, Werner H, Wegener E, Gärtner J, Nudelman I, Baasov T, Huppke P (2011): Readthrough of nonsense mutations in Rett syndrome: evaluation of novel aminoglycosides and generation of a new mouse model. J Mol Med (Berl) $\underline{89}, 389-398$

Brigelius-Flohé R, Traber MG (1999): Vitamin E: function and metabolism. Faseb J $\underline{13}, 1145-1155$

Buchovecky CM, Hill MG, Borkey JM, Kyle SM, Justice MJ (2013): A protocol for evaluation of Rett Syndrome symptom improvement by metabolic modulators in mutant mice. Curr Protoc Mouse Biol 2013,

Buettner GR (1993): The pecking order of free radicals and antioxidants: lipid peroxidation, alpha-tocopherol, and ascorbate. Arch Biochem Biophys $\underline{300}$, 535-543

Buyse IM, Fang P, Hoon KT, Amir RE, Zoghbi HY, Roa BB (2000): Diagnostic testing for Rett syndrome by DHPLC and direct sequencing analysis of the MECP2 gene: identification of several novel mutations and polymorphisms. Am J Hum Genet $\underline{67}$, 1428-1436

Castegna A, Thongboonkerd V, Klein JB, Lynn B, Markesbery WR, Butterfield DA (2003): Proteomic identification of nitrated proteins in Alzheimer's disease brain. J Neurochem $\underline{85}$, 1394-1401

Chahrour M, Zoghbi HY (2007): The story of Rett syndrome: from clinic to neurobiology. Neuron $\underline{56}, 422-437$

Chahrour M, Jung SY, Shaw C, Zhou X, Wong ST, Qin J, Zoghbi HY (2008): MeCP2, a key contributor to neurological disease, activates and represses transcription. Science $\underline{320}$, 1224-1229

Chen RZ, Akbarian S, Tudor M, Jaenisch R (2001): Deficiency of methyl-CpG binding protein-2 in CNS neurons results in a Rett-like phenotype in mice. Nat Genet 27 , 327-331

Christen HJ, Hanefeld F (1995): Male Rett variant. Neuropediatrics $\underline{26}$, 81-82

Christodoulou J, Grimm A, Maher T, Bennetts B (2003): RettBASE: The IRSA MECP2 variation database-a new mutation database in evolution. Hum Mutat 21 , 466-472

Coker SB, Melnyk AR (1991): Rett syndrome and mitochondrial enzyme deficiencies. J Child Neurol $\underline{6}, 164-166$

Cornford ME, Philippart M, Jacobs B, Scheibel AB, Vinters HV (1994): Neuropathology of Rett syndrome: case report with neuronal and mitochondrial abnormalities in the brain. J Child Neurol $\underline{9}$, 424-431

Dalle-Donne I, Rossi R, Giustarini D, Milzani A, Colombo R (2003): Protein carbonyl groups as biomarkers of oxidative stress. Clin Chim Acta $\underline{329}$, 23-38 
De Felice C, Ciccoli L, Leoncini S, Signorini C, Rossi M, Vannuccini L, Guazzi G, Latini G, Comporti M, Valacchi G (2009): Systemic oxidative stress in classic Rett syndrome. Free Radic Biol Med 47, 440-448

De Felice C, Signorini C, Durand T, Ciccoli L, Leoncini S, D'Esposito M, Filosa S, Oger C, Guy A, Bultel-Ponce V (2012): Partial rescue of Rett syndrome by omega-3 polyunsaturated fatty acids (PUFAs) oil. Genes Nutr $\underline{7}$, 447-458

De Felice C, Cortelazzo A, Signorini C, Guerranti R, Leoncini S, Pecorelli A, Durand T, Galano JM, Oger C, Zollo G (2013): Effects of omega-3 polyunsaturated fatty acids on plasma proteome in Rett syndrome. Mediators Inflamm 2013, 1-9

De Felice C, Della Ragione F, Signorini C, Leoncini S, Pecorelli A, Ciccoli L, Scalabri F, Marracino F, Madonna M, Belmonte G (2014): Oxidative brain damage in Mecp2mutant murine models of Rett syndrome. Neurobiol Dis $\underline{68}, 66-77$

Dorfman AL, Dembinska O, Chemtob S, Lachapelle P (2006): Structural and functional consequences of trolox $C$ treatment in the rat model of postnatal hyperoxia. Invest Ophthalmol Vis Sci 47, 1101-1108

Dotti MT, Manneschi L, Malandrini A, De Stefano N, Caznerale F, Federico A (1993): Mitochondrial dysfunction in Rett syndrome. An ultrastructural and biochemical study. Brain Dev $\underline{15}, 103-106$

Dröge W (2002): Free radicals in the physiological control of cell function. Physiol Rev 82, 47-95

Duchen MR (1999): Contributions of mitochondria to animal physiology: from homeostatic sensor to calcium signalling and cell death. J Physiol $\underline{516}, 1-17$

Eeg-Olofsson O, al-Zuhair AG, Teebi AS, Daoud AS, Zaki M, Besisso MS, Al-Essa MM (1988): Rett syndrome: a mitochondrial disease? J Child Neurol $\underline{5}, 210-214$

Emaus RK, Grunwald R, Lemasters JJ (1986): Rhodamine 123 as a probe of transmembrane potential in isolated rat-liver mitochondria: spectral and metabolic properties. Biochim Biophys Acta $\underline{850}$, 436-448

Erecinska M, Silver IA (1989): ATP and brain function. J Cereb Blood Flow Metab $\underline{9}$, 2-19

Fischer M, Reuter J, Gerich FJ, Hildebrandt B, Hägele S, Katschinski D, Müller M (2009): Enhanced hypoxia susceptibility in hippocampal slices from a mouse model of Rett syndrome. J Neurophysiol 101, 1016-1032

Formichi P, Battisti C, Dotti MT, Hayek G, Zappella M, Federico A (1998): Vitamin E serum levels in Rett syndrome. J Neurol Sci 156, 227-230

Forrest VJ, Kang YH, McClain DE, Robinson DH, Ramakrishnan N (1994): Oxidative stress-induced apoptosis prevented by Trolox. Free Radic Biol Med 16, 675-684 
Foster KA, Galeffi F, Gerich FJ, Turner DA, Müller M (2006): Optical and pharmacological tools to investigate the role of mitochondria during oxidative stress and neurodegeneration. Prog Neurobiol $\underline{79}, 136-171$

Funke F, Dutschmann M, Müller M (2007): Imaging of respiratory-related population activity with single-cell resolution. Am J Physiol Cell Physiol 292, 508-516

Gerich FJ, Funke F, Hildebrandt B, Faßhauer M, Müller M (2009): $\mathrm{H}_{2} \mathrm{O}_{2}$-mediated modulation of cytosolic signaling and organelle function in rat hippocampus. Pflügers Arch $\underline{458}, 937-952$

Gibson JH, Slobedman B, K NH, Williamson SL, Minchenko D, El-Osta A, Stern JL, Christodoulou J (2010): Downstream targets of methyl CpG binding protein 2 and their abnormal expression in the frontal cortex of the human Rett syndrome brain. BMC Neurosci $\underline{11}, 1-16$

Gilgun-Sherki Y, Melamed E, Offen D (2004): The role of oxidative stress in the pathogenesis of multiple sclerosis: the need for effective antioxidant therapy. $\mathrm{J}$ Neurol 251, 261-268

Großer E, Hirt U, Janc OA, Menzfeld C, Fischer M, Kempkes B, Vogelgesang S, Manzke TU, Opitz L, Müller M et al.(2012): Oxidative burden and mitochondrial dysfunction in a mouse model of Rett syndrome. Neurobiol Dis $\underline{48}, 102-114$

Guo W, Tsujimura K, Otsuka IM, Irie K, Igarashi K, Nakashima K, Zhao X (2014): VPA alleviates neurological deficits and restores gene expression in a mouse model of Rett syndrome. PLoS One $\underline{9}, 1-9$

Guy J, Hendrich B, Holmes M, Martin JE, Bird A (2001): A mouse Mecp2-null mutation causes neurological symptoms that mimic Rett syndrome. Nat Genet 27 , 322-326

Haas RH, Light M, Rice M, Barshop BA (1995): Oxidative metabolism in Rett syndrome: 1 . Clinical studies. Neuropediatrics $\underline{26}$, 90-94

Hagberg B (1985): Rett's syndrome: prevalence and impact on progressive severe mental retardation in girls. Acta Paediatr Scand $\underline{74}$, 405-408

Hagberg B, Witt-Engerström I (1986): Rett syndrome: a suggested staging system for describing impairment profile with increasing age towards adolescence. Am J Med Genet Suppl 1, 47-59

Huppke P, Laccone F, Kramer N, Engel W, Hanefeld F (2000): Rett syndrome: analysis of MECP2 and clinical characterization of 31 patients. Hum Mol Genet $\underline{9}$, 1369-1375

Huppke P, Kohler K, Brockmann K, Stettner GM, Gartner J (2007): Treatment of epilepsy in Rett syndrome. Eur J Paediatr Neurol 11, 10-16 
Janc OA (2015): Pharmacotreatment of a mouse model of Rett syndrome with the radical scavenger Trolox: Detailed assassment of potential merits in vitro and in vivo. Biol. Diss. Göttingen 2015

Janc OA, Müller M (2014): The free radical scavenger Trolox dampens neuronal hyperexcitability, reinstates synaptic plasticity, and improves hypoxia tolerance in a mouse model of Rett syndrome. Front Cell Neurosci $\underline{8}, 56$

Jenner P (2003): Oxidative stress in Parkinson's disease. Ann Neurol $\underline{53}$, 26-38

Julu PO, Kerr AM, Apartopoulos F, Al-Rawas S, Engerström IW, Engerström L, Jamal GA, Hansen S (2001): Characterisation of breathing and associated central autonomic dysfunction in the Rett disorder. Arch Dis Child $\underline{85}$, 29-37

Kaempf-Rotzoll DE, Traber MG, Arai H (2003): Vitamin E and transfer proteins. Curr Opin Lipidol 14, 249-254

Knapp LT, Klann E (2002): Role of reactive oxygen species in hippocampal long-term potentiation: contributory or inhibitory? J Neurosci Res $\underline{70}$, 1-7

Kong J, Xu Z (1998): Massive mitochondrial degeneration in motor neurons triggers the onset of amyotrophic lateral sclerosis in mice expressing a mutant SOD1. $\mathrm{J}$ Neurosci 18, 3241-3250

Kriaucionis S, Paterson A, Curtis J, Guy J, Macleod N, Bird A (2006): Gene expression analysis exposes mitochondrial abnormalities in a mouse model of Rett syndrome. Mol Cell Biol 26, 5033-5042

Lenaz G, Genova ML (2012): Supramolecular organisation of the mitochondrial respiratory chain: a new challenge for the mechanism and control of oxidative phosphorylation. Adv Exp Med Biol $\underline{748}$, 107-144

Leonard H, Bower C, English D (1997): The prevalence and incidence of Rett syndrome in Australia. Eur Child Adolesc Psychiatry 6 Suppl 1, 8-10

Levine RL, Garland D, Oliver CN, Amici A, Climent I, Lenz AG, Ahn BW, Shaltiel S, Stadtman ER (1990): Determination of carbonyl content in oxidatively modified proteins. Methods Enzymol 186, 464-478

Lewis JD, Meehan RR, Henzel WJ, Maurer-Fogy I, Jeppesen P, Klein F, Bird A (1992): Purification, sequence, and cellular localization of a novel chromosomal protein that binds to methylated DNA. Cell $\underline{69}, 905-914$

Lyon MF (1961): Gene action in the X-chromosome of the mouse (Mus musculus L.). Nature $\underline{190}, 372-373$

Maffei S, De Felice C, Cannarile P, Leoncini S, Signorini C, Pecorelli A, Montomoli B, Lunghetti S, Ciccoli L, Durand T (2014): Effects of omega-3 PUFAs supplementation on myocardial function and oxidative stress markers in typical Rett syndrome. Mediators Inflamm 2014, 1-8 
Mari F, Azimonti S, Bertani I, Bolognese F, Colombo E, Caselli R, Scala E, Longo I, Grosso S, Pescucci C (2005): CDKL5 belongs to the same molecular pathway of MeCP2 and it is responsible for the early-onset seizure variant of Rett syndrome. Hum Mol Genet 14, 1935-1946

Massaad CA, Klann E (2011): Reactive oxygen species in the regulation of synaptic plasticity and memory. Antioxid Redox Signal 14, 2013-2054

Matsuishi T, Urabe F, Percy AK, Komori H, Yamashita Y, Schultz RS, Ohtani Y, Kuriya N, Kato H (1994): Abnormal carbohydrate metabolism in cerebrospinal fluid in Rett syndrome. J Child Neurol $\underline{9}$, 26-30

Menzfeld C, Dudek J, Rehling P, Müller M (2014): Mitochondrial dysfunction in Rett syndrome viewed from the biochemical perspective. 13th annual Rett syndrome symposium, Chantilly, VA, Abstract p.78

Miller NJ, Rice-Evans C, Davies MJ, Gopinathan V, Milner A (1993): A novel method for measuring antioxidant capacity and its application to monitoring the antioxidant status in premature neonates. Clin Sci (Lond) $\underline{84}$, 407-412

Moreira PI, Zhu X, Wang X, Lee HG, Nunomura A, Petersen RB, Perry G, Smith MA (2010): Mitochondria: a therapeutic target in neurodegeneration. Biochim Biophys Acta 1802, 212-220

Müller M, Can K (2014): Aberrant redox homoeostasis and mitochondrial dysfunction in Rett syndrome. Biochem Soc Trans 42, 959-964

Nolan NA, Parkes MW (1973): The effects of benzodiazepines on the behaviour of mice on a hole-board. Psychopharmacologia 29, 277-286

Ouahchi K, Arita M, Kayden H, Hentati F, Ben Hamida M, Sokol R, Arai H, Inoue K, Mandel JL, Koenig M (1995): Ataxia with isolated vitamin E deficiency is caused by mutations in the alpha-tocopherol transfer protein. Nat Genet $\underline{9}, 141-145$

Panighini A, Duranti E, Santini F, Maffei M, Pizzorusso T, Funel N, Taddei S, Bernardini N, Ippolito C, Virdis A (2013): Vascular dysfunction in a mouse model of Rett syndrome and effects of curcumin treatment. PLOS ONE $\underline{8}, 1-9$

Pecorelli A, Leoni G, Cervellati F, Canali R, Signorini C, Leoncini S, Cortelazzo A, De Felice C, Ciccoli L, Hayek J (2013): Genes related to mitochondrial functions, protein degradation, and chromatin folding are differentially expressed in lymphomonocytes of Rett syndrome patients. Mediators Inflamm 2013, 1-18

Petronilli V, Costantini P, Scorrano L, Colonna R, Passamonti S, Bernardi P (1994): The voltage sensor of the mitochondrial permeability transition pore is tuned by the oxidation-reduction state of vicinal thiols. Increase of the gating potential by oxidants and its reversal by reducing agents. J Biol Chem 269, 16638-16642

Qi X, Disatnik MH, Shen N, Sobel RA, Mochly-Rosen D (2011): Aberrant mitochondrial fission in neurons induced by protein kinase $\mathrm{Cd}$ under oxidative stress conditions in vivo. Mol Biol Cell 22, 256-265 
Rampon C, Tang YP, Goodhouse J, Shimizu E, Kyin M, Tsien JZ (2000): Enrichment induces structural changes and recovery from nonspatial memory deficits in CA1 NMDAR1-knockout mice. Nat Neurosci $\underline{3}$, 238-244

Rett A (1966): Über ein eigenartiges hirnatrophisches Syndrom bei Hyperammonämie im Kindesalter. Wien Med Wochenschr 116, 723-726

Ruch A, Kurczynski TW, Velasco ME (1989): Mitochondrial alterations in Rett syndrome. Pediatr Neurol $\underline{5}$, 320-323

Ryabinin AE, Wang YM, Finn DA (1999): Different levels of Fos immunoreactivity after repeated handling and injection stress in two inbred strains of mice. Pharmacol Biochem Behav $\underline{63}, 143-151$

Scala E, Ariani F, Mari F, Caselli R, Pescucci C, Longo I, Meloni I, Giachino D, Bruttini M, Hayek G (2005): CDKL5/STK9 is mutated in Rett syndrome variant with infantile spasms. J Med Genet $\underline{42}, 103-107$

Schmedes A, Hølmer G (1989): A New Thiobarbituric Acid (TBA) Method for Determining Free Malondialdehyde (MDA) and Hydroperoxides Selectively as a Measure of Lipid Peroxidation. J Am Oil Chem Soc $\underline{66}$, 813-817

Schmidt-Kastner R, Freund TF (1991): Selective vulnerability of the hippocampus in brain ischemia. Neuroscience $\underline{40}, 599-636$

Schwartzman JS, Bernardino A, Nishimura A, Gomes RR, Zatz M (2001): Rett syndrome in a boy with a $47, X X Y$ karyotype confirmed by a rare mutation in the MECP2 gene. Neuropediatrics $\underline{32}, 162-164$

Serrano F, Klann E (2004): Reactive oxygen species and synaptic plasticity in the aging hippocampus. Ageing Res Rev $\underline{3}, 431-443$

Shahbazian M, Young J, Yuva-Paylor L, Spencer C, Antalffy B, Noebels J, Armstrong D, Paylor R, Zoghbi H (2002): Mice with truncated MeCP2 recapitulate many Rett syndrome features and display hyperacetylation of histone H3. Neuron $\underline{35}$, 243-254

Sierra C, Vilaseca MA, Brandi N, Artuch R, Mira A, Nieto M, Pineda M (2001): Oxidative stress in Rett syndrome. Brain Dev $\underline{23}, 236-239$

Signorini C, De Felice C, Leoncini S, Moller RS, Zollo G, Buoni S, Cortelazzo A, Guerranti R, Durand T, Ciccoli L et al. (2016): MECP2 Duplication Syndrome: Evidence of Enhanced Oxidative Stress. A Comparison with Rett Syndrome. PLoS One $\underline{11}, 1-12$

Stearns NA, Schaevitz LR, Bowling H, Nag N, Berger UV, Berger-Sweeney J (2007): Behavioral and anatomical abnormalities in Mecp2 mutant mice: a model for Rett syndrome. Neuroscience 146, 907-921 
Stettner GM, Huppke P, Gärtner J, Richter DW, Dutschmann M (2008): Disturbances of breathing in Rett syndrome: Results from patients and animal models. Adv Exp Biol Med $\underline{605}, 503-507$

Sticozzi C, Belmonte G, Pecorelli A, Cervellati F, Leoncini S, Signorini C, Ciccoli L, De Felice C, Hayek J, Valacchi G (2013): Scavenger receptor B1 post-translational modifications in Rett syndrome. FEBS Lett $\underline{587}$, 2199-2204

Suter B, Treadwell-Deering D, Zoghbi HY, Glaze DG, Neul JL (2014): Brief report: MECP2 mutations in people without Rett syndrome. J Autism Dev Disord 44, 703711

Tao J, Van Esch H, Hagedorn-Greiwe M, Hoffmann K, Moser B, Raynaud M, Sperner J, Fryns JP, Schwinger E, Gecz J (2004): Mutations in the X-linked cyclin-dependent kinase-like 5 (CDKL5/STK9) gene are associated with severe neurodevelopmental retardation. Am J Hum Genet $\underline{75}$, 1149-1154

Toloe J, Mollajew R, Kügler S, Mironov SL (2014): Metabolic differences in hippocampal 'Rett' neurons revealed by ATP imaging. Mol Cell Neurosci $\underline{59 C}$, 47-56

Traber MG, Stevens JF (2011): Vitamins C and E: beneficial effects from a mechanistic perspective. Free Radic Biol Med 51, 1000-1013

Trappe R, Laccone F, Cobilanschi J, Meins M, Huppke P, Hanefeld F, Engel W (2001): MECP2 mutations in sporadic cases of Rett syndrome are almost exclusively of paternal origin. Am J Hum Genet $\underline{68}$, 1093-1101

Turrens JF (1997): Superoxide production by the mitochondrial respiratory chain. Biosci Rep 17, 3-8

Turrens JF, Boveris A (1980): Generation of superoxide anion by the NADH dehydrogenase of bovine heart mitochondria. Biochem J 191, 421-427

Uttara B, Singh AV, Zamboni P, Mahajan RT (2009): Oxidative stress and neurodegenerative diseases: a review of upstream and downstream antioxidant therapeutic options. Curr Neuropharmacol $\underline{7}, 65-74$

Valko M, Leibfritz D, Moncol J, Cronin MT, Mazur M, Telser J (2007): Free radicals and antioxidants in normal physiological functions and human disease. Int $\mathrm{J}$ Biochem Cell Biol $\underline{39}, 44-84$

Villemagne PM, Naidu S, Villemagne VL, Yaster M, Wagner HN, Jr., Harris JC, Moser HW, Johnston MV, Dannals RF, Wong DF (2002): Brain glucose metabolism in Rett Syndrome. Pediatr Neurol 27, 117-122

Wagener KC, Kolbrink B, Dietrich K, Kizina KM, Terwitte LS, Kempkes B, Bao G, Müller M (2016): Redox-indicator mice stably expressing genetically-encoded neuronal roGFP: Versatile tools to decipher subcellular redox dynamics in neuropathophysiology. Antioxid. Redox Signal. in press. doi:10.1089/ars.2015.6587 
Wan M, Lee SS, Zhang X, Houwink-Manville I, Song HR, Amir RE, Budden S, Naidu S, Pereira JL, Lo IF (1999): Rett syndrome and beyond: recurrent spontaneous and familial MECP2 mutations at CpG hotspots. Am J Hum Genet $\underline{65}, 1520-1529$

Wang X, Pal R, Chen XW, Kumar KN, Kim OJ, Michaelis EK (2007): Genome-wide transcriptome profiling of region-specific vulnerability to oxidative stress in the hippocampus. Genomics $\underline{90}$, 201-212

Weaving LS, Ellaway CJ, Gecz J, Christodoulou J (2005): Rett syndrome: clinical review and genetic update. J Med Genet $\underline{42}, 1-7$

Wegener E, Brendel C, Fischer A, Hülsmann S, Gärtner J, Huppke P (2014): Characterization of the MeCP2R168X Knockin Mouse Model for Rett Syndrome. PLoS One $\underline{9}, 1-14$

Wilde GJ, Pringle AK, Wright P, lannotti F (1997): Differential vulnerability of the CA1 and CA3 subfields of the hippocampus to superoxide and hydroxyl radicals in vitro. $\mathrm{J}$ Neurochem $\underline{69}$, 883-886

Zoghbi HY, Percy AK, Schultz RJ, Fill C (1990): Patterns of X chromosome inactivation in the Rett syndrome. Brain Dev 12, 131-135

http://edisonpharma.com/wpcontent/files_mf/1409757666RettSyndromepressrelease140903.pdf Zugriff am 07.04.2016

http://www.dimdi.de/static/de/klassi/icd-10-

gm/kodesuche/onlinefassungen/htmlgm2016/block-f80-f89.htm\#F84

Zugriff am 29.07.2016 


\section{Danksagung}

Mein besonderer Dank gilt meinem Doktorvater Prof. Dr. Michael Müller für die Überlassung des Themas sowie seine besonders aufmerksame Betreuung nicht nur in Bezug auf theoretische, sondern auch auf praktische Fragestellungen. Ohne seine motivierende und zugleich beratende Unterstützung wäre diese Arbeit nicht möglich gewesen. Vielen Dank, dass mir auf diese Weise ein besonderer Zugang zur Wissenschaft gewährt wurde.

Weiterhin gilt mein Dank der technischen Assistentin der Arbeitsgruppe, Frau Belinda Kempkes. Ihre fachliche Kompetenz und ihr technisches Know-how sind einzigartig, ebenso wie ihre freundliche und kollegiale Art.

Ganz besonders möchte ich mich bei Frau Dr. Oliwia Janc bedanken. Nicht nur ihre fachliche Versiertheit weiß ich sehr zu schätzen, sondern auch die Freundschaft, die mir entgegengebracht wurde. Zu jedem Zeitpunkt meiner Arbeit durfte ich mich auf sie verlassen.

Der gesamten Arbeitsgruppe Müller und der Arbeitsgruppe Hülsmann möchte ich danken. Das Arbeitsklima war hervorragend. Vielen Dank an alle Arbeitsgruppenmitglieder auch für all die Freizeitaktivitäten. 


\section{Lebenslauf}

Am 11.08.1990 wurde ich, Marc Albert Hüser, als Sohn der Eheleute Susanne Hüser, geb. Hölting, und Dr. Albert Hüser in Steinheim geboren. Meine beiden Geschwister, Dr. Anne Christin Hüser und Eva Sophie Hüser, sind 1981 und 1983 geboren.

Ich besuchte von 1997 bis 2001 die Grundschule Reelkirchen und wechselte 2001 an das Hermann-Vöchting-Gymnasium in Blomberg, wo ich 2010 meine allgemeine Hochschulreife erlangte.

Im August 2010 begann ich am Klinikum Lippe den Zivildienst in den Abteilungen OP sowie Orthopädie und Unfallchirurgie.

Seit April 2011 studiere ich an der Georg-August-Universität Göttingen Humanmedizin, an der ich nach erfolgreichem Abschluss der Ersten Ärztlichen Prüfung die Zweite Ärztliche Prüfung voraussichtlich im Wintersemester 2016/2017 ablegen werde.

Die vorliegende Arbeit fertigte ich am Zentrum für Physiologie und Pathophysiologie der Georg-August-Universität Göttingen im Institut für Neuro- und Sinnesphysiologie unter Anleitung von Herrn Professor Dr. rer. nat. Michael Müller an. 